\title{
Recent Advances in Total Synthesis via Metathesis Reactions
}

\author{
Iván Cheng-Sánchez \\ Francisco Sarabia*
}

Department of Organic Chemistry, Faculty of Sciences, University of Málaga, Campus de Teatinos s/n. 29071Málaga, Spain

frsarabia@uma.es

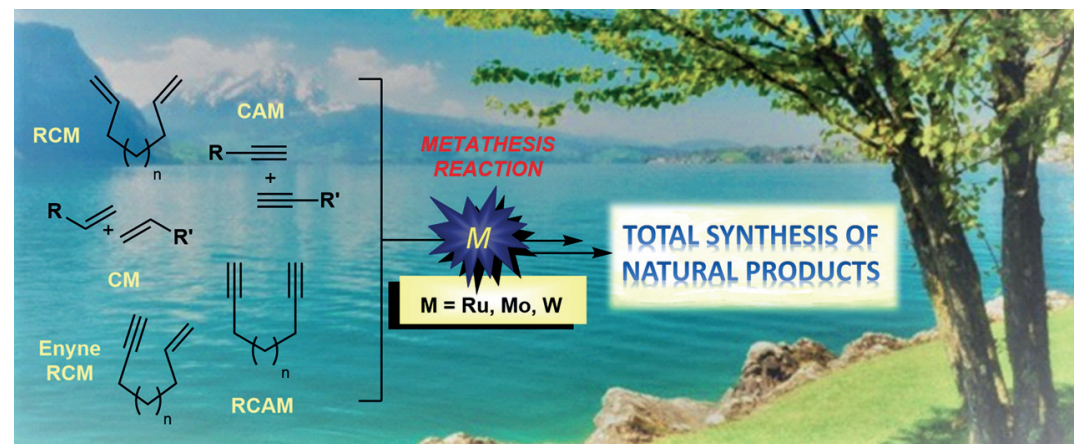

Received: 16.04.2018

Accepted after revision: 30.05 .2018

Published online: 18.07 .2018

DOI: 10.1055/s-0037-1610206; Art ID: ss-2018-z0262-r

Abstract The metathesis reactions, in their various versions, have become a powerful and extremely valuable tool for the formation of carbon-carbon bonds in organic synthesis. The plethora of available catalysts to perform these reactions, combined with the various transformations that can be accomplished, have positioned the metathesis processes as one of the most important reactions of this century. In this review, we highlight the most relevant synthetic contributions published between 2012 and early 2018 in the field of total synthesis, reflecting the state of the art of this chemistry and demonstrating the significant synthetic potential of these methodologies.

1 Introduction

2 Alkene Metathesis in Total Synthesis

2.1 Total Synthesis Based on a Ring-Closing-Metathesis Reaction

2.2 Total Synthesis Based on a Cross-Metathesis Reaction

2.3 Strategies for Selective and Efficient Metathesis Reactions of Alkenes

2.3.1 Temporary Tethered Ring-Closing Metathesis

2.3.2 Relay Ring-Closing Metathesis

2.3.3 Stereoselective Alkene Metathesis

2.3.4 Alkene Metathesis in Tandem Reactions

3 Enyne Metathesis in Total Synthesis

3.1 Total Syntheses Based on a Ring-Closing Enyne-Metathesis Reaction

3.2 Total Syntheses Based on an Enyne Cross-Metathesis Reaction

3.3 Enyne Metathesis in Tandem Reactions

4 Alkyne Metathesis in Total Synthesis

4.1 Total Synthesis Based on a Ring-Closing Alkyne-Metathesis Reaction

4.2 Other Types of Alkyne-Metathesis Reactions

5 Conclusions

Key words alkene metathesis, alkyne metathesis, enyne metathesis, natural products, total synthesis

\section{Introduction}

The outstanding and impressive level that organic synthesis has reached in the last few decades, especially in the field of the total synthesis of natural products, can be large- ly explained by the emergence, design, and development of powerful catalysts that are capable of promoting striking transformations in highly efficient and selective fashions. In fact, the ability of many of them to forge C-C bonds between or within highly functionalized and sensitive compounds has allowed for the preparation of complex frameworks, whose access were previously hampered by the limitations of conventional synthetic methods. Among the myriad of recent catalysts, those developed and designed to promote metathesis reactions have had a profound impact and created a real revolution in the field of total synthesis, by virtue of their ability to promote a stunning number of synthetic transformations, depending on the nature of the starting materials and reaction conditions. Metathesis reactions $^{1}$ include the alkene-, enyne-, and alkyne-metathesis reactions, together with multiple variants of polyalkenic or polyalkenynic systems as starting precursors involved in cascade processes. ${ }^{2}$ Among these, the alkene metathesis reaction (Scheme 1, A), in which cyclic olefins or linear alkenes are formed through ring-closing metathesis (RCM), cross-metathesis (CM) process, or their different guises (stereoselective, rearrangement, tethered or relay ring-closing metatheses), is the most extensively employed. Indeed, these transformations occupy a privileged position in modern organic synthesis. Less frequently used, but no less important, are the enyne and alkyne metatheses (Scheme 1, B and $\mathrm{C}$ ), which have also become valuable synthetic reactions with additional advantages over alkene metatheses. Such is the case of enyne metathesis involved in cascade processes, or the case of alkyne metathesis owing to the versatility of the alkyne group by allowing for further transformations, thus considerably expanding the structural diversity of the products that can be formed.

Certainly, behind the success of all these processes are the unique catalysts themselves that enable these transformations. Since the discovery of the first well-defined tungsten carbene catalyst by Katz ${ }^{3}$ and the elucidation of the mechanism of alkene metathesis by Chauvin ${ }^{4}$ in the 1970 s, 
key innovations were the Schrock catalyst 1 in $1990^{5}$ and the discovery of the ruthenium-based catalyst 2 by Grubbs in $1993 .{ }^{6}$ These discoveries marked the beginning of an extraordinary and burgeoning race towards more efficient catalysts in terms of activity, stability, and functional group tolerance, represented by the ruthenium species $\mathbf{3 - 1 4} \mathbf{1 4}^{\mathbf{- 1}}$ (Figure 1).

These highly efficient catalysts are representative members of three generations of ruthenium complexes, in which the introduction of an N-heterocyclic carbene (NHC) ligand (see 4, 6-14) resulted in an increase in the catalytic activity and thermal stability of the catalysts. The catalysts, developed between 1996-2007, gave rise to the rational design of new catalysts to enable both stereoselective and stereoretentive metathesis processes, leading to the molybdenum, tungsten, and ruthenium carbene complexes 15-27, among others. ${ }^{19-22}$ Additions to this armory of valuable catalysts, are the water-soluble catalysts in form of PEGylated complexes $^{23}$ or ruthenium-based catalysts supported on activated surfaces, ${ }^{24}$ which expand even further the scope and applications of the chemistry, particularly in regards to addressing environmental concerns. ${ }^{25}$ All these catalysts are appropriate for alkene and enyne metatheses. ${ }^{26}$ Interestingly, for the latter case, the process can be also effected by other transition-metal-based catalysts such as those based on Pt, Pd, or Ir via a completely different mechanism. A separate case is the alkyne-metathesis reaction, which despite the mechanistic similarity with alkene metathesis, requires a different type of catalyst. Indeed, in this case, the variety of catalysts available is not as great as those developed for the alkene metathesis reactions, as will be discussed in more detail later in the alkyne metathesis section. Together with the prominent activity and stability of the aforementioned catalysts, another feature that has been improved in the evolution of catalyst design ${ }^{27}$ is the exceptional functional group tolerance that all these catalysts display, which in turn has positioned them as one of the most powerful synthetic tools in modern organic synthesis. Consequently, total synthesis has enormously benefitted from the metathesis reactions, as demonstrated by the extensive use of these reactions in their intramolecular and intermolecular versions. In fact, the flurry of contributions, in which the metathesis reaction represents either the key step for the successful completion of a synthesis or a useful and efficient synthetic tool employed along the synthetic course, is a growing component of the organic chemistry literature.

Given the relevance and impact of this reaction in the field of organic chemistry, a large number of reviews, books, and book chapters have been devoted to all aspects of these reactions. Among all the excellent reviews focused on the applications of metathesis reactions in natural products synthesis, ${ }^{28}$ some key contributions by Nicolaou (2005), ${ }^{29}$ Pérez-Castells (2006), ${ }^{30}$ and Prunet (2011) ${ }^{31}$ are notable. A review published in 2017 by Vanderwal ${ }^{32}$ is noteworthy, wherein the most relevant contributions in the field of the last years were highlighted, but in a very generic form. On the other hand, an excellent book was published dealing with metathesis reactions in the synthesis of natural products, covering all the aspects of these reactions in the field of total synthesis up to $2010 .^{33}$ In addition, numerous reviews have been published on very specific items, dealing with a particular type of metathesis reaction or a

\section{Biographical Sketches}
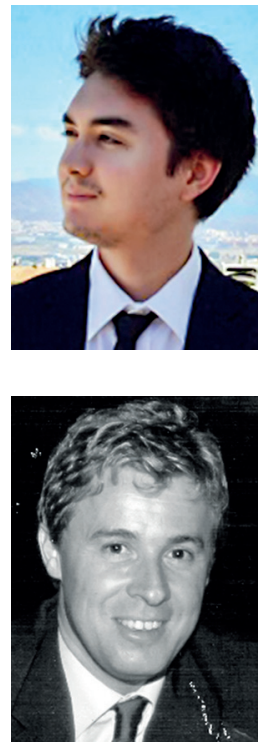

Iván Cheng Sánchez was born in Málaga (Spain) in 1992. He received his B.Sc. in chemistry in 2014 and his M.Sc. in chemistry in 2015 from Málaga University, after conducting research in the laboratories of Prof. F. Sarabia. In November

Francisco Sarabia received his Ph.D. degree from University of Málaga (Spain) in 1994 under the supervision of Prof. LópezHerrera. After postdoctoral research with Prof. K. C. Nicolaou at the Scripps Research Institute in La Jolla (1995-1997), he returned to the University of Málaga in 1998 as Assistant Professor, where he was promoted
2015 he started his Ph.D. studies under the guidance of Prof. F. Sarabia. In 2017 he joined the laboratories of Prof. C. Nevado at University of Zurich for a short research stay of 3 months where he was involved in the synthesis of novel ATAD2 bro-

to Full Professor in 2011. Prof. Sarabia has been visiting professor in the Technological Institute of Zürich (ETH) in 1998 with Prof. A. Vasella, The Scripps Research Institute in 2001 with Prof. Nicolaou, and Scripps Florida in 2013 with Prof. W. R. Roush. His research interests include the total synthesis of natural products, development of modomain inhibitors for cancer treatment. His current research focuses on total synthesis of natural products and design and synthesis of new bioactive agents inspired by natural products through novel asymmetric methodologies.

new synthetic methodologies and medicinal chemistry, and the discovery of new bioactive compounds. He is the chairman of the Department of Organic Chemistry since 2014 and scientific responsible of the NMR facilities of the University of Málaga. 


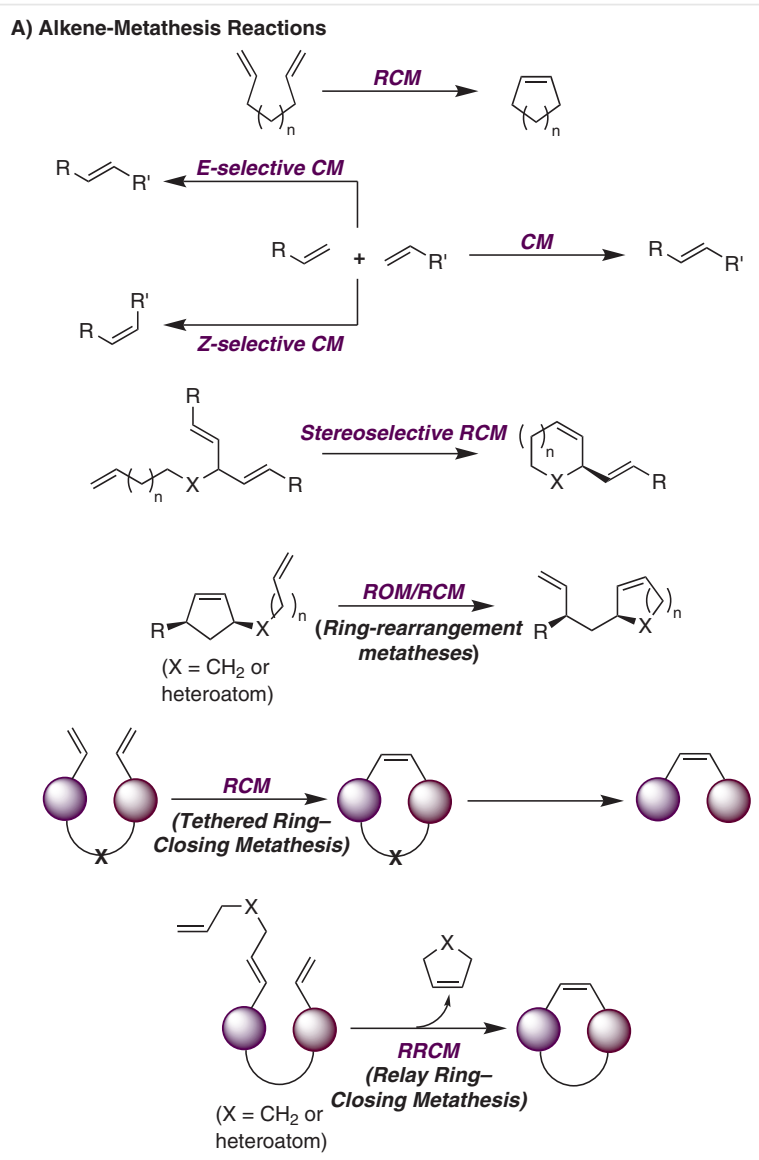

B) Enyne-Metathesis Reactions

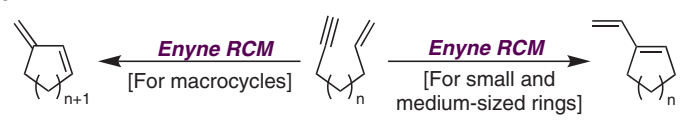

C) Alkyne-Metathesis Reactions

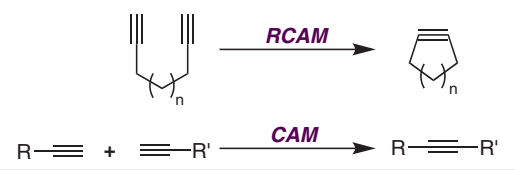

Scheme 1 Metathesis reactions in organic synthesis

particular kind of natural products. ${ }^{34}$ In light of this publication landscape, the current review intends to cover the recent advances reported in the field of total synthesis, in which a metathesis reaction has been essential for the completion of the synthesis, for the period 2012 to early 2018, with particular emphasis on recent pioneering contributions, as well as exciting applications in the context of total synthesis. With this review, we are confident that we will provide an updated state of the art of this field and will further demonstrate the power that this chemistry has to offer and the prospects that it provides for the future.

\section{Alkene Metathesis in Total Synthesis}

\subsection{Total Syntheses Based on a Ring-Closing- Metathesis Reaction}

The ring-closing metathesis (RCM) reaction is one of the most frequently employed methodologies to construct cyclic systems, becoming a common synthetic tool in the modern organic synthetic laboratory.

Indeed, a practically limitless array of carbocyclic or heterocyclic ring systems, including small-, medium-, and large-sized rings, can be constructed utilizing this transformation. In the context of total synthesis, the preparation of small- and medium-sized rings usually plays a complementary role implemented along the synthetic path. However, in the case of macrocyclic systems, the RCM reaction commonly constitutes a crucial step for the completion of the synthesis. For this reason, in this section, we would like to highlight representative examples reported in the last few years in which the RCM reaction was the key step. As a first series of examples in this category, it is worth mentioning the polyketide-type compounds ripostatin B $(\mathbf{2 8})^{35}$ and A (29), ${ }^{36}$ FD-895 (30), ${ }^{37}$ cruentaren A (31), ${ }^{38}$ pikromycin (32), ${ }^{39}$ zampanolide (33), ${ }^{40}$ amphidinolide $G(\mathbf{3 4}),{ }^{41}$ palmerolide A (35), ${ }^{42}$ ecklonialactone $B(36),{ }^{43}$ gambieric acid A (37), ${ }^{44}$ nominal gobienine $\mathrm{A}(\mathbf{3 8}),{ }^{45}$ trienomycin $\mathrm{A}(\mathbf{3 9})$ and $\mathrm{F}$ (40), ${ }^{46}$ 13-demethyllyngbyasolide $B(\mathbf{4 1}),{ }^{47}$ incednam $(\mathbf{4 2}),{ }^{48}$ sekothrixide (43), ${ }^{49}$ aspicillin (44), ${ }^{50}$ macrolide fragment of FD-891 (45), ${ }^{51}$ carolacton (46) ${ }^{52}$ (Figure 2), cytospolide P (47), ${ }^{53}$ pectenotoxin $(\mathbf{4 8}),{ }^{54}$ Sch725674 (49), ${ }^{55}$ aspergillide B (revised structure, 50), ${ }^{56}$ iriometolide $3 a(\mathbf{5 1}),{ }^{57}$ paecilomycin B (52), ${ }^{58}$ fidaxomicin (53), ${ }^{59}$ exiguolide $(\mathbf{5 4}),{ }^{60}$ neopeltolide (55), ${ }^{61}$ methynolide (56), ${ }^{62}$ and iriomoteolide-2a $(\mathbf{5 7})^{63}$ (Figure 3 ). In addition, the group of alkaloids and cyclodepsipeptides are illustrated with the examples of manzamine A (58) ${ }^{64}$ isoschizogamine (59), ${ }^{65}$ vertine $(\mathbf{6 0}),{ }^{66}$ haliclamide (61), ${ }^{67}$ 5-epi-torrubiellutin $(\mathbf{6 2}),{ }^{68}$ petrosin $(\mathbf{6 3}),{ }^{69}$ the YM-254890 analogue $\mathbf{6 4},{ }^{70}$ nannocystin $A(\mathbf{6 5})$ and $A 0$ (66), ${ }^{71}$ nakadomarin $A(67),{ }^{72}$ marineosin $A(68),{ }^{73}$ kanamienamide (69), ${ }^{74}$ and 15 -epi-aetheramide $\mathrm{A}(\mathbf{7 0})^{75}$ (Figure 4).

Finally, among the total syntheses of terpenes that employ the RCM reaction, particularly noteworthy are the syntheses of 17-deoxyprovidencin (71) ${ }^{76}$ uprolide $G$ acetate (72), ${ }^{77}$ terreumol C (73), ${ }^{78}$ pavidolide $B(\mathbf{7 4}),{ }^{79}$ and boscartin $\mathrm{F}(\mathbf{7 5})^{80}$ (Figure 5). As an indication of the effectiveness of the RCM processes, the yields achieved in many cases were reasonable to excellent (44-99\% yields), with some exceptions with lower yields (17-34\%), and in general excellent stereoselectivities, with some exceptions [ecklonialactone B (36), ${ }^{43}$ fidaxomicin (53), ${ }^{59}$ iriomoteolide-2a (57), ${ }^{63}$ nakadomarin $\mathrm{A}(\mathbf{6 7})^{72}$ ], for which the isomeric ratios are indicated. 

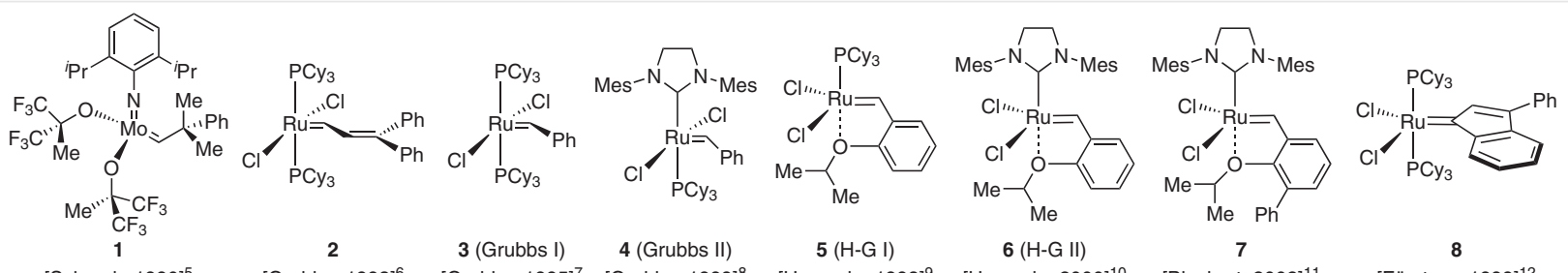

[Schrock, 1990] $]^{5}$

[Grubbs, 1993] ${ }^{6}$

$\begin{array}{cc}3 \text { (Grubbs I) } & \mathbf{4} \text { (Grubbs II) } \\ \text { [Grubbs, 1995] }^{7} & \text { [Grubbs, 1999] }^{8}\end{array}$

[Hoveyda, 1998]

$$
6 \text { (H-G II) }
$$

7
[Blechert, 2002] $^{11}$

$\left[\right.$ Hoveyda, 2000] ${ }^{10}$

8
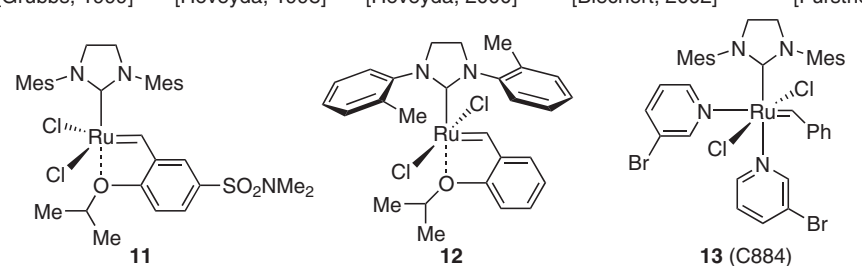

[Fürstner, 1999] ${ }^{12}$

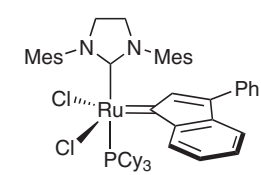

9

[Nolan, 1999] $^{13}$

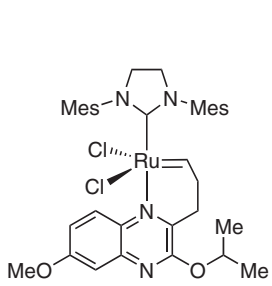

[Williams, 2016] $^{18}$

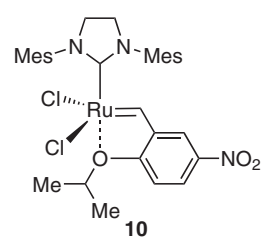

[Grela, 2002] ${ }^{14}$

[Zhan, 2007] ${ }^{15}$

[Grubbs-Stewart, 2007] ${ }^{16}$

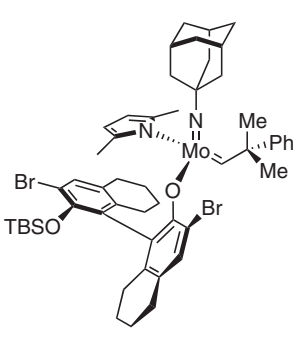

15

[Schrock, Hoveyda, 2008] ${ }^{19}$

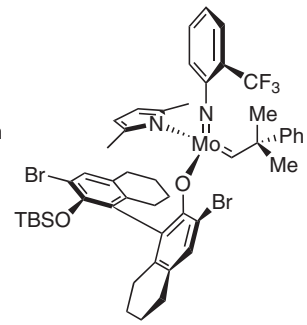

16

[Schrock, Hoveyda, 2008] $]^{19}$

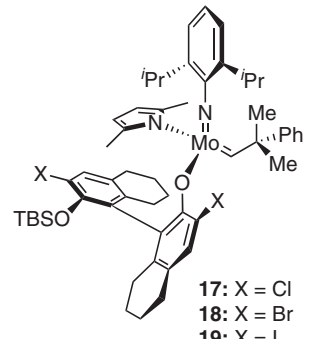

[Schrock, Hoveyda, 2008] ${ }^{19}$
13 (C884)

[Grubbs, 2002] $]^{17}$

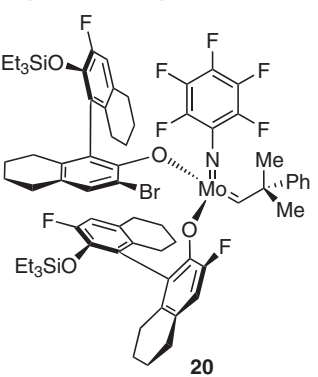

[Schrock, Hoveyda, 2008] ${ }^{19}$

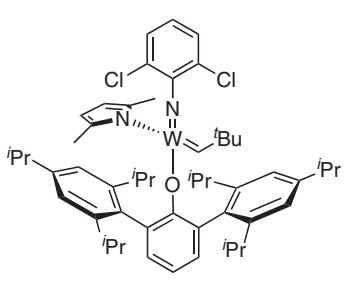

21

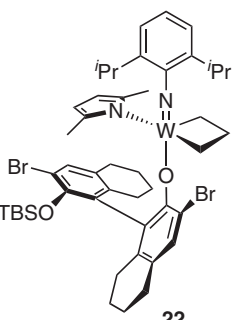

[Schrock, 2009] ${ }^{20}$

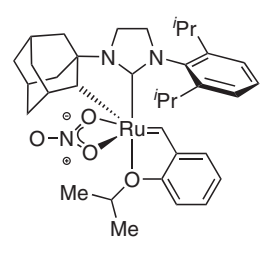

23

Grubbs, 2013] $]^{21}$

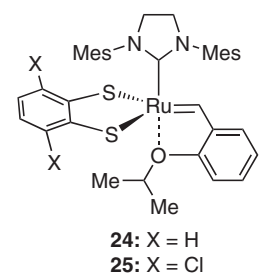

26: $\mathrm{X}=\mathrm{Br}$

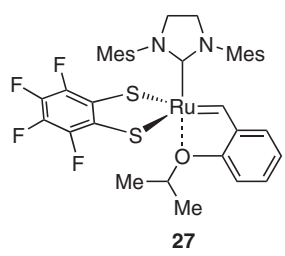

[Hoveyda, 2013] $]^{22}$

Figure 1 Common catalysts used for alkene- and enyne-metathesis reactions: evolution of their design and development

In addition to the previous contributions, we can find in the literature other cases that deserve a more detailed description. A first example is the synthesis by Brimble and co-workers of palmyrolide A (76) (Scheme 2), ${ }^{81}$ a macrolide isolated from Leptotyngbya cf. sp. and Oscillatoria sp. that displays interesting neuroprotective properties, combined with low cytotoxicity. The synthesis was initially based on a RCM reaction of a starting enamide precursor; however, this RCM attempt failed despite screening of a wide variety of reaction conditions. As a consequence of these disappointing results, they considered a sequential RCM/olefin isomerization from the diolefin $\mathbf{7 7}$, with the possibility that the desired isomerization may occur in the presence of the corresponding Grubbs catalyst. However, despite the RCM reaction of diolefin $\mathbf{7 7}$ proceeding efficiently when treated with the Grubbs II catalyst (4) to give macrocycle $\mathbf{7 8}$, the isomerization was not observed. This result led them to force the isomerization by subsequent treatment of the RCM product with $\mathrm{RuH}\left(\mathrm{PPh}_{3}\right)_{3}(\mathrm{CO}) \mathrm{Cl}$, which then afforded the natural product $\mathbf{7 6}$ in a good overall yield. This synthetic study constituted the first reported isomerization of an $\mathrm{N}$-allylated tertiary amide in a macrocyclic setting and, furthermore, allowed the revision of the structure of the natural product, which was erroneously assigned to the initial proposed structures $\mathbf{7 9}$ and $\mathbf{8 0}$ (Scheme 2).

A second relevant example is from Carreira and coworkers, who in a stereodivergent-oriented approach, described the synthesis of the four diastereomers of $\Delta^{9}$-tetrahydrocannabinol (81) via a RCM reaction from the acyclic precursors 82 (Scheme 3). ${ }^{82}$ Interestingly, the four stereoisomers of $\mathbf{8 2}$ were efficiently prepared by an elegant and novel dual catalytic process based on the use of a set of two chiral catalysts [Ir/(P, olefin) and a secondary amine] for the enantioselective allylation of 5-methylhex-5-enal. The RCM 
reaction of each stereoisomer of $\mathbf{8 2}$ was achieved under very mild conditions $\left(25^{\circ} \mathrm{C}\right.$ ) with the Grubbs II catalyst (4) to provide the corresponding THC precursors 83 in excellent $85-92 \%$ yields, which were transformed into the final products in three additional steps (Scheme 3). Previous syntheses of $\Delta^{9}$-THC 81 and related cannabinoid-type compounds have also employed the RCM reaction to construct the cyclohexene ring containing in these intriguing natural products. ${ }^{83}$

The construction of medium-sized rings containing cyclobutanes represents a challenging ring-closing metathesis due to the highly strained character of the resulting bicyclic system. Despite this potential difficulty, the RCM reaction has proven to be highly efficient in many cases. An instructive example of this is demonstrated in the synthesis of the polycyclic xanthone-type antibiotic IB-00208 (84), reported by Martin and co-workers (Scheme 4). ${ }^{84}$ Thus, the synthesis of the key cyclobutenone $\mathbf{8 6}$ was successfully achieved via a RCM reaction of precursor $\mathbf{8 5}$ when subjected to the Grubbs II catalyst (4). The resulting cyclobutenone was rearranged to the desired xanthone $\mathbf{8 7}$ under thermal conditions and represents a general route to construct polycyclic benzoquinones. A few more steps then converted the xanthone $\mathbf{8 7}$ into the targeted natural product 84 .

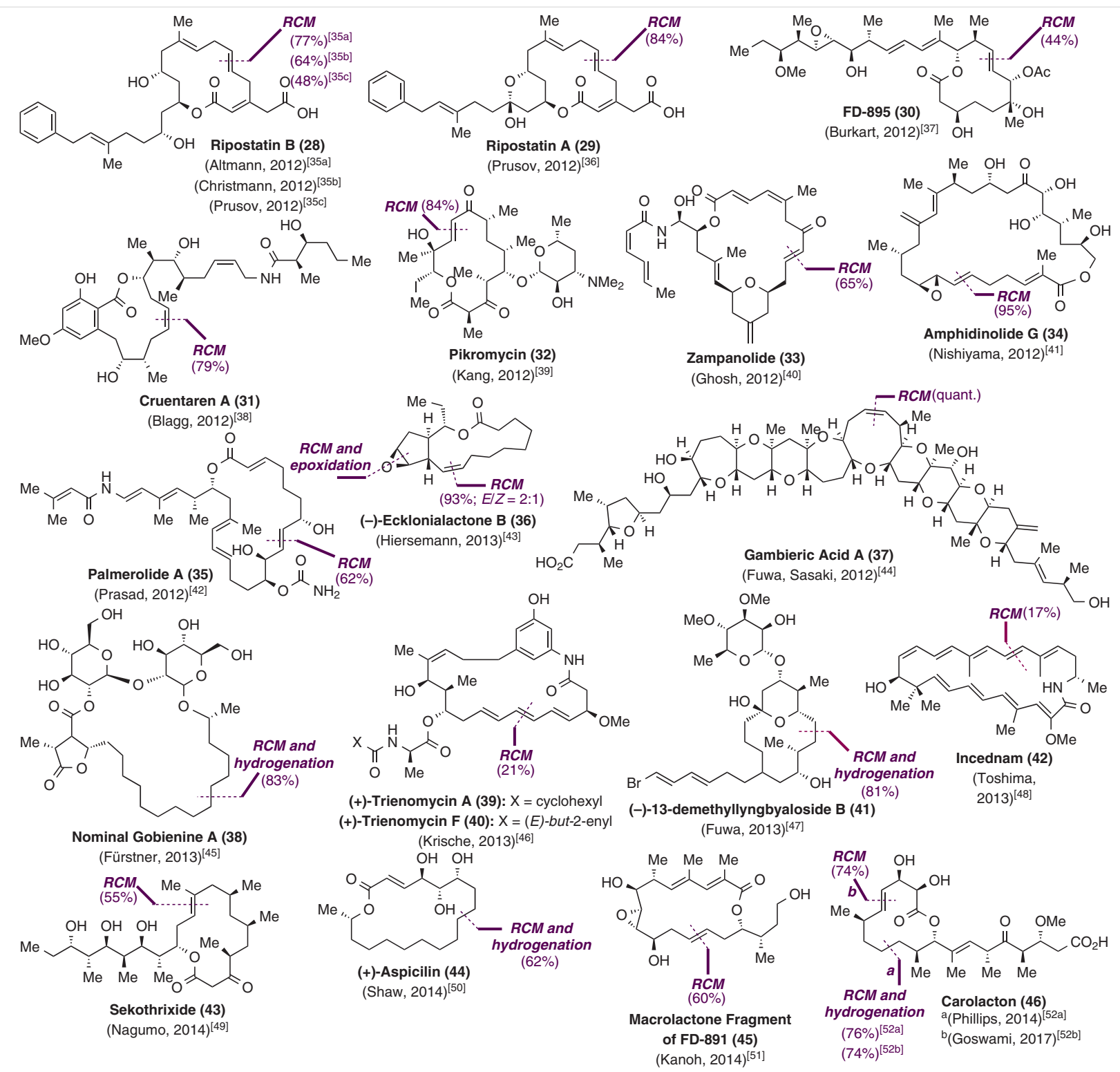

Figure 2 Selected macrocyclic polyketides synthesized via a RCM reaction (yields refer only to the RCM reaction) 


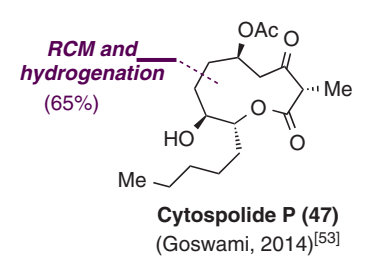

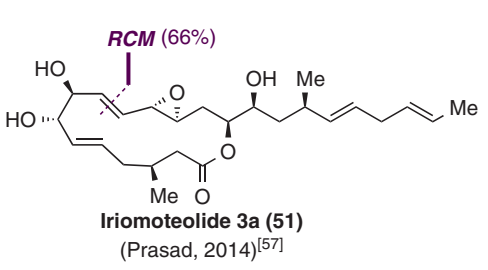

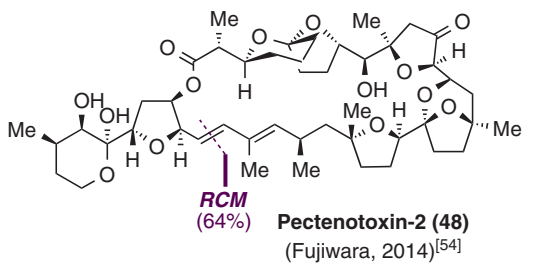

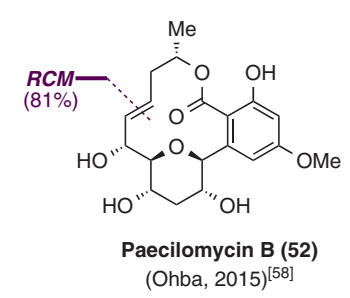
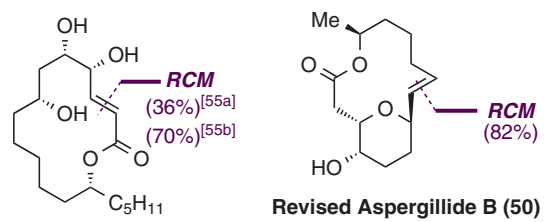

Revised Aspergillide B (50) (Mohapatra, 2014) ${ }^{[56]}$

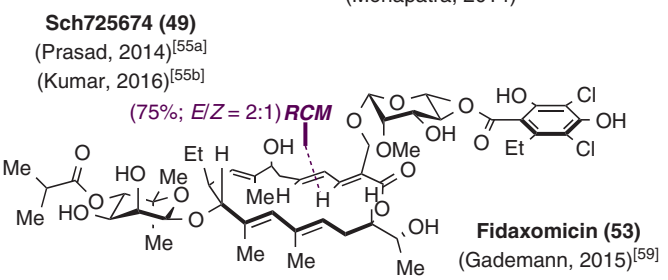

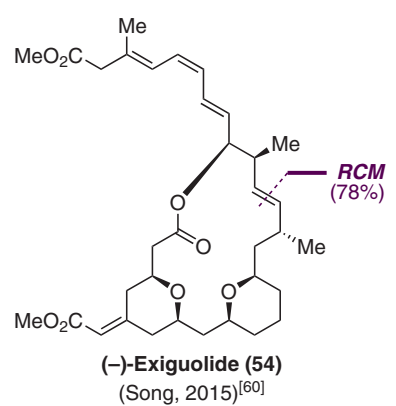
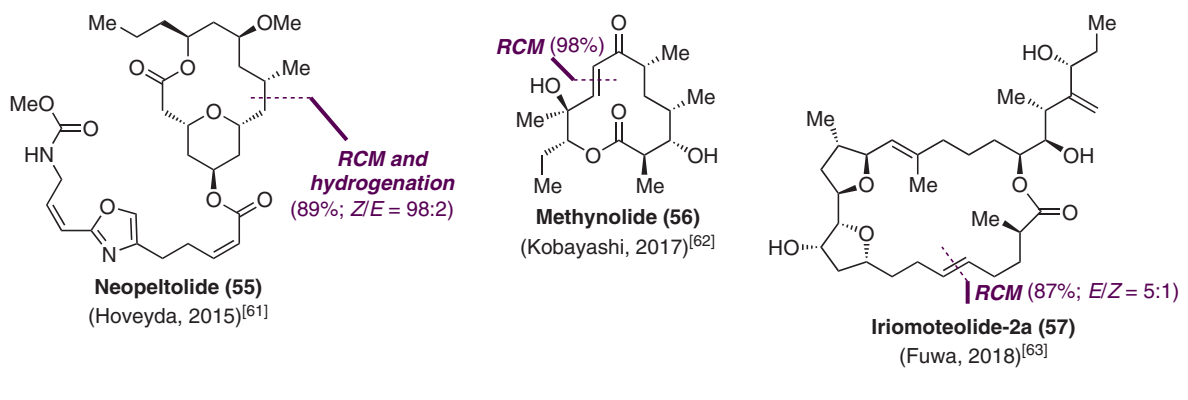

Figure 3 Selected macrocyclic polyketides synthesized via a RCM reaction (yields refer only to the RCM reaction)<smiles>C=CC=CC(=O)OC(CC(C)C)C(C)(C)C</smiles>

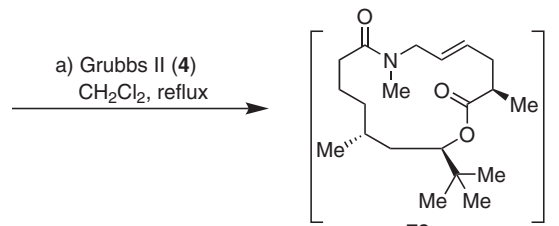

\begin{tabular}{l|l} 
b) $\operatorname{RuH}\left(\mathrm{PPh}_{3}\right)_{3}(\mathrm{CO}) \mathrm{Cl}$ \\
toluene, reflux & $\begin{array}{c}(64 \% \text { over } \\
2 \text { steps })\end{array}$
\end{tabular}
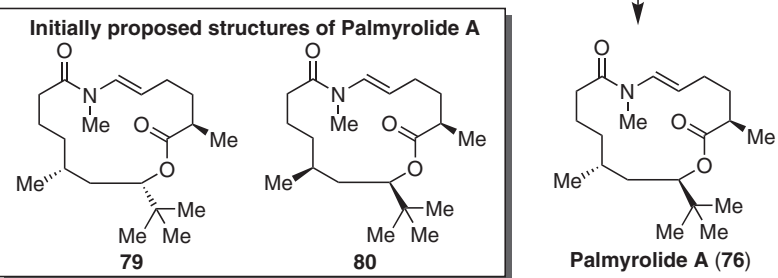

Scheme 2 Total synthesis of palmyrolide A

As another example of the use of the RCM reaction to fashion cyclobutane-containing polycyclic systems, we highlight the total synthesis of the cytotoxic meroterpenoid psiguadial B (88) by Reisman and co-workers (Scheme 5), 85 in which the RCM reaction of diolefinic cyclobutane $\mathbf{8 9}$, carried out with the H-G II catalyst (6) in the presence of 1,4benzoquinone, afforded in an excellent $93 \%$ yield the corresponding tricyclic derivative $\mathbf{9 0}$. After a formidable chemoselective hydrogenation of $\mathbf{9 0}$, which was accomplished in

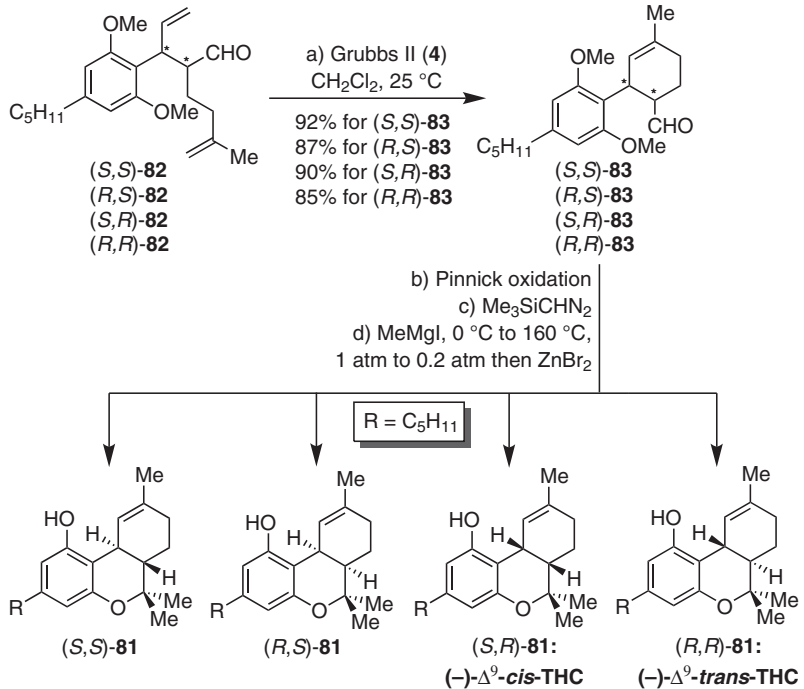

Scheme 3 Total synthesis of $\Delta^{9}$-THC and its stereoisomers

an excellent $90 \%$ yield by the action of Crabtree's catalyst, the resulting product 91 was carried towards the natural product in four additional steps.

A stunning example of the power of the RCM reaction can be found in the construction of strained ring systems via a transannular process as applied in the recent synthesis of the cembranolides sarcophytonolide $\mathrm{H}(\mathbf{9 2})$ and isosarco- 


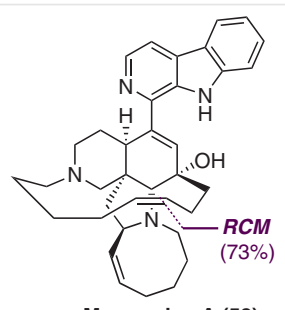

Manzamine A (58)

(Dixon, 2012) [64] $^{[58)}$

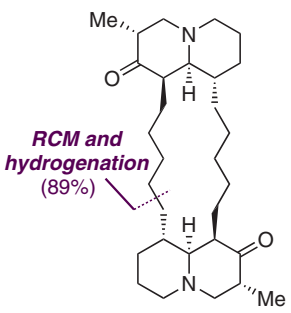

(+)-Petrosin (63) (Tokuyama, 2014) ${ }^{[69]}$

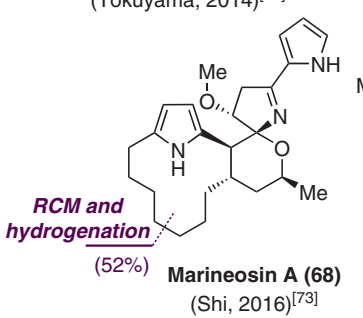

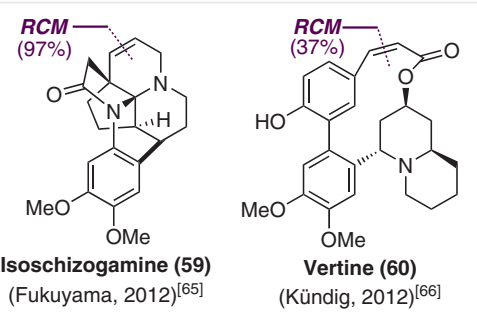

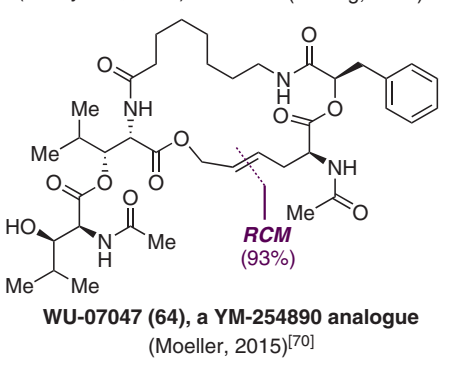

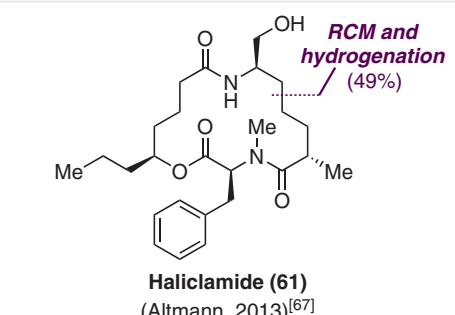

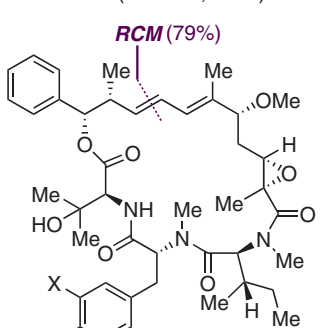

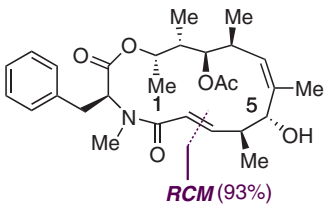

5-epi-Torrubiellutin (62) (Chandrasekhar, 2013) ${ }^{[68]}$

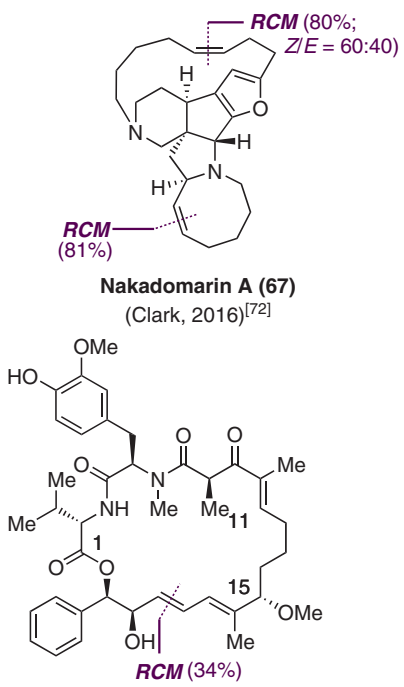

(+)-15-epi-Aetheramide A (70) (Prasad, 2017) $^{[75]}$

Figure 4 Selected alkaloids and cyclodepsipeptides synthesized via a RCM reaction (yields refer only to the RCM reaction)

phytonolide D (93) by Takamura and co-workers (Scheme 6). ${ }^{86}$ These natural products, isolated from the soft coral of the genus Sarcophyton, exhibit potent antifouling activities against the larval settlement of barnacle Balanus amphirite with $\mathrm{EC}_{50}$ values in the low $\mu \mathrm{g} / \mathrm{mL}$ range. In these syntheses, the construction of the butenolide contained in the macrocyclic framework, which is a structural feature of this class of diterpenes, was achieved via a RCM reaction of the corresponding precursors 94 and 96 by treatment with the H-G II catalyst (6) in toluene at $100{ }^{\circ} \mathrm{C}$. The efficiency of these processes is quite remarkable, given both the steric encumbrance around the ring-closure site and the complexity of the system. The completion of the synthesis of both natural products was carried out in three additional steps from the RCM products.

Further evidence for the utility of the RCM reaction in the construction of sterically crowded and highly functionalized ring systems is provided by the recent total synthesis of the highly oxidized diterpenoids ryanodol (97) and related diterpenes, natural products that display powerful pharmacological and insecticidal activities via their interactions with the ryanodine receptors. ${ }^{87}$ The synthesis of the C-ring of ryanodol was undertaken by Inoue and co-workers via the RCM reaction of the precursor 99 (Scheme 7), ${ }^{88}$ prepared from the allylic diketone $\mathbf{9 8}$ in three steps, in $\mathbf{5 8 \%}$

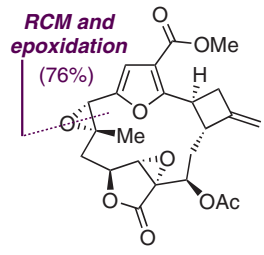

17-Deoxyprovidencin (71) (Mulzer, 2014) $^{[76]}$ RCM and

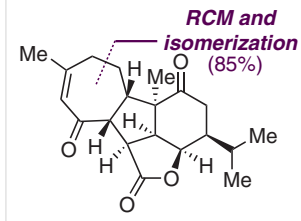

Pavidolide B (74) (Yang, 2017) ${ }^{[79]}$

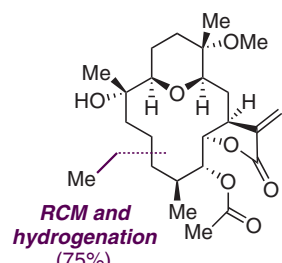
$(75 \%)$

Uprolide G acetate (72) (Tong, 2015) ${ }^{[77]}$

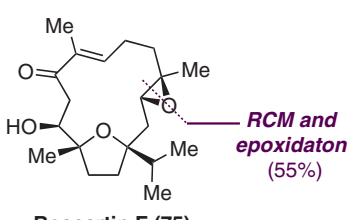

Boscartin F (75)

(Sugita, 2018) $^{[80]}$
Figure 5 Selected terpenes synthesized via a RCM reaction (yields refer only to the RCM reaction)

yield over four steps, to obtain advanced precursor 100. Remarkably, once again, the presence of unprotected functionalities was well tolerated under these ruthenium-catalyzed reaction conditions, thus underscoring the mildness and efficiency of these reactions in a complex setting. From 


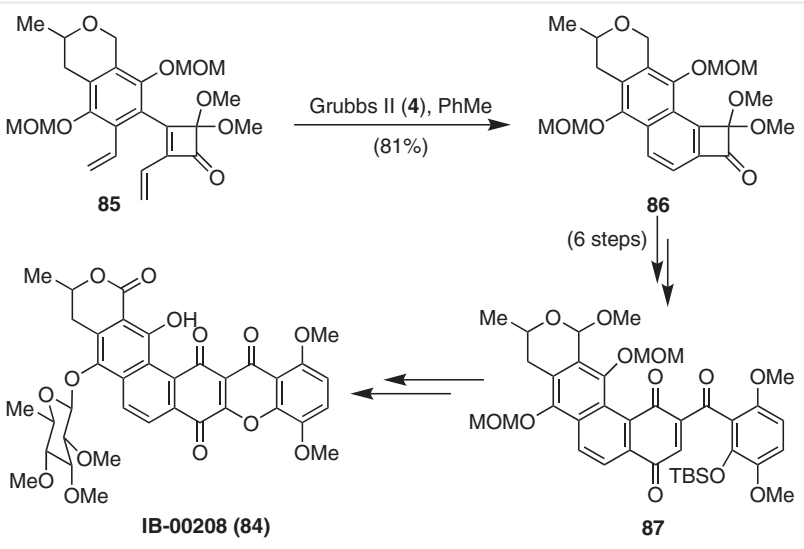

Scheme 4 Total synthesis of IB-00208
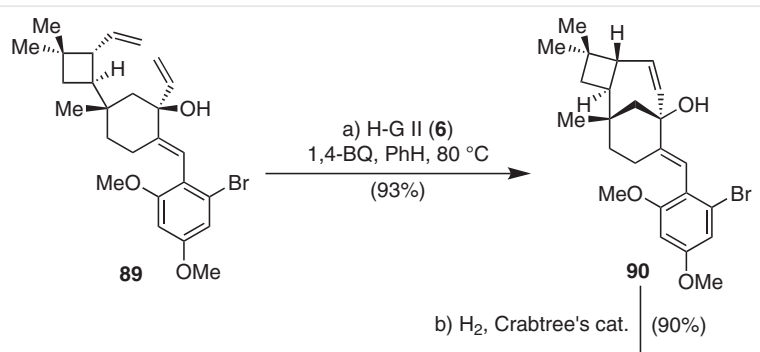

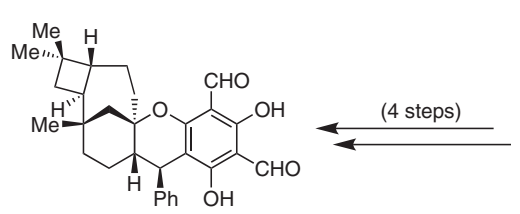

(+)-Psiguadial B (88)

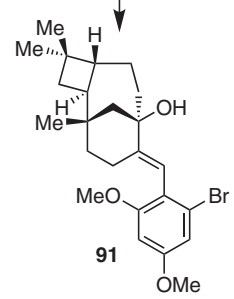

Scheme 5 Total synthesis of psiguadial B

compound 100, the completion of the synthesis of ryanodol (97) was accomplished in ten additional steps with minimal difficulty.

Within the stereoselective RCM processes, the use of chiral catalysts, such as the catalysts 15-22 designed by Hoveyda, Schrock, and co-workers (see Figure 1), allows for the preparation of enantiomerically enriched products. ${ }^{89}$ Their applications and level of enantioselective control is nicely illustrated in the synthesis of the alkaloid deoxoapodine (101), a member of a family of alkaloids that share the pentacyclic aspidosperma core. This asymmetric synthesis was devised by Movassaghi and co-workers based on a desymmetrization process of the achiral triolefin $\mathbf{1 0 2}$ (Scheme 8). ${ }^{90}$ Thus, achiral compound 102 was subjected to the catalytic activity of the chiral molybdenum pyrrolide complex 17, which proved to be efficient in terms of chemical yield and stereoselectivity in the synthesis of quebrachamine, ${ }^{19 c}$ however, in this case, the catalyst offered only moderate enantioselectivity [er (-)-103/(+)-103 82:18].
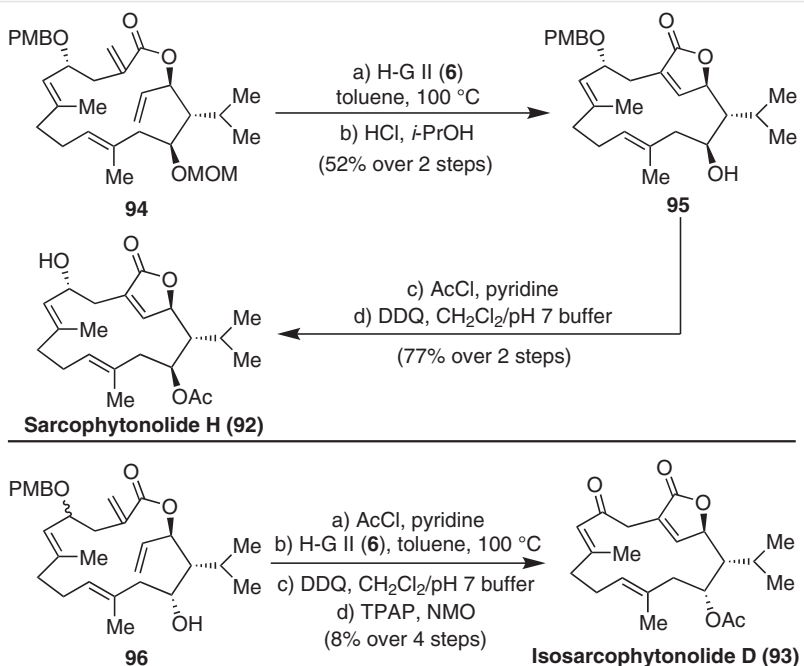

Scheme 6 Total synthesis of sarcophytonolide $\mathrm{H}$ and isosarcophytonolide $D$

This stereochemical outcome was likely influenced by the presence of the amide group in the starting precursor, which could coordinate with the transition metal resulting in a consequent reduction of the catalytic activity. In light of these results, an exploration of other chiral catalysts led to the observation that as the size of the halide substituent on the complex increased, the level of enantioselectivity was improved, with a (-)-103/(+)-103 93:7 ratio of enantiomers being achieved when the diiodo complex 19 was employed. As the natural product possessed the opposite configuration, this result was extended to the enantiomer catalyst ent-19 to obtain the product $\mathbf{1 0 3}$ with the configuration of the natural product in $92 \%$ yield and with an enantiomeric ratio of $(+)-\mathbf{1 0 3} /(-)-\mathbf{1 0 3} 94: 6$. With the key product $(+)-103$ in hand, the synthetic route to the natural product was delineated through the pentacyclic derivative 104, which was prepared in an efficient manner from (+)-103 according to the steps indicated in Scheme 8. From pentacycle 104, seven additional steps were required for completion of the synthesis of deoxoapodine (101).

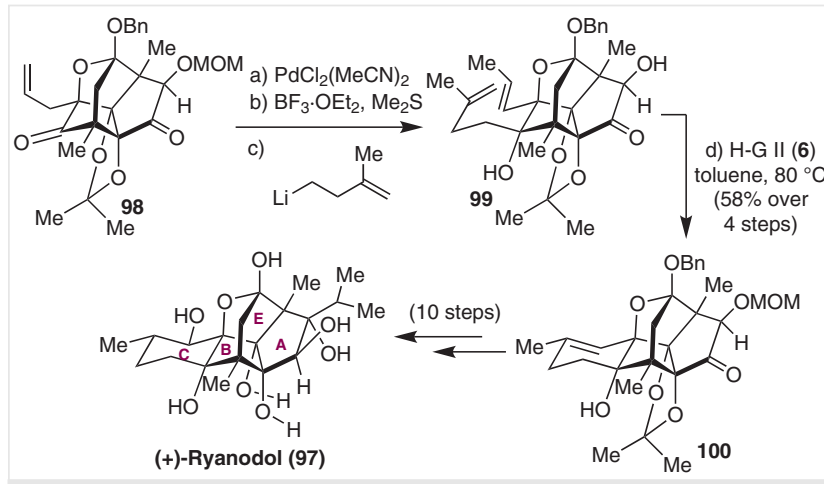

Scheme 7 Total synthesis of ryanodol 

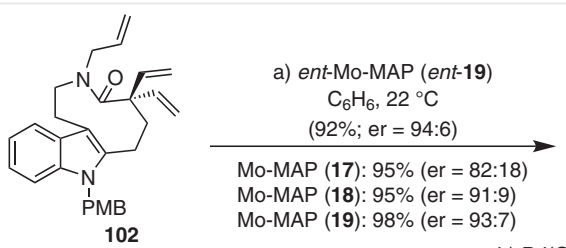

Mo-MAP (19): $98 \%$ (er = 93:7)

b) $\mathrm{Pd}(\mathrm{OAc})_{2}, \mathrm{HClO}_{4}$ then $\mathrm{NaBH}_{4}$ (56\% over 4 steps) d) $\mathrm{Bu}_{3} \mathrm{SnH}, \mathrm{Tf}_{2} \mathrm{O}$ e) $\mathrm{NaBH}(\mathrm{OMe})_{3}$

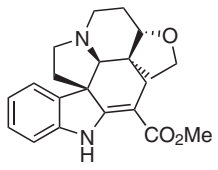

(-)-Deoxoapodine (101)

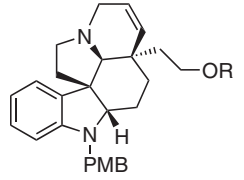

104: $\mathrm{R}=p$-nitrobenzoyl
Scheme 8 Total synthesis of deoxoapodine

Despite the excellent functional group tolerance and the low sensitivity to steric hindrances displayed by these catalysts, we can find in the literature numerous examples in which steric factors appear to play a crucial role in unsuccessful ring-closure reactions. This is the case for compound 105, which was devised as a potential precursor for the synthesis of the natural product pseudotabersonine (106) by Martin and co-workers (Scheme 9). ${ }^{91}$ Thus, when 105 was treated with different ruthenium catalysts, including Grubbs I (3), Grubbs II (4), H-G II (6), or even the Grubbs-Stewart catalyst (12), which is especially reactive towards sterically hindered olefins, the desired product 107, resulting from a double RCM process was not observed, instead obtaining the monocyclized product 108 in
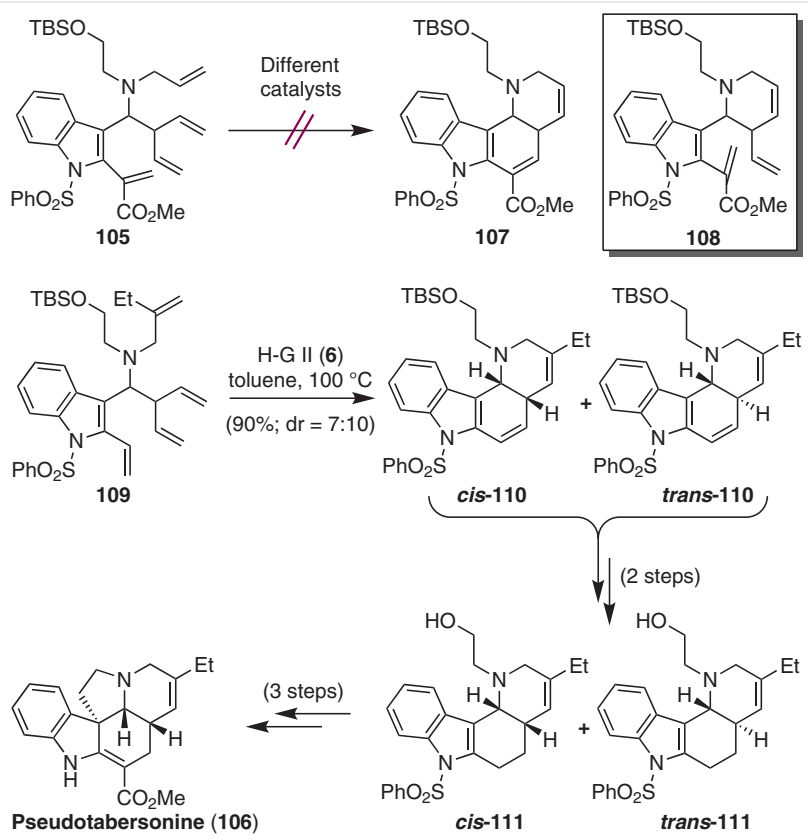

moderate yields, together with degradation products. They explored structural modifications of the precursor, by increasing its reactivity by removing the ester group, together with a complete optimization study of the RCM reaction. This extensive study led them to define a set of suitable structural requisites and reaction conditions to enable the targeted product. Accordingly, having established 109 as a suitable precursor, when this compound was treated with $\mathrm{H}-\mathrm{G}$ II catalyst $(\mathbf{6})$ in toluene at $100{ }^{\circ} \mathrm{C}$, the desired metathesis product 110 was obtained in $90 \%$ yield albeit as an inseparable mixture of cis/trans isomers in 7:10 ratio. After transformation of the diastereomeric mixture $\mathbf{1 1 0}$ into the reduced product 111, the isomers could be separated, and then the required cis isomer was taken forward to completion of the natural product in three more steps.

A noteworthy case in point is the natural product soraphen $A_{1 \alpha}$ (112), whose biological activities, including antimicrobial, antifungus, antidiabetes, and, more recently, anticancer properties, has prompted great interest in chemical and biological circles. Preliminary synthetic efforts conducted by Ciufolini and co-workers, ${ }^{92}$ towards this compound based on RCM were met with failure when they attempted to effect a ring closure with various acyclic precursors 113-116, different catalysts and several reaction conditions to obtain the corresponding coveted macrocycles 117-120 (Scheme 10). Reasoning that steric factors were responsible for the failed RCM reactions, other investigators attempted the metathesis macrocyclization at less sterically encumbered sites. To this aim, Kalesse and co-workers ${ }^{93}$ explored the RCM reaction of precursor 121 by treatment with different ruthenium-based catalysts, however the results were similarly unfruitful in all cases (Scheme 10). In contrast to all these discouraging results, the RCM reaction of the desmethoxy precursor 123, explored by Micalizio and co-workers (Scheme 10), ${ }^{94}$ provided in high yield (90\%) the corresponding macrocycle 124 with Grubbs II catalyst (4), proof that steric factors were responsible for the previous failures. From compound 124, they completed the synthesis of the soraphen analogue 125. Interestingly, this soraphen analogue displayed promising cytotoxic activities against B-lymphoma cell lines, revealing that the methoxy group present in the natural product was not essential for biological activity.

A paradigmatic example in which the RCM reaction proved to be completely useless was in the synthesis of the bryostatins. The well-known fascinating synthesis of the bryostatins by Trost and co-workers was preceded by an initial attempt of its total synthesis via a RCM reaction of the diolefins 126 and 127 (Scheme 11). ${ }^{95}$ However, after extensive screening of different catalysts and conditions, they were unable to obtain the corresponding macrocycles $\mathbf{1 2 8}$ and 129. Furthermore, the implementation of the relay RCM (RRCM) strategy, as we will describe later, did not provide the expected macrocyclic olefin, when the RRCM pre-

Scheme 9 Total synthesis of pseudotabersonine 


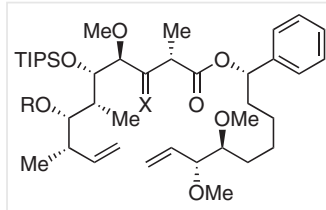

113: $\mathrm{X}=\mathrm{H}, \mathrm{OH} ; \mathrm{R}=$ MEM 114: $\mathrm{X}=\mathrm{H}, \mathrm{OH} ; \mathrm{R}=\mathrm{TBS}$ 115: $X=H$, OTES; $R=$ TBS 116: $X=O ; R=T B S$

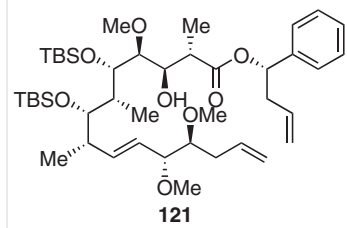
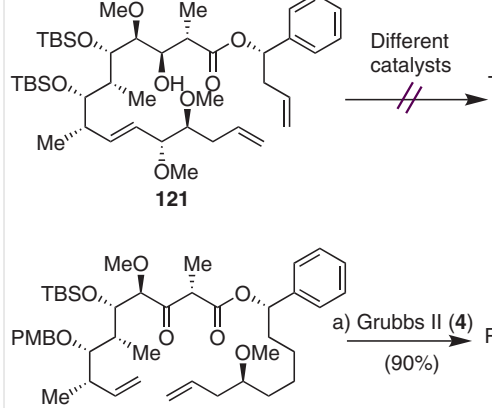

123

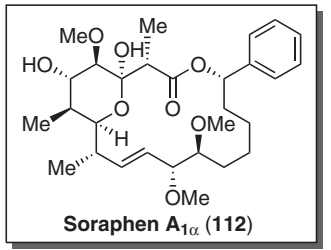

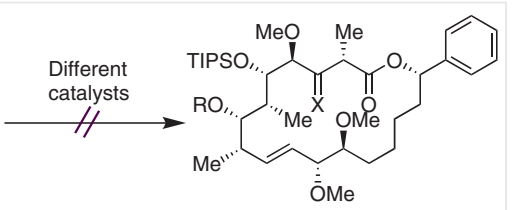

117: $\mathrm{X}=\mathrm{H}, \mathrm{OH} ; \mathrm{R}=\mathrm{MEM}$ 118: $\mathrm{X}=\mathrm{H}, \mathrm{OH} ; \mathrm{R}=\mathrm{TBS}$ 119: $X=H$, OTES; $R=$ TBS 120: $X=O ; R=$ TBS

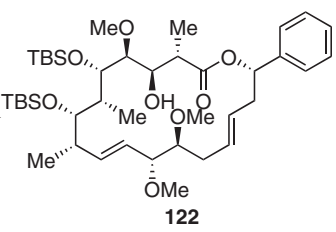
122

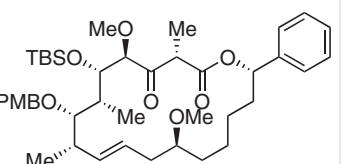

$M e^{\prime \prime \prime}$ b) $\mathrm{DDQ}$
c) TBAF $\downarrow$ ( $46 \%$ over
2 steps $)$ c) TBAF $\downarrow 2$ steps)

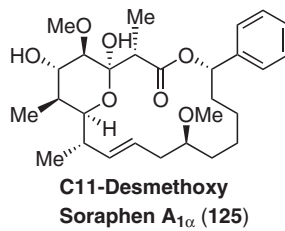

Scheme 10 Synthetic attempts towards soraphen $A_{1 \alpha}$ via RCM and synthesis of the C11-desmethoxy analogue

cursor 130 was subjected to different ruthenium-based catalysts, providing instead the macrocyclic product 131 as a result of the incorporation of the extended olefin onto the final cyclization product. Having ascribed the importance of steric hindrance, imposed by the presence of the gem-dimethyl system at the allylic position, as the reason for these disappointing results, in 2017 Thomas and co-workers studied the RCM reaction in model systems of the bryostatins in which the gem-dimethyl group was removed (Scheme 11). ${ }^{96}$ In their study, the RCM reaction of model compound 132 by exposure to the Grubbs II catalyst (4) furnished the macrocyclic compound $\mathbf{1 3 3}$, albeit in a poor $17 \%$ yield (Scheme 11). These results are an indication of the serious hurdles that this class of systems presents for the metathesis reaction.

A recent 2018 example in which a RCM reaction was combined with a final $\mathrm{CM}$ reaction to append the side chain in a stereoselective manner is the synthesis of the halogenated marine metabolites chlorofucins 134 and 135 and bromofucins 136 and 137 by Paton, Kim, and co-workers (Scheme 12). ${ }^{97}$ These natural products belong to the family of the bioactive acetogenins isolated from the Laurencia red algae that have generated great synthetic interest, particularly in the development of efficient methodologies for the

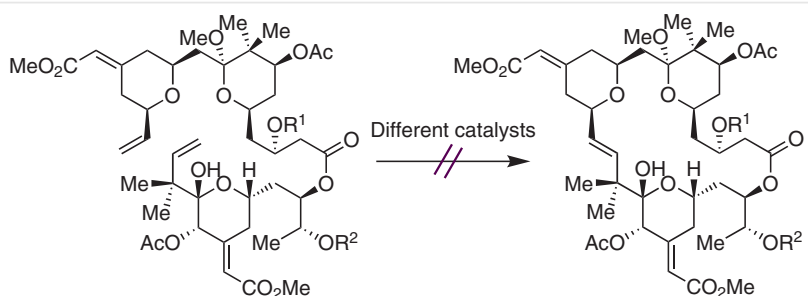

126: $R^{1}=$ TBDPS; $R^{2}=$ TES 127: $R^{1}=R^{2}=H$

128: $R^{1}=$ TBDPS; $R^{2}=$ TES 129: $R^{1}=R^{2}=H$

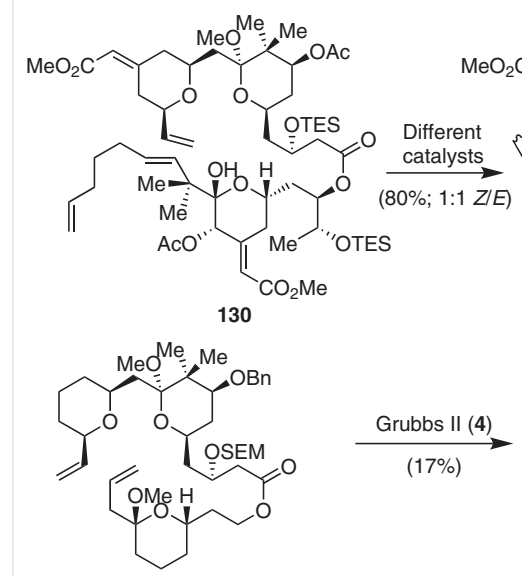

132

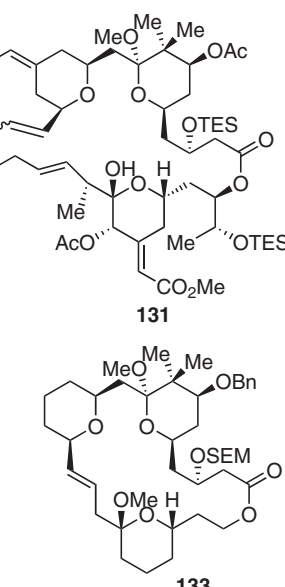

133
Scheme 11 Synthetic studies on bryostatins via RCM reactions

regio- and stereocontrolled construction of the mediumring oxacycle that characterize these appealing natural products. ${ }^{98}$ Furthermore, for the chlorofucins 134 and 135 and bromofucins 136 and 137, their absolute configurations were not established so their asymmetric syntheses could unambiguously confirm their proposed configurations. Thus, the formation of the common oxocene derivative 139 was efficiently undertaken by exposure of the acyclic precursor 138 to Grubbs II catalyst (4). For the incorporation of the halogen with concomitant intramolecular etherification, oxocene 139 was previously transformed into the alcohol 140 in an excellent overall yield and stereoselectivity. With this compound in hand, treatment with $t$ $\mathrm{BuOCl}$ or NBS efficiently furnished the corresponding chloro and bromo bicyclic ethers, which were prepared for the key $\mathrm{CM}$ reaction by transformation into the terminal olefins 141 and 142, respectively. For the E-selective installation of the enyne moiety, they carried out a CM reaction of compounds 141 and 142 with crotonoaldehyde in the presence of the Grubbs II catalyst (4) to yield the corresponding $(E)-\alpha, \beta$-unsaturated aldehydes, which after a final reaction with lithium TMS-diazomethane delivered the final products 135 and 137 in 74\% and 61\% overall yields, respectively. For the synthesis of the Z-isomers, they applied the Lee methodology, ${ }^{99}$ based on a cross metathesis with enyne $\mathbf{1 4 5}$ in the presence of the H-G II catalyst (6) for the direct delivery of the $Z$-isomers of both natural products 
134 and 136 in good yields, albeit in modest stereoselectivities in favor of the $Z$-isomer (3.8:1 mixture for $134 ; 4: 1$ for 136) (Scheme 12). Finally, the described stereodivergent strategy to the chlorofucins and bromofucins allowed confirmation of the absolute configurations of these natural products by comparison of the spectroscopic properties and optical rotations of the synthetic compounds with those reported for the natural products.
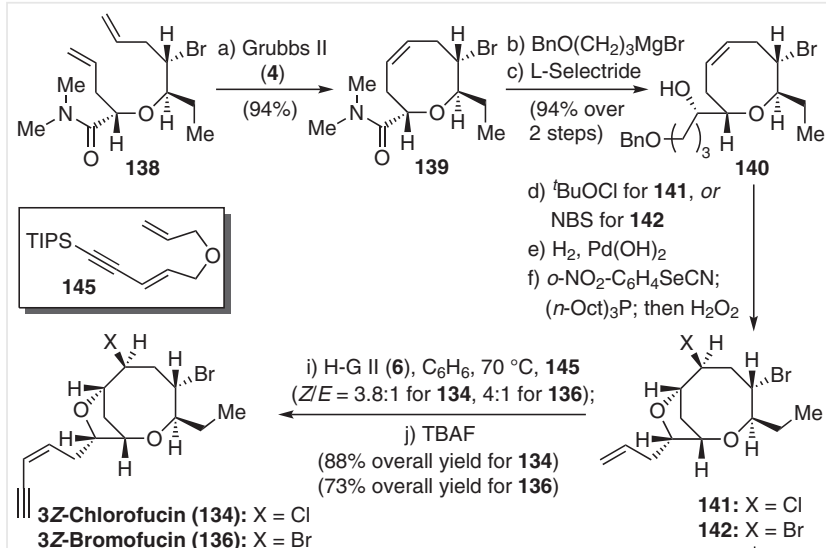
142: $\mathrm{X}=\mathrm{Br}$
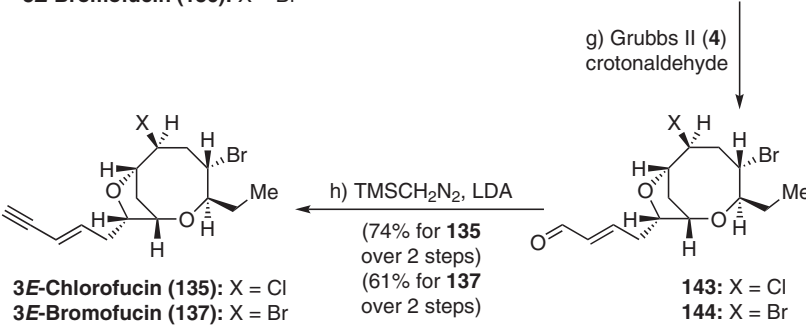

Scheme 12 Total synthesis of chlorofucins and bromofucins

Metathesis-based methodologies have been used in combination with other innovative technologies in organic synthesis laboratories. Indeed such a case is continuous flow technology, which has been recently implemented in combination with metathesis reactions to enhance their synthetic value. ${ }^{100,101}$ An interesting application of this can be found in the total synthesis of neomarchantin A (146), a natural product belonging to the macrocyclic bisbibenzyl family, which has been paid much attention from chemical and biological standpoints due to its intriguing structural and biological features. For example, these compounds exhibit a wide range of biological activities, including antibacterial, antimycotic, antitumoral, and antiviral activities. The total synthesis of neomarchantin A (146) (Scheme 13), described by Collins and co-workers, ${ }^{102}$ represents the first synthesis of this natural product, which is based on a RCM reaction of the diolefin 147 , to obtain the corresponding macrocyclic derivative in a modest $43 \%$ yield when $\mathrm{H}-\mathrm{G}$ II catalyst (6) was employed in toluene at $110{ }^{\circ} \mathrm{C}$. Interestingly, when the cyclization reaction was done in continuous flow, the yield of the macrocyclic product could be increased to a $49 \%$ yield. Final hydrogenation and methyl ether cleavage afforded the targeted natural product in $88 \%$ overall yield (Scheme 13).

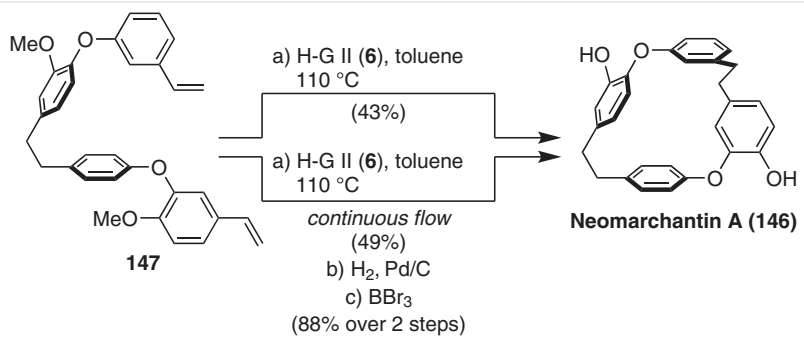

Scheme 13 Total synthesis of neomarchantin A

As a final example for this section, an interesting strategy was delineated for the synthesis of the cyclopropane fatty acid (+)-majusculoic acid (148), an interesting secondary metabolite with significant antifungal activity, by Zhang and co-workers (Scheme 14) ${ }^{103}$ Accordingly, they devised a stereoselective cyclopropanation from the $C_{2}$-symmetric 14-membered dilactone according to previously performed DFT calculations that revealed a preference of the $\beta$-faces of both olefins for the attack of the corresponding cyclopropanating reagents. For the synthesis of the required dilactone 150, they envisioned an unusual RCM dimerization from diolefinic monomer 149. To this aim, after an extensive study in which an array of catalysts, solvents, and temperatures were screened, they found the Grubbs II catalyst (4) in refluxing dichloromethane as the best reaction conditions to obtain the dilactone $\mathbf{1 5 0}$ (53\%), accompanied by the monomeric RCM product 151 in $26 \%$ yield. With the dilactone 150 in hand, it was possible to demonstrate the reliability of the theoretical predictions regarding the stereochemical outcome of the cyclopropanation. Indeed, the formation of the biscyclopropane $\mathbf{1 5 2}$ was realized in 80\% yield as a single stereoisomer when $\mathbf{1 5 0}$ was treated with diazomethane in the presence of palladium(II) acetate. The dimerization process was then continued by a dedimerization process by opening of the dilactone 152 with $\mathrm{N}, \mathrm{O}$-dimethylhydroxylamine and reduction of the resulting Weinreb amide to the aldehyde 153. In a final sequence of eight steps, in which the awkward $(E, Z)$-bromodiene system was installed via their newly developed new Kocienski-Juliatype reagent 154 , the synthesis was complete, obtaining a product which matched all the spectroscopic and physical properties with those reported for the natural product, except for the optical rotation, which was the opposite. Therefore, this asymmetric synthesis allowed the confirmation of the absolute configuration for the natural product that corresponded to ent-148, as initially proposed (Scheme 14). 


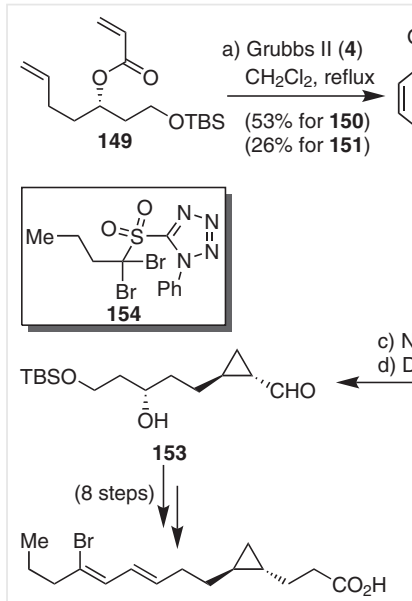

(+)-Majusculoic acid (148)

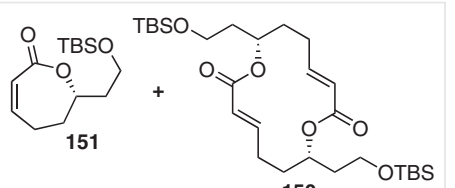
150 c) $\mathrm{NH}(\mathrm{OMe}) \mathrm{Me}$ d) DIBAL-H

$$
(82 \%)
$$<smiles>C1CCC1</smiles>

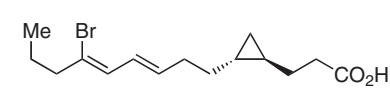

(-)-Majusculoic acid (ent-148) (Absolute configuration for the natural product)

Scheme 14 Total synthesis of (+)-majusculoic acid

\subsection{Total Syntheses Based on a Cross-Metathesis Reaction}

In contrast to the RCM reactions, the cross-metathesis (CM) reaction has received less attention in the field of total synthesis, probably due to the inherent difficulties of the intermolecular assembly of two alkenes, in which dimerization processes compete substantially. Despite these difficulties, the appealing features of the metathesis reactions, in terms of functional group tolerance and mild reaction conditions, have prompted intense research activity with the goal of minimizing the chemo- and stereoselective issues associated with this modality. As a consequence, CM reactions have emerged as a common chain-elongation method to append small side chains or to assemble linear complex molecular frameworks. Concerning the stereoselectivity of the reaction, the thermodynamic control that governs these reactions leads to the preferred formation of the $E$-alkene. Within the field of total synthesis, several interesting syntheses of natural products have been reported in which the $\mathrm{CM}$ represented the key step for the coupling of the important fragments of the molecule, thus allowing the completion of the synthesis. Among the most outstanding contributions of the last few years are the total syntheses of the fluorinated cryptophycin (155), ${ }^{104}$ FD-891 (156), ${ }^{105}$ murisolin (157), ${ }^{106}$ ledoglucomides A (158) and B (159), ${ }^{107}$ epicoccamide D (160), ${ }^{108}$ synargentolide B (161), ${ }^{109}$ homaline $(\mathbf{1 6 2}),{ }^{110}$ bitungolide $\mathrm{F}(\mathbf{1 6 3}),{ }^{111}$ penarolide $(\mathbf{1 6 4}),{ }^{112}$ cytospolide D (165), ${ }^{113}$ goniocin (166), ${ }^{114}$ cryptomoscatone F1 (167), ${ }^{115}$ curvicollide C (168), ${ }^{116}$ proposed structures for cryptorigidifoliol $\mathrm{K}$ 169a-d, ${ }^{117}$ and alotaketal A (170) $)^{118}$ (Figure 6).

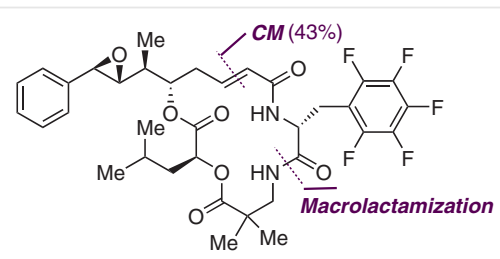

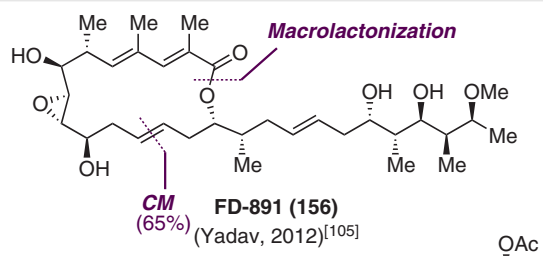

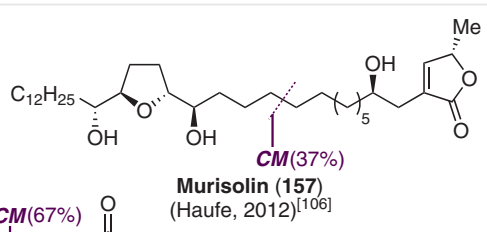

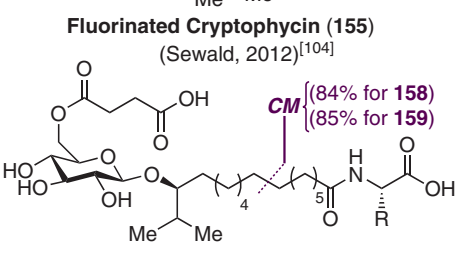

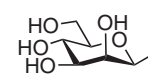<smiles>CCCCCCO</smiles><smiles>c1ccc(C23CC4CC(CC(C4)C2)C3)cc1</smiles><smiles>CO</smiles>
(1)

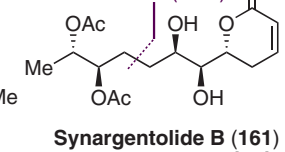
Epicoccamide D (160) (Yajima, 2014) $^{[108]}$ ledoglucomide $A: R=M e(158)$ ledoglucomide $A: R=M e(158)$
ledoglucomide $B: R=H(159)$ (Reddy, 2013) ${ }^{[107]}$

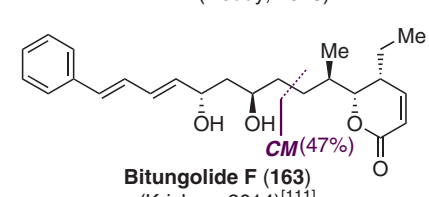

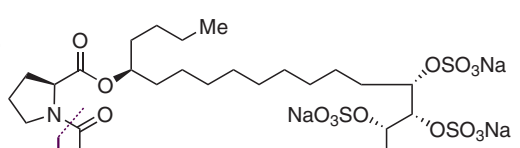

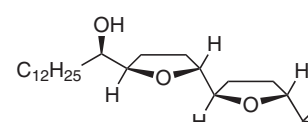<smiles>CCCCN1CCCN(CCCCN2CCCN(C)C(c3ccccc3)CC2=O)C(=O)CC1c1ccccc1</smiles>
(Davies, 2012) ${ }^{[110]}$<smiles>[Mg][Mg]</smiles>
ve 
However, there are some specific cases that deserve a more detailed description. As a first example within this category is the formal total synthesis of spirangien A (171), a highly potent cytotoxic spiroketal isolated from the prolific myxobacterium Sorangium cellulosum. Among the various total syntheses described for this natural product, that reported by Rizzacasa and co-workers (Scheme 15) ${ }^{119}$ utilized a CM reaction in the union of the olefins $\mathbf{1 7 2}$ and $\mathbf{1 7 3}$ under the assistance of the Grela-Grubbs-Hoveyda catalyst (10). This $\mathrm{CM}$ reaction afforded the E-enone $\mathbf{1 7 4}$ in an excellent $80 \%$ yield, providing a straightforward alternative to the use of a Horner-Wadsworth-Emmons reaction, which requires additional steps for the preparation of the required phosphonate. In this way, the backbone of the spiroketal core found in the natural product was constructed, requiring only six additional steps for the rapid and efficient preparation of the spiroketal precursor 176. From the advanced spiroketal precursor 176, the completion of the natural product was reported earlier by Paterson and co-workers (Scheme 15). ${ }^{120}$

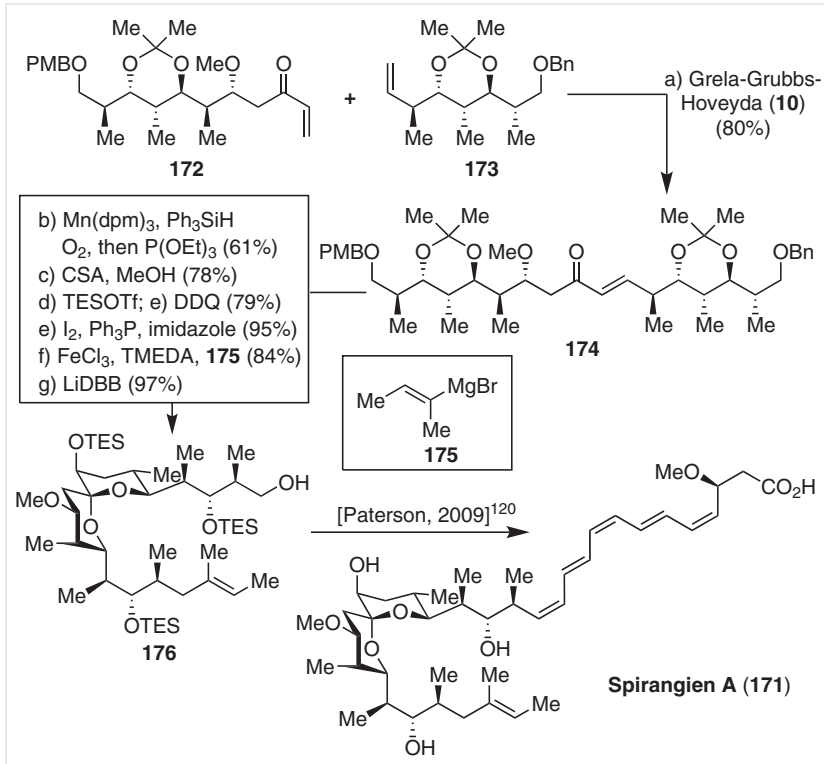

Scheme 15 Formal total synthesis of spirangien A

Another case of note is represented by the total synthesis of mueggelone (177), an inhibitor of fish embryo larval development. After several total syntheses reported for this interesting natural product, some of which required around 20 steps, Meshram and Kumar $^{121}$ described a convergent total synthesis utilizing only eight steps in the longest linear sequence, featuring a final CM step in which olefins $\mathbf{1 7 8}$ and 179 were assembled by treatment with the Grubbs II catalyst (4) to directly deliver the natural product $\mathbf{1 7 7}$ in $40 \%$ yield (Scheme 16 ).

The prominent antitumor activities of spliceostatin $\mathrm{E}$ (180) and related compounds, such as spliceostatin A (181) and FR901464 (182), have elicited great interest in their

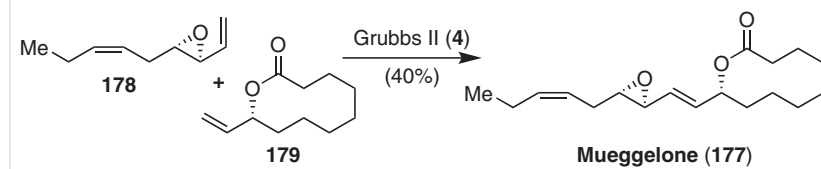

Scheme 16 Total synthesis of mueggelone

syntheses. Among them, the total syntheses developed by Ghosh and co-workers is based on a CM reaction, ${ }^{122}$ representing a brilliant example of the power and robustness of the methodology (Scheme 17).
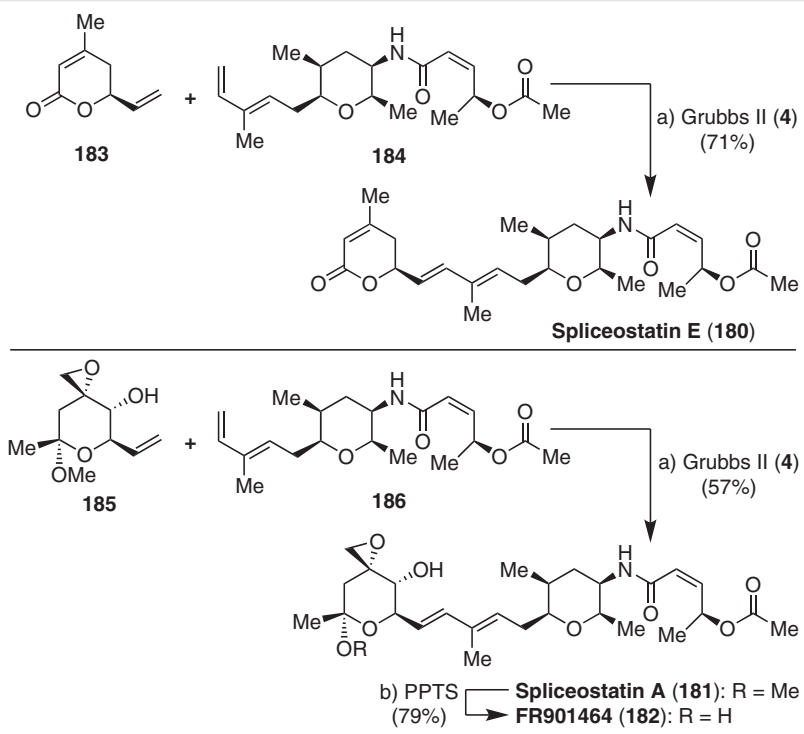

Scheme 17 Total synthesis of spliceostatins E and A and FR901464

The ability of these natural products to inhibit the cellular splicing process, an essential step for the gene expression, renders them a novel class of anticancer products. In fact, spliceostatin E (180) and FR901464 (182) exhibit potent anticancer activities in the ranges from 1.5 to 4.1 and from 0.6 to $3.4 \mathrm{nM}$, respectively, against various human cancer cell lines. The syntheses of both compounds were achieved via a final key CM that efficiently joined fragments 183 and 184 for spliceostatin $\mathrm{E}(\mathbf{1 8 0})^{122}$ and 185 and 186 for spliceostatin A (181), ${ }^{123}$ in $71 \%$ and $57 \%$ yields, respectively, with both reactions displaying exquisite chemo- and stereoselectivities. A final acidic treatment of compound 181 afforded the natural product 182 (Scheme 17).

An excellent example that illustrates the advantage that the $\mathrm{CM}$ reaction can offer, especially for macrocyclic compounds, over a RCM reaction, are the synthesis of the natural products mycalolide A (187) and B (188) by Kigoshi, Kita, and co-workers (Scheme 18). ${ }^{124}$ Both compounds, isolated from the marine sponge Mycale sp., are members of a family of natural products characterized by the presence of a trisoxazole macrocycle with potent cytotoxic activities as a consequence of actin-depolymerizing activity. A first at- 
tempt at the total synthesis was carried out by them via a $\mathrm{RCM}$ reaction of the diolefins $\mathbf{1 8 9}$ a and $\mathbf{1 8 9 b}$. However, despite this reaction affording the macrocyclic derivatives 190a and 190b in reasonably good yields (40-76\% depending on the employed catalysts and solvents), the reaction was not stereoselective in either case, providing a mixture of the $E / Z$ isomers in ratios of $1: 1$ to $1.9: 1.0$. This proportion could be increased to a 2.7:1.0 ratio in favor of the required E-olefin when the desilylated derivative $\mathbf{1 8 9 b}$ was employed as the starting precursor. As an alternative, they at-
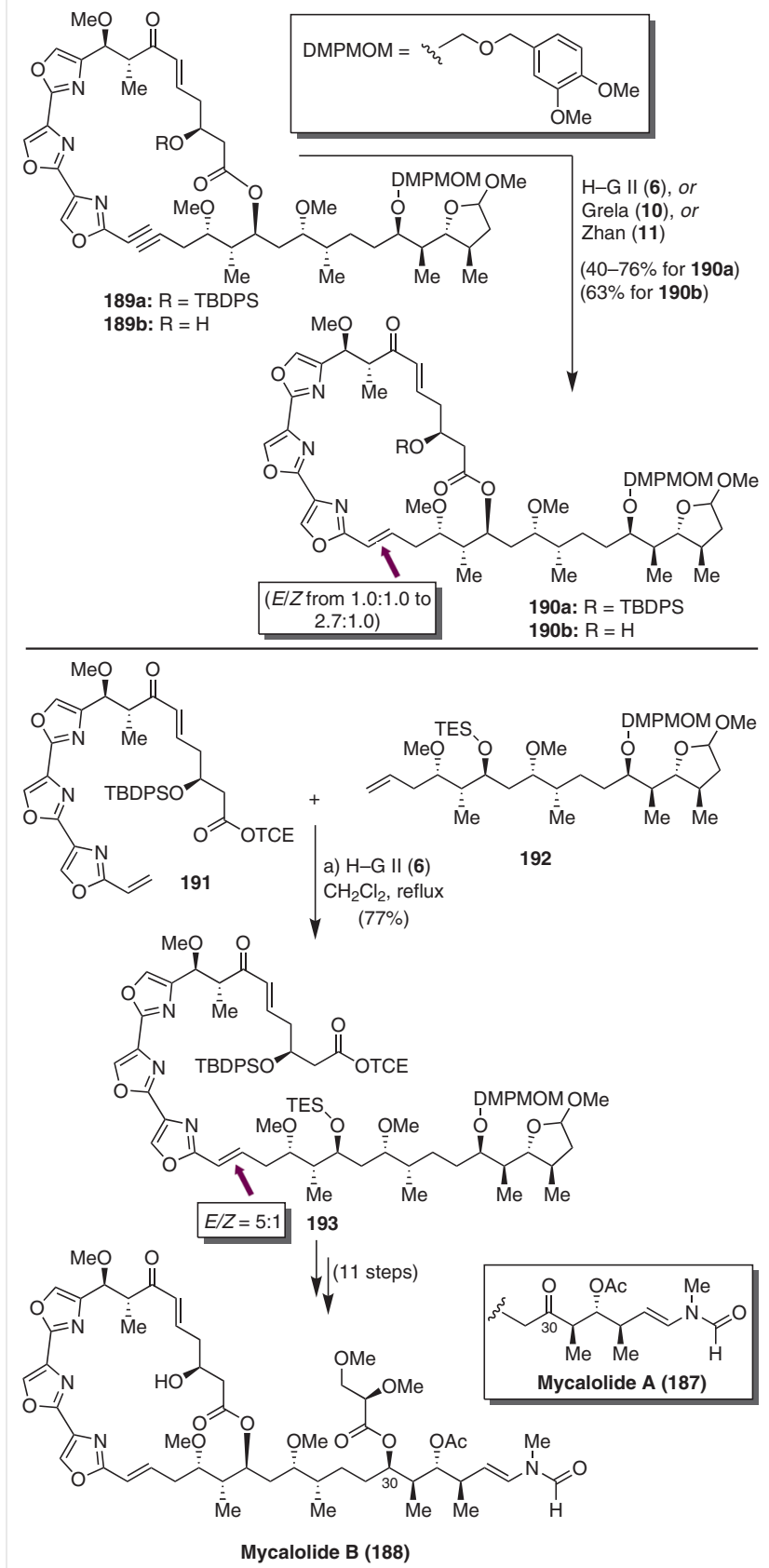

Scheme 18 Total synthesis of mycalolides A and B tempted a $\mathrm{CM} /$ macrolactonization approach which proved to be more efficient. Thus, when a mixture of olefins $\mathbf{1 9 1}$ and 192 was subjected to the catalytic action of the H-G II catalyst (6) in refluxing dichloromethane, the olefin 193 was obtained in an impressive $77 \%$ yield and in an improved 5:1 mixture of the $E / Z$ isomers. After the successful $C M$ step, a Yamaguchi macrolactonization was conducted to prepare the corresponding macrolactone in a remarkable $77 \%$ yield, which was finally directed to the natural products mycalolides A (187) and B (188) in ten additional steps (Scheme 18).

The scope of the CM reaction has been expanded to conjugated dienes by Altmann and Glaus in $2015^{125}$ during their synthetic studies directed towards the aglycone of tiacumicin B (194), a macrocylic antibiotic with potential application against Mycobacterium tuberculosis and whose total synthesis was not reported when the studies were published (Scheme 19). Thus, combination of olefin 195 and the conjugated diene $\mathbf{1 9 6}$ in the presence of the H-G II catalyst (6) provided a 56\% yield of compound 197 as an inseparable mixture of $E / Z$ isomers in a 6.7:1 ratio. The preparation of ester 199 was followed by a Suzuki macrocycliza-
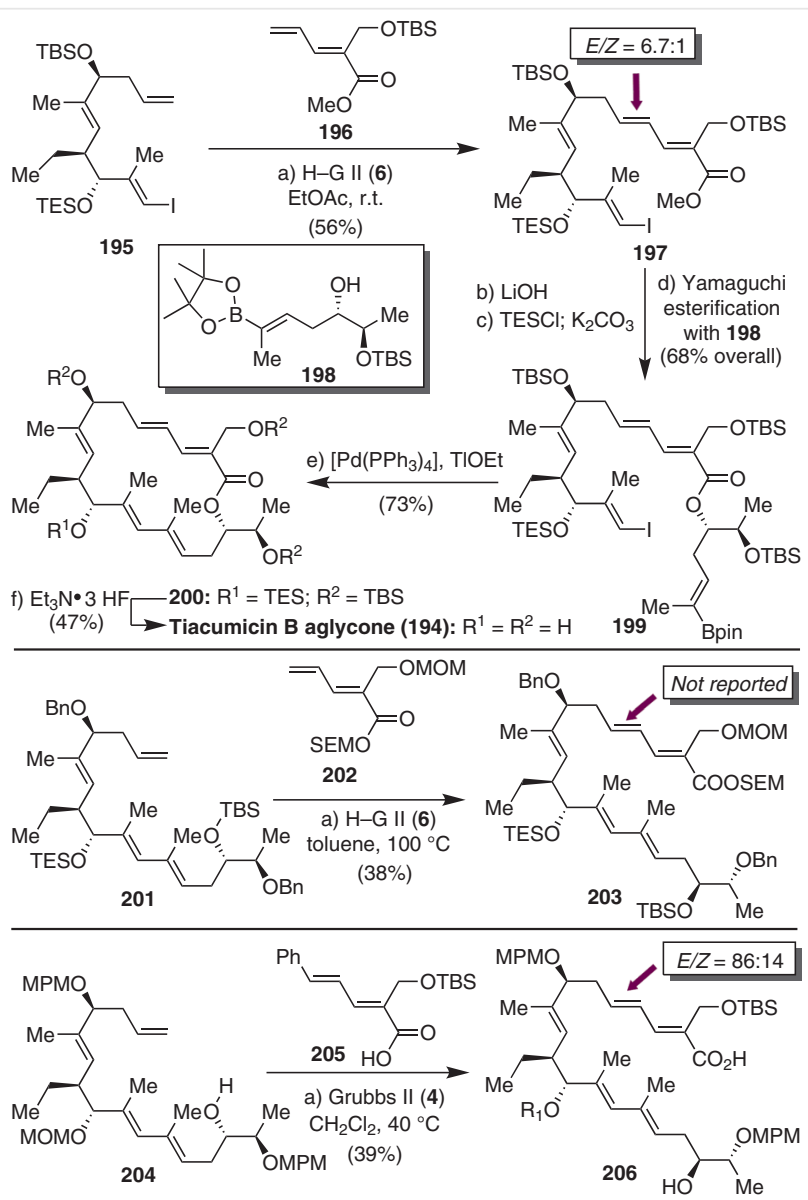

Scheme 19 Total synthesis of tiacumicin B aglycone 
tion, to afford the macrocyclic aglycone derivative of tiacumicin B (200) in 73\% yield. Global desilylation of the macrocyclic derivative $\mathbf{2 0 0}$ was performed with $\mathrm{Et}_{3} \mathrm{~N} \cdot 3 \mathrm{HF}$ to obtain tiacumicin B aglycone (194). In 2015, Gademann and co-workers reported the total synthesis of tiacumicin B, also named fidaxomicin or lipiarmycin A3 (53), based on a RCM strategy, as depicted in Figure $3 .{ }^{59}$ In addition to the synthetic studies by Altmann and Glaus, ${ }^{125}$ closely related strategies have been reported by Zhu and co-workers (2015) ${ }^{126}$ and Roulland and co-workers (2017), ${ }^{127}$ also using CM reactions (Scheme 19). The former achieved the assembly of olefin 201 and diene 202, while the latter carried out the assembly of olefin $\mathbf{2 0 4}$ with diene $\mathbf{2 0 5}$ to yield the corresponding CM products 203 and $\mathbf{2 0 6}$ in 38\% and 39\% yields, respectively and with stereoselectivities comparable to those obtained by Altmann and Glaus. However, unlike the studies of Altmann and Glaus, in these cases they found serious difficulties, mainly with the subsequent removal of the employed protecting groups within the products 203 and 206, thus forcing them to explore different synthetic strategies in both cases, to overcome these synthetic hurdles and to reach the targeted tiacumicin B aglycone (194).

Another relevant contribution of the use of the CM reaction in total synthesis was published in 2016 by Takahashi and co-workers for the total synthesis of aromin (207) (Scheme 20), ${ }^{128 a}$ a member belonging to the wide family of the Annonaceous acetogenins, isolated from the Annonaceae plants and which exhibits a broad spectrum of biological activities including anticancer, antibiotic, immunosuppressive, antifeedant, and pesticidal activities. Aromin (207), isolated together with aromicin in 1996 by McLaughlin and co-workers, ${ }^{129}$ has been recognized as an antitumoral compound with a significant cytotoxicity profile against various tumor cell lines, albeit lower compared to other acetogenins. The synthetic work by Takahashi and co-workers, ${ }^{128 a}$ based on their previous synthetic work, ${ }^{128 b}$ is interesting for two reasons. On one hand, they demonstrated the utility of the CM reaction by using the Grubbs II catalyst (4) to connect a terminal olefin and an enone to construct the corresponding linear $E$-enone. On the other hand, this work also led to the structural revision of aromin (207). Thus, the assembly of olefin 208 and enone 209 proceeded smoothly when they were exposed to the Grubbs II catalyst (4) to provide the E-enone $\mathbf{2 1 0}$ in 68\% yield and excellent stereoselectivity. With this compound $\mathbf{2 1 0}$ in hand, they accomplished the completion of the proposed structure for aromin in four additional steps in 73\% overall yield. Surprisingly, the spectroscopic and physical properties of the synthetic material $\mathbf{2 0 7}$ were notably different from those reported for the natural aromin. According to the detected discrepancies found in the ${ }^{1} \mathrm{H}$ NMR spectra, they suggested a structural difference around the central THF ring and, for this reason, they prepared the stereoisomer 211, according to a similar synthetic sequence as for $\mathbf{2 0 7}$, but once again, the NMR data were inconsistent with those of the natural product. After an exhaustive comparative analysis of the NMR data of a wide set of acetogenins possessing a 4-hydroxy group adjacent to the $\gamma$-lactone ring, together with a detailed analysis of the MS fragmentations, they were led to propose the structure of the natural product montanacin D (212), whose synthesis was similarly accomplished by them according to the same CM strategy, for the revised structure for aromin (Scheme 20). ${ }^{128}$

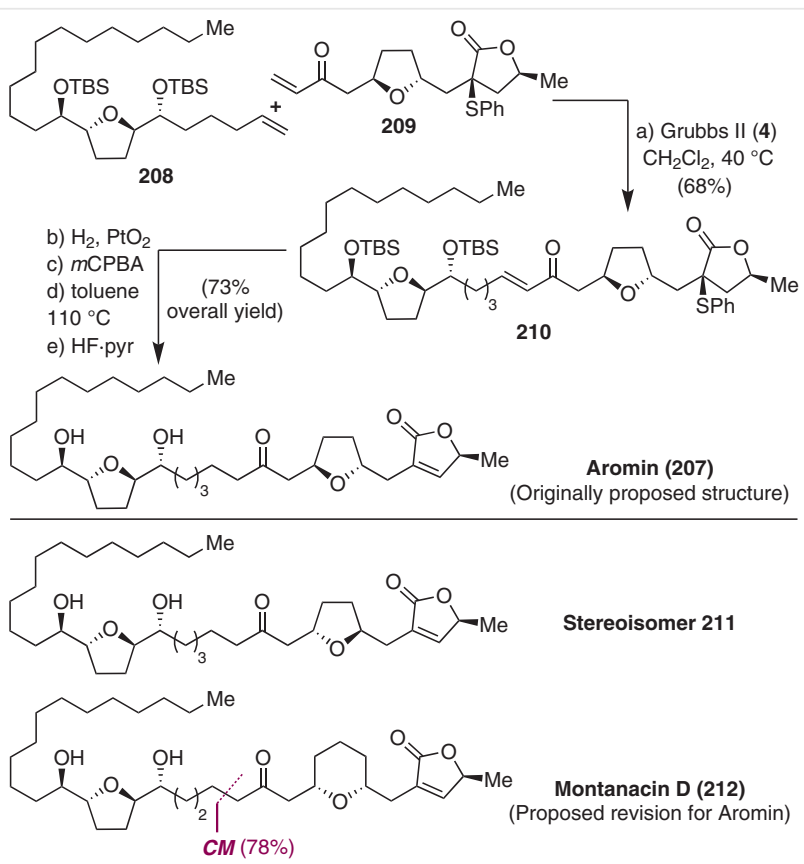

Scheme 20 Total synthesis of proposed structure for aromin and its structural revision

Another interesting application of the CM reaction was the recent total synthesis of depudecin (213) by Sarabia and co-workers, ${ }^{130}$ in which functional group tolerance provided by the employed catalysts was verified, in particular with the especially sensitive oxirane rings (Scheme 21). Depudecin represents an unprecedented natural product that selectively inhibits histone deacetylases I and II in the low $\mu \mathrm{M}$ range. With respect to its total synthesis, the construction of the complete framework of depudecin was accomplished via an efficient CM reaction of epoxy olefin $\mathbf{2 1 4}$ and diepoxy olefin $\mathbf{2 1 5}$ by using the H-G II catalyst (6) to obtain the resulting triepoxy olefin $\mathbf{2 1 6}$ in a reasonable 50\% yield, exclusively as the $E$-isomer. With the product $\mathbf{2 1 6}$ in hand, its transformation into the final natural product was successfully achieved, requiring the reductive opening of the terminal epoxy alcohol, carried out in three steps, and final removal of the protecting group of the resulting product 217 (Scheme 21). It is important to point out that this total synthesis represents the third total synthesis reported thus far for this interesting molecule, resulting in an improvement upon the previous syntheses reported by Sch- 
reiber and co-workers in $1990,{ }^{131}$ and also by Sarabia and co-workers group utilizing a linear strategy. ${ }^{132}$ In addition, the new convergent $\mathrm{CM}$ synthetic strategy provided rapid access to different stereoisomers of depudecin, which allowed for an evaluation of the influence of the stereochemistry upon biological activities.

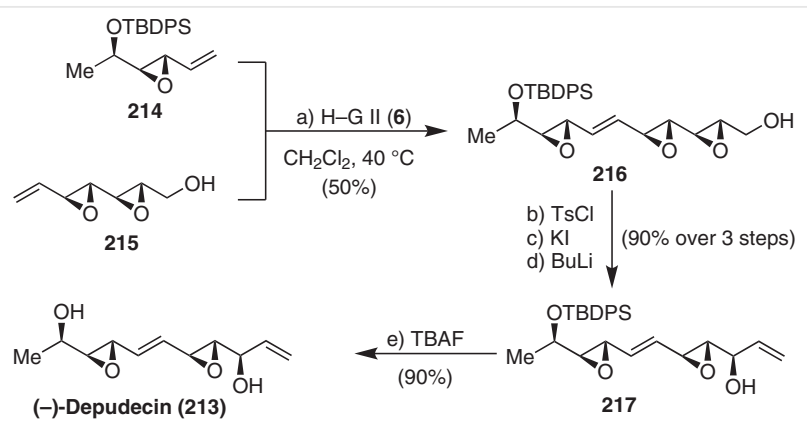

Scheme 21 Total synthesis of depudecin

A final example within this section is represented by the interesting synthetic strategy reported by Pietruszka and co-workers for the synthesis of putaminoxins $\mathrm{B} / \mathrm{D}$ (218), identified as a C-9 epimeric mixture and whose absolute configurations were not yet established (Scheme 22). ${ }^{133}$ In order to unambiguously establish their absolute configurations, the four possible stereoisomers $218 a-d$ were prepared by a CM reaction of dimers $(S, S)$ - and $(R, R)$ 219, previously prepared by a dimerization CM reaction of the corresponding monomers, with olefins $(S)$ - and $(R)-\mathbf{2 2 0}$. The choice to use the dimers $\mathbf{2 1 9}$ instead of the corresponding monomeric olefins was justified because better yields were obtained for the desired cross-metathesis products 221 versus $C M$ reactions with the monomers, in which the dimeric products $\mathbf{2 1 9}$ were the main compounds detected. Indeed, when each isomer of $\mathbf{2 1 9}$ was treated with the corresponding $(S)$ - and $(R)-\mathbf{2 2 0}$ in the presence of the Grubbs II catalyst (4) the corresponding products 221a-d were obtained in $36 \%, 72 \%, 24 \%$, and $83 \%$ yields, respectively. Then, each isomer was subjected to a sequence that included basic treatment, a Yamaguchi macrolactonization and final THP protecting group removal to provide all the possible stereoisomers of the macrolactone $\mathbf{2 1 8}$ in high yields. With all the isomers in hand, an extensive spectroscopic study, in which they compared the NMR data collected from all these compounds with those reported for the natural products, resulted in disappointment. This was due to the inability to correlate the resulting NMR data of the synthetic compounds with those reported for the natural products, thus leading them to reconsider the initially proposed structures for putaminoxins B/D. Intriguingly, after a thorough inspection of the NMR data of related nonenolides, they found that the data reported for the natural products hypocreo- lide $\mathrm{A}(\mathbf{2 2 2})$ and aspinolide $\mathrm{A}$ (223) matched with those reported for the natural products putaminoxins B/D (Scheme 22).

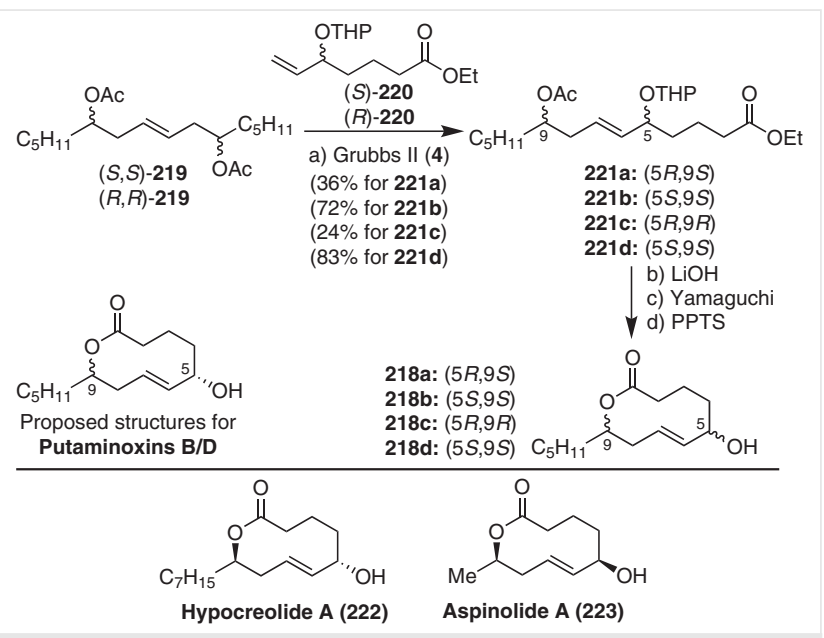

Scheme 22 Total synthesis and structural studies of putaminoxins B/D

\subsection{Strategies for Selective and Efficient Metathe- sis Reactions of Alkenes}

\subsubsection{Temporary Tethered Ring-Closing Metathesis}

A highly inventive and clever strategy to transform the intermolecular character of the cross-metathesis of alkenes into an intramolecular variant has been explored by means of the development of temporary tethers, through which the corresponding olefinic partners can be transiently coupled. This strategy not only provides the advantage of improved efficiency, which is a feature of RCM versus the CM reaction, but also the possibility of controlling the geometry of the resulting double bond to favor the Z-olefin when a strained ring is temporarily formed. However, this strategy is limited to molecular structures in which a possible linkage of the tether system is present, usually in form of hydroxy groups at allylic or homoallylic positions. Due to the versatility, stability, and ease of cleavage, silicon-based tethers have been the most frequently employed for this strategy. In fact, the temporary silicon-tethered RCM (TSTRCM) was described initially by Grubbs and Fu in $1992 .^{134}$ Thus, in order to favor the formation of the $Z$-isomer, a temporary [7]-membered ring is required, for which the silicon tethered is represented by precursor $\mathbf{A}$. In case of precursor B, whose RCM would deliver an [8]-membered ring, the preference would be the formation of the $E$-isomer (Scheme 23, A). In 2012, the applications of silicon-tethered RCM in synthesis of natural products was reviewed ${ }^{135}$ and, as a consequence, in this section, we will focus on recent examples published after 2012, together with other cases of tethered RCM reactions based on other tethers and their applications in the total synthesis of natural products. Some relevant 
contributions to this field are those by Kobayashi, ${ }^{136}$ Hoye, ${ }^{137}$ and Evans, ${ }^{138}$ as well as numerous syntheses of natural products belonging to the family of 6-substituted 5,6dihydro- $\alpha$-pyrones, such as hyptolide (224), ${ }^{139}$ pectinolide $\mathrm{C}(\mathbf{2 2 5}),{ }^{140}$ and umuravumbolide (226), ${ }^{141}$ all of which have been efficiently achieved according to this strategy from precursors 227, 228, and 229, respectively (Scheme 23, B).

A)<smiles>[R]C(C=C)O[Si](OC([R])C=C)(c1ccccc1)c1ccccc1</smiles>

A<smiles>[R]C1CC[Si](OC(F)C=C)(c2ccccc2)O1</smiles>

B
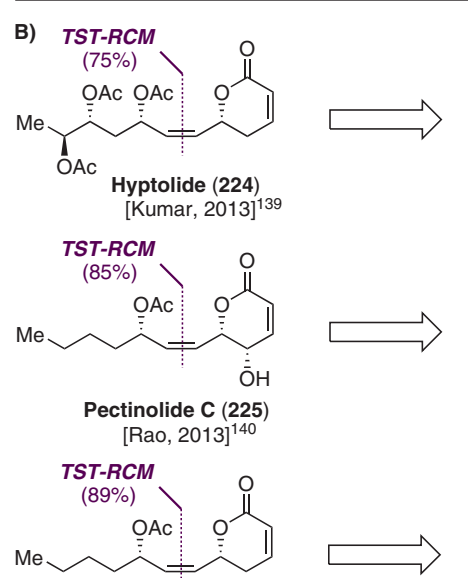

Umuravumbolide (226)
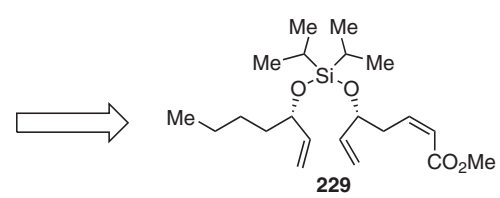

Scheme 23 General temporary silicon-tethered RCM (TST-RCM) reactions and selected natural products synthesized via this strategy

In addition to silicon-tethered RCM reactions containing an $\mathrm{O}-\mathrm{Si}-\mathrm{O}$ linkage, this strategy has also been utilized with substrates containing an $\mathrm{O}-\mathrm{Si}-\mathrm{C}$ linkage, in which an oxidative or base-induced ring cleavage step is required after the RCM reaction. Prominent amongst these cases is the 2013 synthesis of the potent cytotoxic natural product amphidinolide V (230) by Lee and Volchkov (Scheme 24), ${ }^{142}$ in which the stereocontrolled construction of the existing double bonds was devised utilizing a tethered RCM of silyl ether 234 that provided the RCM product 235 in an excellent $96 \%$ yield, which was then subjected to an allylic 1,3transposition mediated by $\operatorname{Re}_{2} \mathrm{O}_{7}$ to afford siloxane 236 as an $85: 15 \mathrm{E} / \mathrm{Z}$ inseparable mixture in $85 \%$ yield. The presence of the trimethylsilyl group in the 1,3-diene subunit was proven to be critical to prevent unwanted side reactions during the metathesis reaction. The RCM precursor 234 was prepared beforehand via an enyne RCM of silyl ether 231 to furnish a cyclic siloxene type $\mathbf{A}$, according to the general reaction depicted in Scheme 24, which was opened by treat- ment with methyllithium, to deliver compound type $\mathbf{B}$. The resulting alcohol 232 was then coupled with silane $\mathbf{2 3 3}$ via a dehydrogenative reaction, mediated by a catalytic amount of (Xantphos) $\mathrm{CuCl}$ and in the presence of lithium tert-butoxide, to afford the targeted precursor 234 in an excellent yield and exquisite control of the geometry of the double bonds. Promptly, with compound 236 in hand, they proceeded with the connection of the other important fragment of the molecule via a cross-aldol condensation to provide aldehyde $\mathbf{2 3 7}$ in a sequence of seven steps, followed by a Yamaguchi macrolactonization that provided macrocyclic derivative 238. The completion of the synthesis from this advanced precursor was then executed in five steps, consisting of a Sharpless asymmetric epoxidation from the corresponding allylic alcohol, reductive opening of the resulting diepoxy alcohol, and final removal of the trimethylsilyl group.

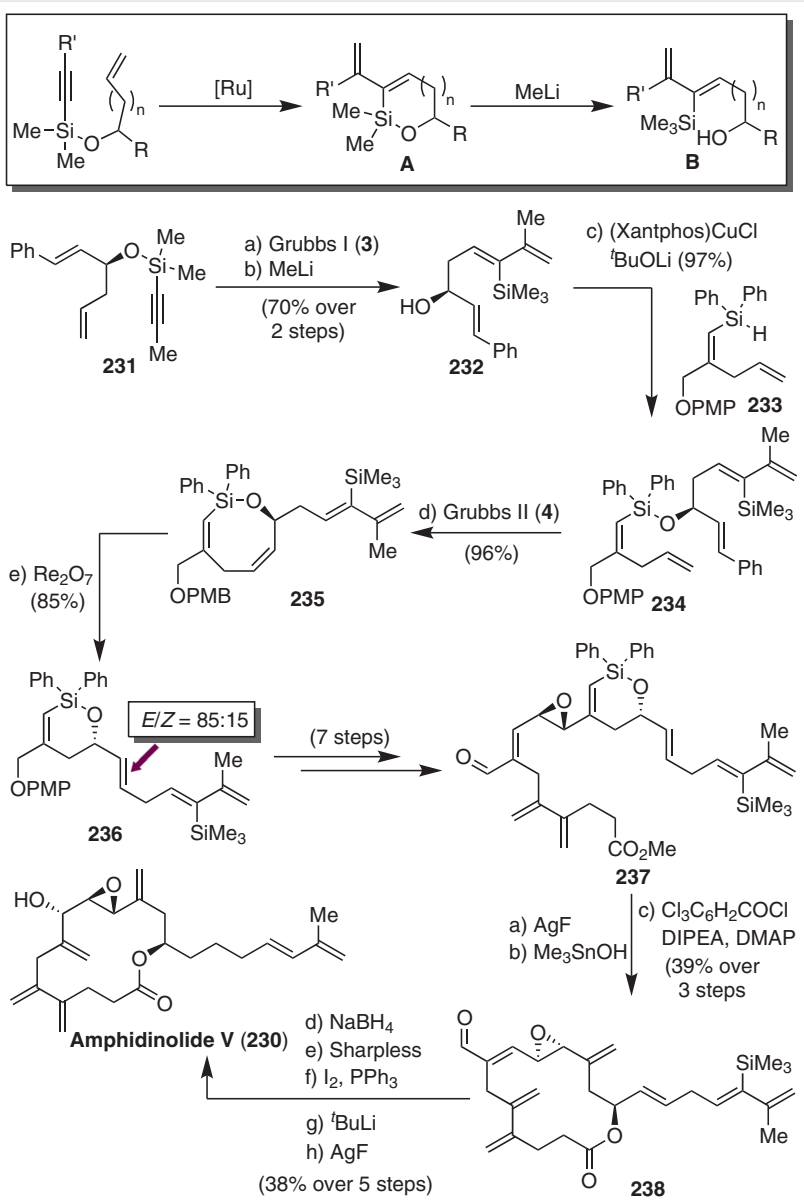

Scheme 24 Total synthesis of amphidinolide V

The use of this strategy for the selective construction of a trisubstituted $Z$-olefin is nicely illustrated in the synthesis of the important antimitotic agent epothilone B (239), in which the required $Z$-olefin at the $\mathrm{C} 12-\mathrm{C} 13$ bond has been 
a critical issue, and which different solutions across the vast number of reported synthesis of this natural product have been found. ${ }^{143}$ Thus, whereas a conventional RCM of an advanced diolefin precursor was devoid of stereoselectivity, a silicon-tethered RCM reaction initially explored by Mulzer and Gaich provided the required $Z$-isomer with a remarkable 5:1 selectivity albeit through a long synthetic sequence. ${ }^{144}$ In a shorter and rapid approach, Lin and coworkers explored the RCM reaction through the formation of a bissiloxane-tethered precursor, to secure the double bond geometry (Scheme 25). ${ }^{145}$ To this aim, the precursor 242, efficiently prepared by joining segments 240 and 241, was subjected to the Grubbs II catalyst (4) to yield the corresponding RCM product $\mathbf{2 4 3}$ in nearly quantitative yield (95\%) as a 1.7:1 mixture of $Z / E$ isomers, which could be separated after selective cleavage of the silicon-tethered by reaction with HF.pyridine. Notably, despite the moderate selectivity of the RCM reaction, the required aldehyde 244 in the form of the pure $Z$-isomer was obtained in $40 \%$ over three steps, representing the most step-economic synthesis reported thus far. From aldehyde 244, the completion of the synthesis of epothilone B was accomplished in an efficient manner in six steps, with a $\mathrm{TiCl}_{4}$-mediated aldol reaction and a Yamaguchi macrolactonization as the key steps (Scheme 25).

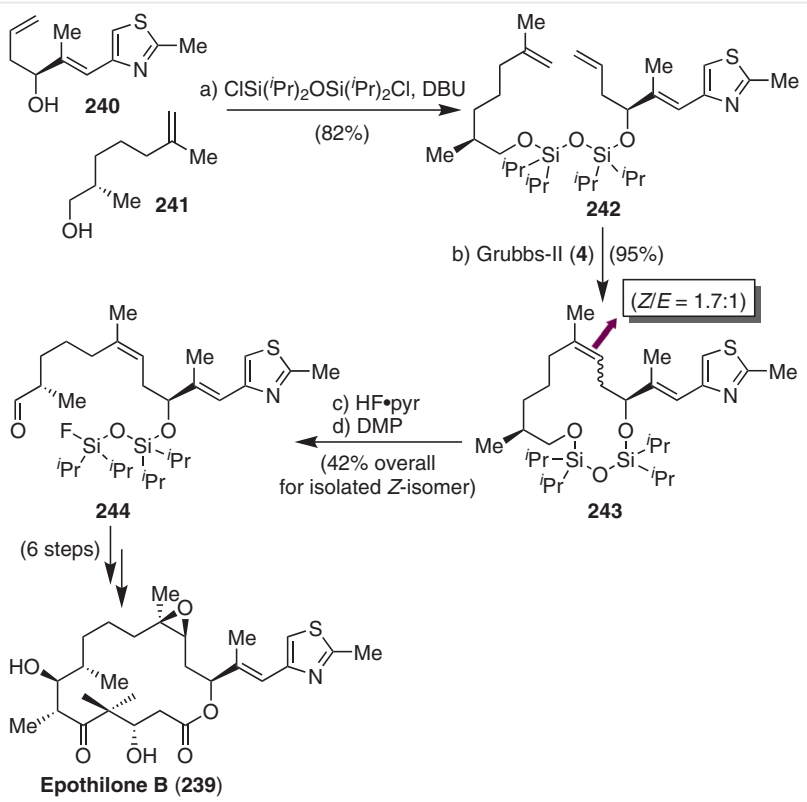

Scheme 25 Total synthesis of epothilone B

The extension of the concept of a temporary tethered RCM to other groups such as esters or acetals would expand the synthetic opportunities that this strategy might offer. One such application is elegantly illustrated with the total syntheses of amphidinolides T1, T3, and T4 by Clark and Romiti (Scheme 26). ${ }^{146}$ As for amphidinolide $\mathrm{V}$, discussed above, the amphidinolides T1, T3, and T4 are also macro- lides isolated from marine dinoflagellates with potent cytotoxic activities. Structurally, the so-named amphidinolides of the $\mathrm{T}$ series are characterized by the presence of a trisubstituted tetrahydrofuran. In the case of amphidinolide T1 (245), the synthesis of the C1-C11 fragment was initially attempted by utilization of a $\mathrm{CM}$ reaction to connect the corresponding olefins, but all attempts were thwarted to obtain the desired CM product. The implementation of a tethered RCM strategy to prepare this fragment was then attempted via a temporary ester, for which diolefin ester 246 was prepared, but again, the reaction was found to be unsuccessful, instead obtaining the RCM product 247 . In light of these discouraging results, the use of a salicylate spacer as an alternative ester-tether RCM was explored; indeed the treatment of $\mathbf{2 4 8}$ with the Hoveyda-Grubbs I catalyst (5) afforded an isomeric mixture (E/Z 1.2:1) of the lactone 249 in an impressive $96 \%$ yield. The removal of the spacer group was carried out by base treatment, followed by a chemoselective hydrogenation to complete the western fragment of the natural product in form of the product 250. The coupling of this fragment with the eastern fragment provided access to the corresponding seco acid, which was subjected to a Yamaguchi macrolactonization to pro-

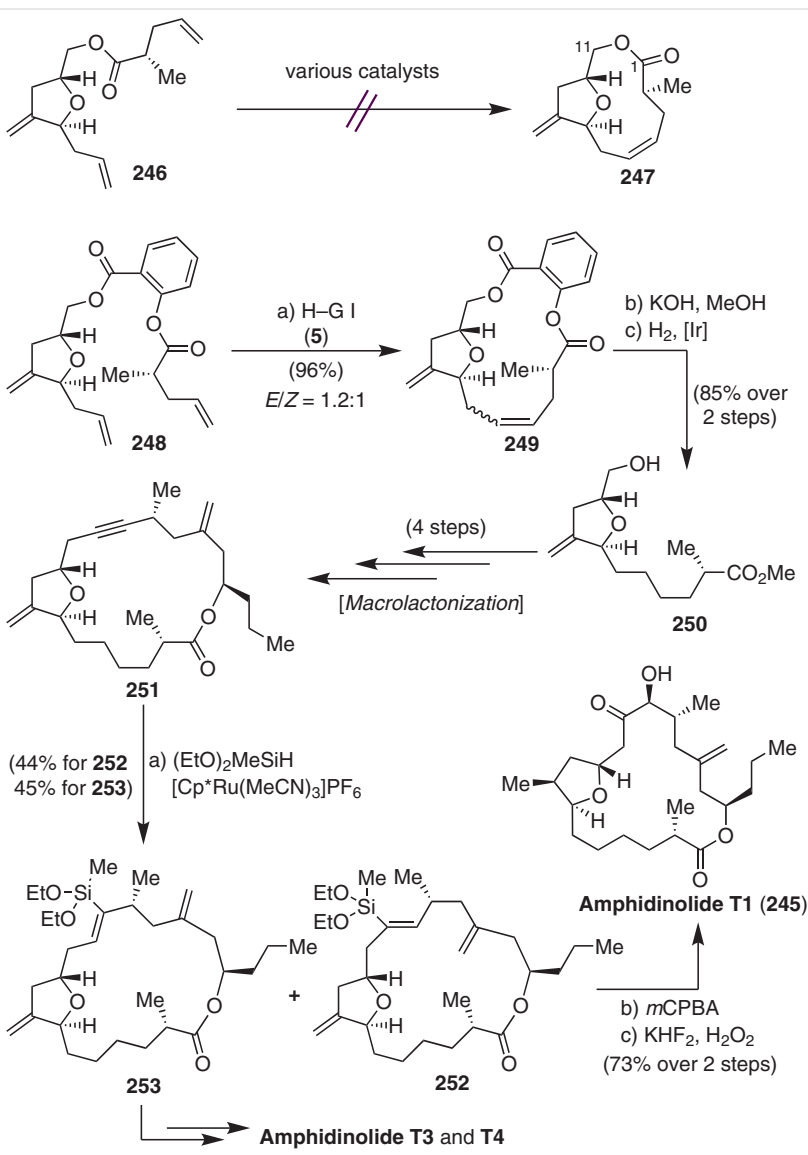

Scheme 26 Total synthesis of amphidinolides T 
vide 251, representing the macrocyclic core of the amphidinolides T. The completion of the synthesis of this natural product was achieved with the hydrosilylation of the alkyne present in 251 using the ruthenium catalyst $\left[\mathrm{Cp}{ }^{*} \mathrm{Ru}(\mathrm{MeCN})_{3}\right] \mathrm{PF}_{6}$ that afforded a 1:1 mixture of isomeric $(Z)$-vinylsilanes 252 and 253 that could be separated by chromatography. Whereas, 252 was transformed into amphidinolide T1 (245) via epoxidation of the vinylsilane, followed by a Fleming-Tamao oxidation, the product 253 provided amphidinolides T3 and T4 under the same synthetic sequence (Scheme 26 ).

The ester-tethered RCM was similarly used in the synthesis of polyacetylene-type metabolites, such as the atractylodemaynes C (254) and F (255) by Schmidt and Audörsch (Scheme 27), ${ }^{147}$ as a way of controlling the geometry of the depicted double bonds. According to a tandem RCM/baseinduced eliminative ring opening, carried out in one pot, they were able to construct a $E, Z$-diene derivative, found in these natural products. Thus, when compound 256 was treated with the Grubbs II catalyst (4), followed by NaHMDS and Meerwein's salt, compound $\mathbf{2 5 7}$ was obtained in 73\% overall yield through intermediates A, B, and C. Starting from the resulting ester 257, the installation of the enediyne moiety of the atractylodemaynes $\mathrm{C}$ and $\mathrm{F}$ was achieved without issues via alkynyl homologation and a Sonogashira coupling (Scheme 27).

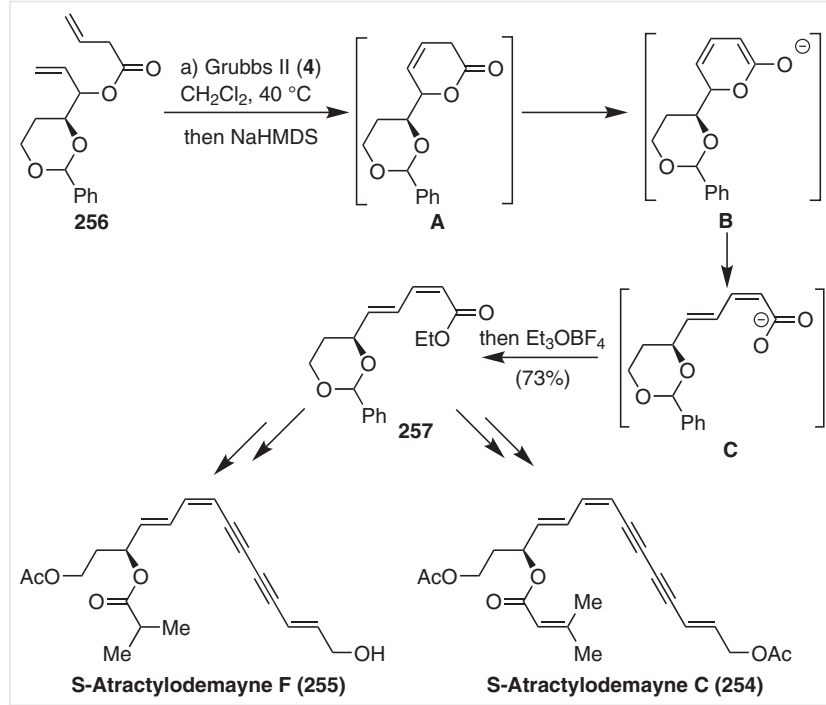

Scheme 27 Total synthesis of S-atractylodemayne C and F

As an alternative to the silicon-tethered RCM reaction, the use of acetals to connect both olefinic partners has also been developed and applied in 2013 in the synthesis of a stereoisomer of squamocin K (258), the 14,21-di-epi isomer 259 by Hou and co-workers (Scheme 28). ${ }^{148}$ Squamocin K, as other Annonaceous acetogenins, displays a wide range of biological activities, such as antitumor, antiparasitic, pesticidal, antimicrobial, and immunosuppressive activities, by virtue of its inhibition of mitochondrial complex I. In this synthetic proposal, precursor $\mathbf{2 6 0}$, readily prepared from a C2 symmetric diene diol, was treated with the Grubbs II catalyst (4) to obtain the resulting RCM product, as a result of a multiple RCM process. In a second step, the assembly of the resulting polyene and 10-chlorodec-1-ene was induced by treatment again with the Grubbs II catalyst (4) to deliver the complete framework of this class of natural products in form of compound 261. Finally, the completion of the synthesis of this stereoisomer of squamocin $\mathrm{K}$ was achieved in 12 additional steps, including the formation of the required tetrahydrofuran rings, via previous activation of the resulting hydroxy groups as mesyl derivatives and subsequent intramolecular displacements to afford 262, and the final introduction of the unsaturated lactone (Scheme 28).

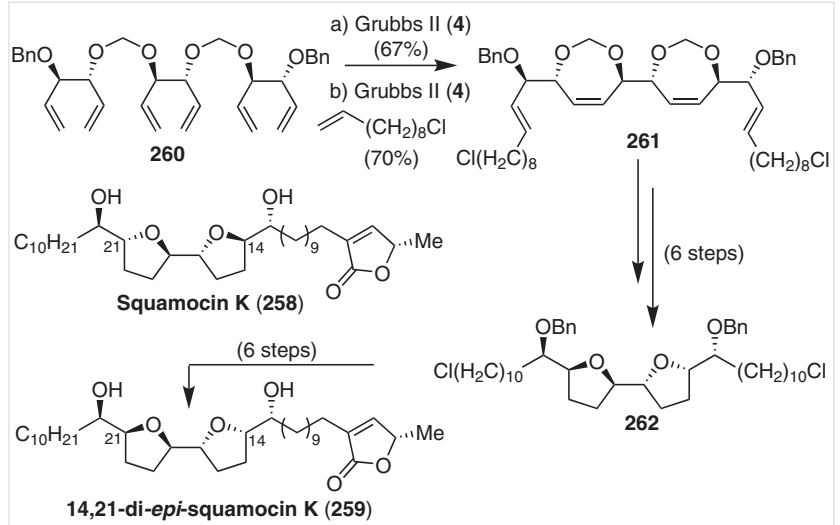

Scheme 28 Total synthesis of 14,21-di-epi-squamocin K

A unique tether for a RCM reaction was employed by Hanson and co-workers in the synthesis of strictifolione (263) (Scheme 29, A), ${ }^{149}$ a natural product isolated from the stem bark of Cryptocaria stritifolia with antifungal activities. In their synthesis, they used a phosphate-tether that allowed in one pot, a sequential RCM, CM, and a chemoselective hydrogenation process, followed by a one-pot, sequential reductive allylic transposition/tether removal and final CM. To this end, olefinic phosphate 264 was treated with the H-G II catalyst (6) and then, after solvent evaporation, addition of cis-stilbene in DCE and heating at $60{ }^{\circ} \mathrm{C}$ for two hours. The subsequent chemoselective diimide reduction provided phosphate $\mathbf{2 6 5}$ in 52\% overall yield. The following one-pot protocol was initiated with the reaction of 265 with $\mathrm{Pd}(\mathrm{OAc})_{2}$ in the presence of formic acid, cesium carbonate, and $\mathrm{PPh}_{3}$ to produce a reductive allylic transposition, followed by addition of methyl sulfate and treatment with $\mathrm{LiAlH}_{4}$ to furnish diol $\mathbf{2 6 6}$ in 65\% overall yield. A final $\mathrm{CM}$ reaction with vinyl lactone $\mathbf{2 6 7}$ in the presence of the $\mathrm{H}-\mathrm{G}$ II catalyst (6) provided the natural product strictifolione (263) in $77 \%$ yield (Scheme 29 , A). In a similar strategy, they described the synthesis of the antifungal macrolide Sch-725674 (49) (Scheme 29, B), ${ }^{150}$ wherein the phosphate 
268 was treated in a similar one-pot RCM/CM/chemoselective hydrogenation sequence as described for 264, with the use of alkene $\mathbf{2 6 9}$ to obtain compound $\mathbf{2 7 0}$ in $59 \%$ yield. The removal of the phosphate tether was accomplished by treatment with $\mathrm{LiAlH}_{4}$ and, then, after a sequence of transformations, including selective protection of the 1,3-diol system as an acetal, Sharpless asymmetric epoxidation of the resulting allylic alcohol, selective tosylation of the primary alcohol, and introduction of the acryloyl unit, provided compound 271. This compound was set up for a reductive opening process, which was carried out in one pot by sequential treatment with $\mathrm{NaI}, \mathrm{Zn}$, and acidic work-up, to deliver diolefin 272. In contrast to a direct RCM reaction of diolefinic triol 272, carried out by Prasad and co-workers (see Figure 3), ${ }^{55}$ that afforded the natural product in a modest 36\%, Hanson and co-workers found that prior protection of compound $\mathbf{2 7 2}$ as the MOM derivative resulted in a more efficient RCM process to provide the final product 49 in $84 \%$ yield after removal of the protecting groups with TFA (Scheme 29, B).
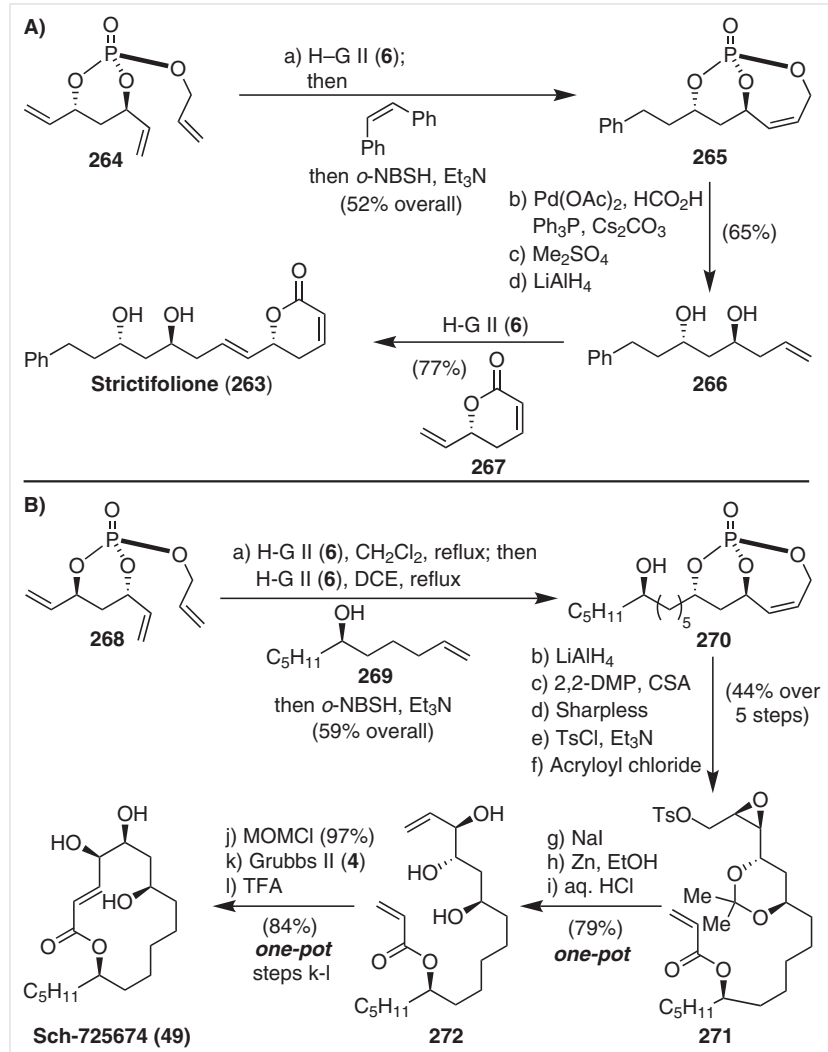

Scheme 29 Total synthesis of strictifolione and Sch-725674

\subsubsection{Relay Ring-Closing Metathesis}

Since the pioneering work of the Hoye group on the relay ring-closing metathesis (RRCM) concept in 2004, ${ }^{151}$ and the first application in total synthesis by the Porco group in the same year, ${ }^{152}$ many syntheses have benefited enormously from this strategy as a method to surmount the instances in which RCM reactions proved ineffective or sluggish, mainly due to steric factors, as well as electronic factors. ${ }^{153}$ A representative example to illustrate the implementation of this strategy and its dramatic effect can be found in the 2012 synthesis of the cytotoxic natural product penostatin B (273) by the Shishido and co-workers (Scheme 30). ${ }^{154}$ Having devised a RCM strategy for the preparation of the dihydropyran system contained in the natural product, the examination of this reaction with the acyclic precursor 274 by using various catalysts and different reaction conditions provided the desired unsaturated $\delta$ lactone $\mathbf{2 7 5}$ in a modest $46 \%$ yield, as the best case, when the H-G I catalyst $\mathbf{5}$ was employed. In an effort to improve upon this yield, they made use of the relay RCM strategy, for which precursors 276 and $\mathbf{2 7 7}$ were prepared. The treatment of these compounds with the H-G I catalyst 5 provided the RCM product $\mathbf{2 7 8}$ in improved $78 \%$ and $83 \%$ yields from 276 and 277, respectively, demonstrating the synthetic value of this strategy. With compound 278 in hand, the introduction of the alkenyl appendage was successfully achieved from acetyl pyranoside $\mathbf{2 7 9}$, via vinylstannane $\mathbf{2 8 0}$ in a highly stereoselective manner. Finally, the manipulation towards the final product was undertaken in six additional steps.

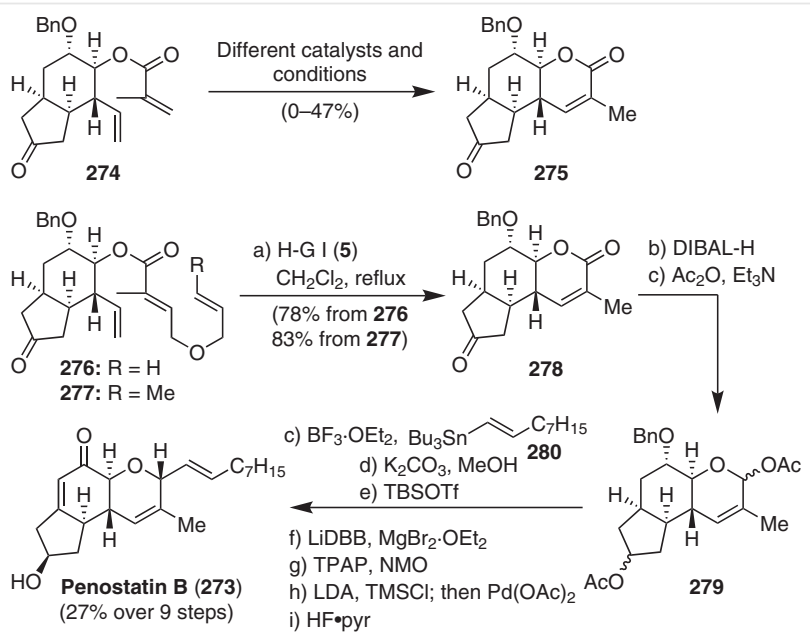

Scheme 30 Total synthesis of penostatin B

In the development of an enabled and flexible strategy for the synthesis of the cyclodepsipeptidic-like natural products related to the jasplakinolide/geodiamolide family, Arndt, Waldmann, and co-workers designed a divergent solid phase synthesis for this class of compounds based on a unique RRCM strategy on solid phase to construct the macrocyclic core, directing the catalyst's action to the required break point (Scheme 31). ${ }^{155}$ With the preparation of a PS resin for the linkage of the peptidic chain, which carried a diene unit, the acyclic precursor loaded onto the resin (res- 
in 281) was synthesized in an efficient manner. The subsequent reaction with the Grubbs II catalyst (4) delivered the protected cyclodepsipeptide $\mathbf{2 8 2}$ in $34 \%$ yield as a 1:1.2 mixture of a separable $E / Z$ isomers, through the formation of the carbene intermediate $\mathbf{A}$ with the concomitant release of resin 283. The removal of the protecting groups of each pure isomer afforded natural product seragamide A (284) and its Z-isomer. In a similar fashion, a collection of jaspamide analogues were generated for biological studies as antitumor agents. ${ }^{155}$

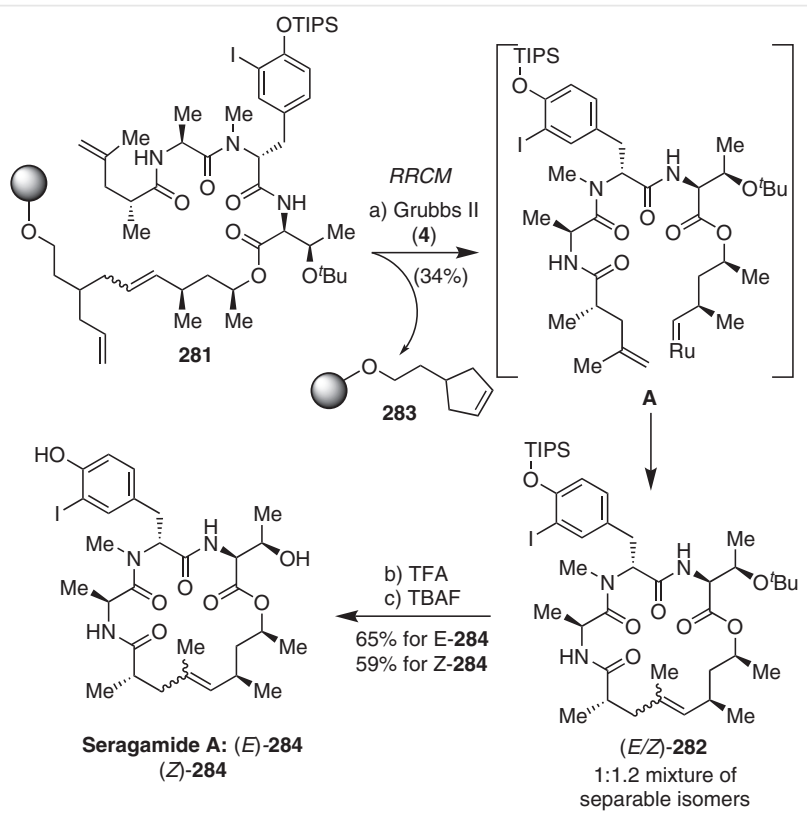

Scheme 31 Total synthesis of seragamide A and related cyclodepsipeptides

\subsubsection{Stereoselective Alkene Metathesis}

The reversible nature of olefin metathesis represents a practically insurmountable barrier to access to the often energetically less favored Z-olefin. As a consequence, the design and development of catalysts capable of providing high $Z$ selectivity, either in RCM as in CM reactions, represents an important challenge. To this aim, initial efforts by Schrock, Hoveyda, and co-workers have been focused largely on the modification of the ancillary ligands bound to the metal center and have led to the identification of the first $Z$-selective catalysts based on molybdenum and tungsten (catalysts 15-22 in Figure 1). ${ }^{156}$ In this family of catalysts, the introduction of a bulky aryloxy moiety forces the substituents on the generated metallacyclobutane intermediate $\mathbf{A}$ (Scheme 32 ) all syn to yield the Z-olefin in a kinetically controlled process. On the other hand, the advent of ruthenium-based catalysts (e.g., catalyst 23 in Figure 1), in which bulky aryl groups are introduced on the N-heterocyclic carbene, by Grubbs and co-workers, allowed similar access to a $Z$-selective process through intermediates type
B. ${ }^{157}$ Despite the formation of the $E$-isomers being generically favored in these reactions for thermodynamic reasons, there are numerous cases in which the small energy difference between the $E$ and the $Z$ isomers results in a mixture of both geometric isomers. In view of this situation, the development of catalysts that promote kinetically $E$-selective processes represents a new challenge. In response to this requirement, Grubbs and co-workers have described the first catalysts capable of generating $E$-olefins starting from E-olefins as the reactants. ${ }^{158}$ These catalysts are a new generation of catalysts that are termed stereoretentive olefin metathesis catalysts, and they feature the presence of a cyclic catecholthiolate unit (catalysts 24-27 in Figure 1) 22,159 and proceed through intermediates of type $\mathbf{C}$. To this arsenal of valuable and useful catalysts developed in the last few years one must also add chiral catalysts, with which it is possible to perform asymmetric olefin metathesis, ${ }^{61,160}$ as described in Scheme 8. A detailed description of the design and development of these new selective catalysts, as well as their applications in the synthesis of natural products, has been widely covered in various reviews. ${ }^{161}$ Nevertheless, we would like to summarize in this section relevant examples of selective RCM and CM reactions as representative applications that prove the synthetic validity and potential of this new generation of catalysts. Thus, Scheme 32 summarizes examples of $Z$-selective $\mathrm{RCM}$ reactions ${ }^{156,162}$ and Scheme 33 shows cases of $Z$-selective $C M$ reactions ${ }^{163}$ in the field of the total synthesis.

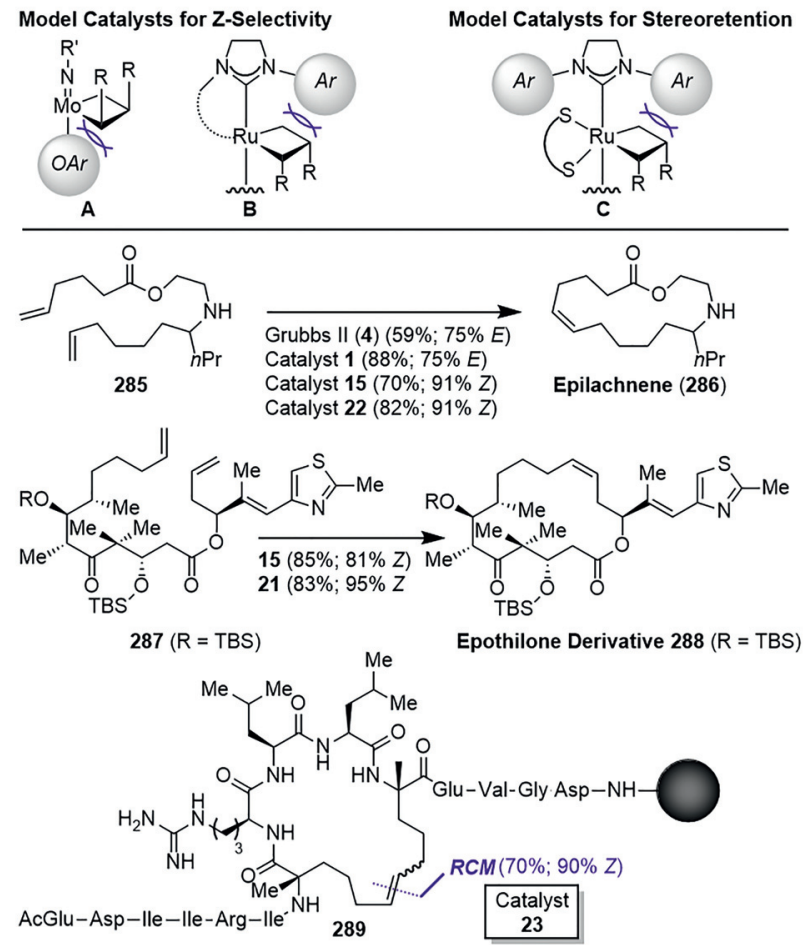

Scheme 32 Applications of Z-selective RCM reactions in total synthesis 
Particularly relevant is the synthesis of prostaglandin F2 $\alpha$ (303) according to the 2017 strategy developed by Hoveyda and co-workers (Scheme 33$)^{163 f}$ based on the original and brilliant concept of methylene capping. This strategy was designed to broaden the scope of the $Z$-selective crossmetathesis protocols, which are inefficient with olefins containing allylic or homoallylic alcohols, aryl groups, aldehydes, or carboxylic acid substituents. Having identified (Z)-but-2-ene (302) as a suitable capping agent, respective treatments of trihydroxy olefin $\mathbf{3 0 0}$ and unsaturated carboxylic acid $\mathbf{3 0 1}$ with alkene $\mathbf{3 0 2}$ and the Ru dithiolate catalyst $\mathbf{2 5}$, followed by mixing and treatment with additional catalyst $\mathbf{2 5}$ under reduced pressure, afforded prostaglandin F2 $\alpha$ (303) in 59\% yield and $>98: 2$ selectivity in favor of the desired $Z$-olefin. The use of this capping agent avoids the formation of the unstable methylidene species in favor of a more stable substituted carbene, allowing the use of substrates without resorting to protecting groups. This elegant strategy was similarly used for the synthesis of Z-macrocyclic alkenes.
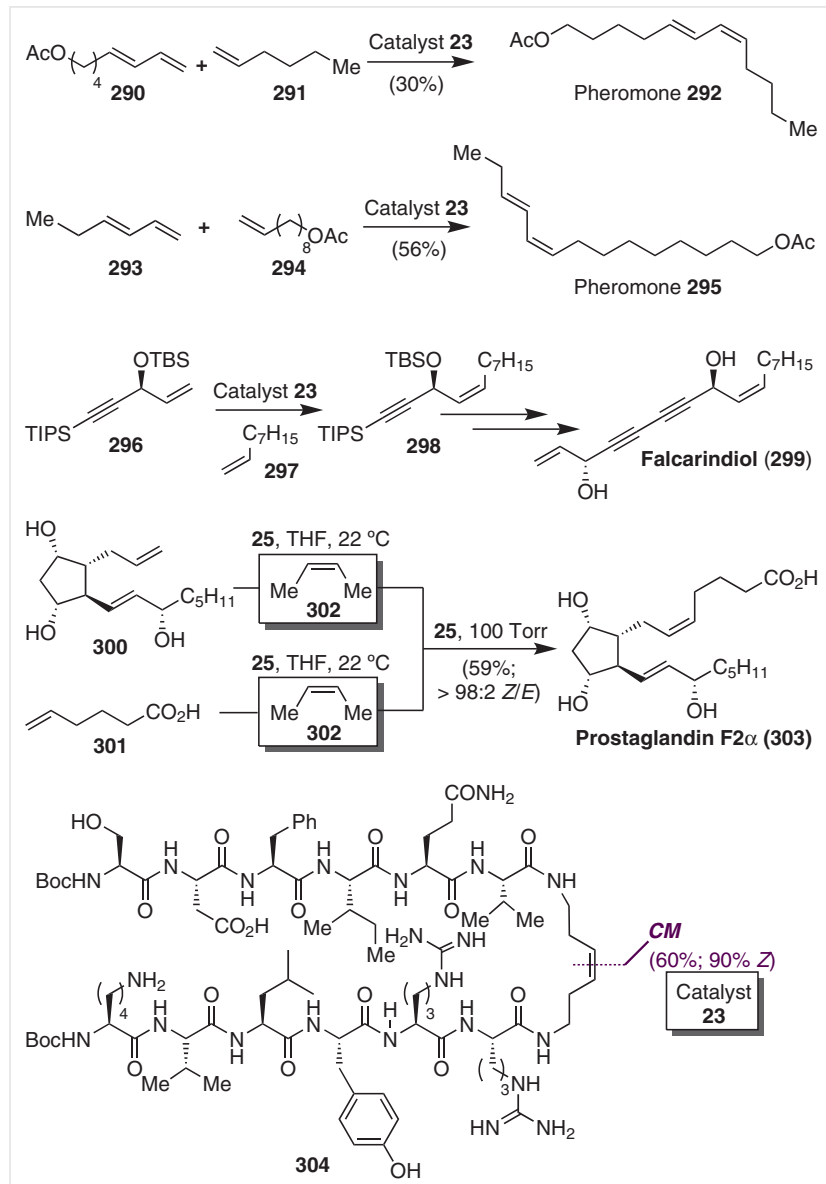

Scheme 33 Applications of Z-selective CM reactions in total synthesis
An outstanding application of these selective catalysts in the synthesis of complex natural products is the synthesis of disorazole $C_{1}(\mathbf{3 0 5})$, a secondary metabolite that displays excellent anticancer and antifungal profiles, described by Hoveyda and co-workers (Scheme 34). ${ }^{164}$ The presence of the $(Z, Z, E)-1,3,5$-triene unit demands an exquisite level of geometric control for the stereoselective synthesis of this fragment. In an initial approach, they prepared the Z-vinyl iodide $\mathbf{3 0 7}$ and the E,Z-diene $\mathbf{3 0 9}$ in excellent yields and complete stereoselectivity by using the catalyst 16 from the terminal olefins 306 and 308, respectively. However, after coupling of both fragments via a Suzuki reaction, the subsequent dimerization process failed to form the resulting coupling product. Therefore, they decided to assemble the acid derived from ester $\mathbf{3 0 8}$ and vinyl iodide $\mathbf{3 1 0}$ and the resulting ester $\mathbf{3 1 1}$ was transformed into the $Z$ boronic ester 312, mediated by the catalyst $\mathbf{1 8}$. With this compound in hand, they conducted the dimerization process in a carefully optimized reaction, where the choice of palladium catalyst, base, and solvent was critical to obtaining a good yield (60\%) of the resulting [30]-membered ring protected disorazole $C_{1}$. Final desilylation provided the coveted natural product $\mathbf{3 0 5}$.
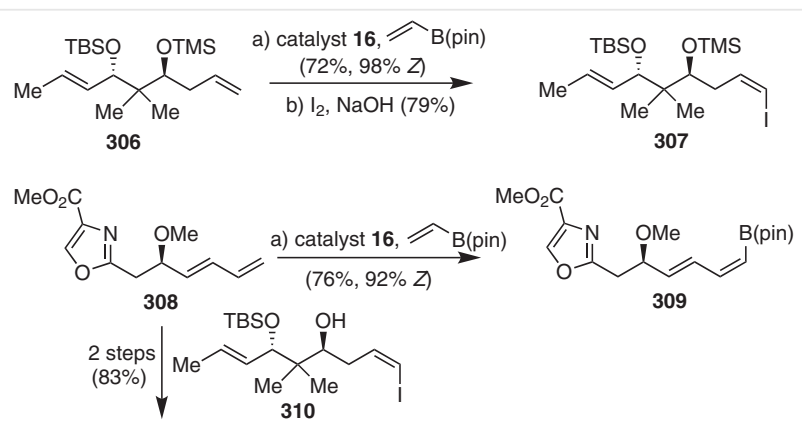

309
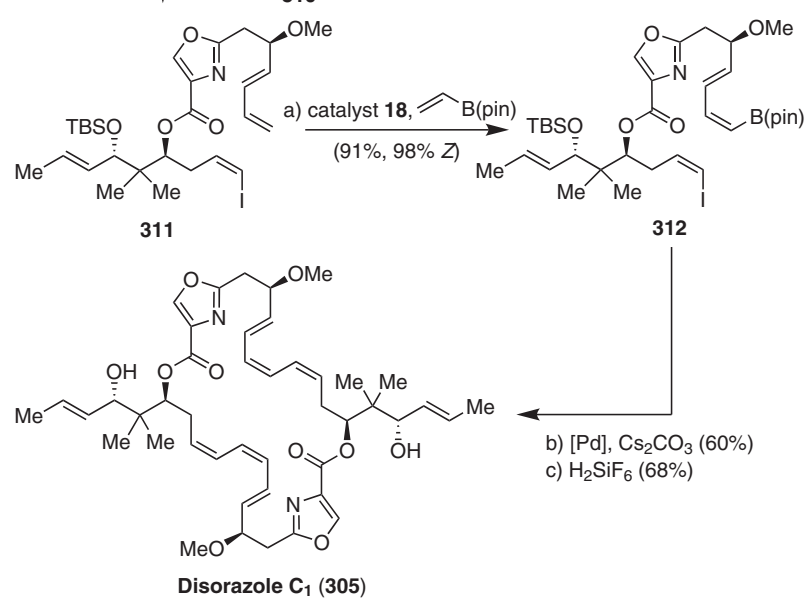

Scheme 34 Total synthesis of disorazole $C_{1}$ 


\subsubsection{Alkene Metathesis in Tandem Reactions}

The design of suitable multifunctional molecules that enable the triggering of a cascade of events, including a sequential alkene metathesis process or a combination of an alkene metathesis with other types of reactions in a welldefined order would provide a formidable increase in structural complexity in a single operation. As a consequence, we can find in the literature a large number of total syntheses and synthetic approaches in which alkene metathesis processes in cascade sequences, by combination of $\mathrm{ROM} / \mathrm{RCM}$ or RCM/CM reactions, have been applied. ${ }^{165} \mathrm{An}$ initial interesting synthetic application of these processes in total synthesis is found in the formal total syntheses of dysiherbaine (313) and neodysiherbaine A (314) by Lee and co-workers (Scheme 35$)^{166}$ through an elegant ROM/RCM tandem process from bicyclic compound 315, which was prepared in enantiomerically pure form through a stereoselective Diels-Alder reaction, followed by resolution of the racemic mixture. This compound $\mathbf{3 1 5}$ underwent an initial ROM process that delivered a ruthenium intermediate $\mathbf{A}$, followed by a RCM reaction when subjected to the Grubbs II catalyst (4) to yield bicyclic derivative 316, which represents the core skeleton of dysiherbaine and related compounds with the correct relative stereochemistry. The need to selectively oxidize the cyclic olefin in the presence of the terminal alkene found in compound $\mathbf{3 1 6}$ forced them to increase the difference of reactivities between the olefins by the preparation of the enol acetate $\mathbf{3 1 7}$, prepared in the same way as $\mathbf{3 1 6}$, but in the presence of vinyl acetate and using H-G II catalyst (6) for a final CM with vinyl acetate. In this way, compound $\mathbf{3 1 7}$ was obtained in an excellent $95 \%$ yield, generating a very well differentiated electronic environment between both alkenes for further selective functionalization. In fact, they succeeded in the preparation of advanced precursor $\mathbf{3 1 8}$ via transformation of the enol acetate into a temporary alcohol, followed by dihydroxylation of the cyclic olefin, protection of the resulting diol as an acetal, oxidation of the primary alcohol to the acid, and esterification. The resulting product $\mathbf{3 1 8}$ was utilized by Sasaki and co-workers (Scheme 35$)^{167}$ in their total syntheses of the natural products dysiherbaine (313) and neodysiherbaine A (314), thus representing the formal synthesis of both natural products.

Particularly interesting are the syntheses of clusianone (319) and clavilactone A (323) which utilize combinations of cascade processes of metathesis reactions. In the case of clusianone (319), a natural product isolated from $C$. congestiflora with antiviral activity against HIV and Epstein-Barr virus, its synthesis was envisaged by Plietker and co-workers (Scheme 36) ${ }^{168}$ from tricyclic derivative 322, prepared from bicyclic compound 321 via an allylation/intramolecular Claisen condensation/benzoylation sequence. Thus,

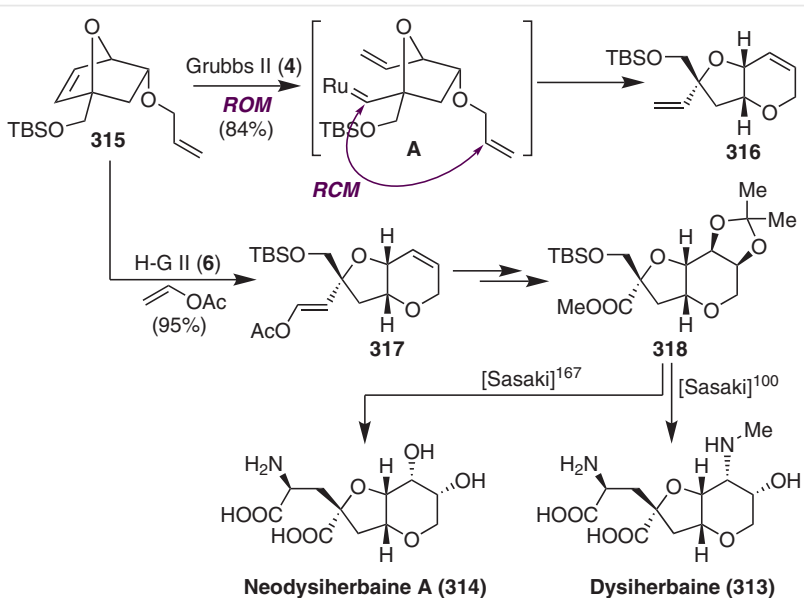

Scheme 35 Formal total synthesis of dysiherbaine and neodysiherbaine $A$

when $\mathbf{3 2 2}$ was treated with the Grubbs II catalyst (4) in the presence of 2-methylbut-2-ene, the natural product clusianone (319) was obtained in 65\% yield as the result of a tandem $\mathrm{ROM} / \mathrm{CM}$ process. The preparation of the bicyclo[4.3.1] decenone derivative $\mathbf{3 2 1}$ via a RCM reaction from 320, was conceived by them as a way of controlling the stereochemical outcome in favor of the desired cis-relative configuration of the final product due to the conformationally restricted environment imposed by the bicyclic system. The subsequent ROM reaction, followed by a CM reaction, in the presence of 2-methylbut-2-ene, allowed the unmasking of the prenylated side chains present in the final product (Scheme 36). The same strategy was employed by them in the synthesis of guttiferone A. ${ }^{169}$ For the clavilactones, a family of natural products structurally characterized by a rigid 10-membered macrocycle fused to a hydroquinone and to an $\alpha, \beta$-epoxy- $\gamma$-lactone, the cyclobutenecarboxylate 324 was devised by Takao and co-workers as an appropriate precursor to promote a tandem ROM/RCM reaction mediat-
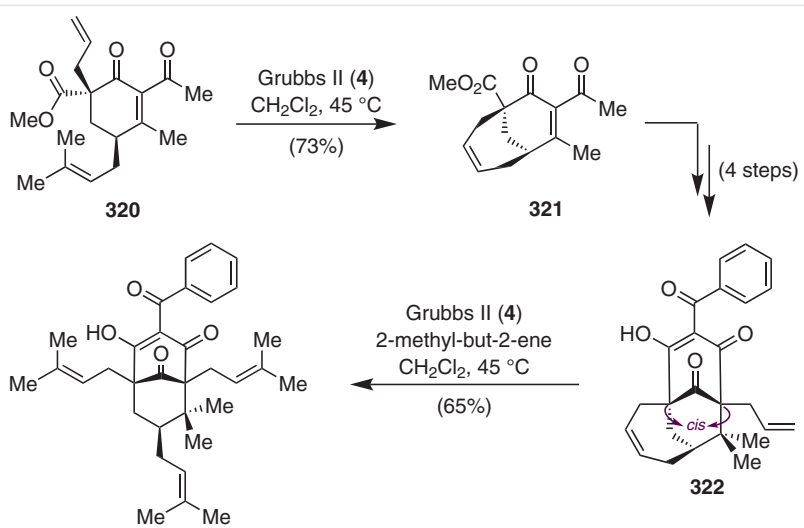

(+)-Clusianone (319)

Scheme 36 Total synthesis of clusianone 
ed by a ruthenium-based catalyst (Scheme 37). ${ }^{170}$ In fact, when 324 was treated with the Grubbs I catalyst (3), the desired ROM/RCM product $\mathbf{3 2 5}$ was obtained, but in only $28 \%$ yield, due to the formation of the dimer $\mathbf{3 2 6}$ in 15\% yield, together with recovered starting material in $47 \%$ yield. In an attempt to improve upon this modest result, they found that exposure of dimer $\mathbf{3 2 6}$ to the Grubbs II catalyst (4) in ethylene atmosphere produced the desired product 325 in good yields. In practice, this tandem process was accomplished in one pot by sequential treatment of 324 with the Grubbs I catalyst (3) in the presence of 2,6-dichloro-1,4-benzoquinone, followed by the treatment with the Grubbs II catalyst (4) in atmospheric ethylene at $80{ }^{\circ} \mathrm{C}$ to provide the final product $\mathbf{3 2 5}$ in $81 \%$ overall yield. The formation of the oxirane ring was carried out in a highly chemo- and stereoselective fashion by reaction of $m \mathrm{CPBA}$ with the cyclic olefinic bis-silyl ether derivative, obtained from 325 by reduction and bis-silylation of the resulting diol. The resulting epoxide $\mathbf{3 2 7}$ was then reacted with the Grubbs II catalyst (4) to obtain the macrocyclic derivative 328 in a notable $83 \%$ yield. The completion of the synthesis of clavilactone A (323) was efficiently accomplished in four additional steps, mainly functional groups interconversions, through quinone $\mathbf{3 2 9}$ that corresponds to clavilactone B. In a similar synthetic sequence, they prepared the originally proposed structure of clavilactone D (330) (Scheme 37), ${ }^{171}$ which led to its structural revision, identifying $\mathbf{3 3 1}$ as the correct structure.

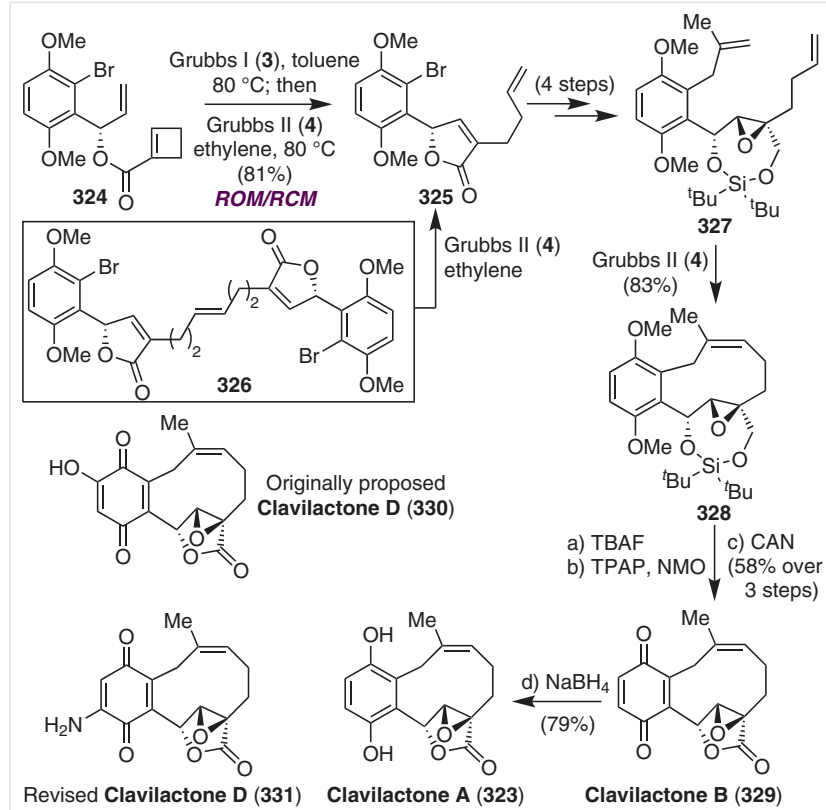

Scheme 37 Total synthesis of clavilactone A, B, and D

A cascade process that involves an alkene metathesis with other types of reactions has also been explored. As such, an application is the tandem CM/oxa-Michael cycliza- tion employed by Krische and Waldeck in the synthesis of the C2-symmetric natural product cyanolide A (332) (Scheme 38), ${ }^{172}$ a potent molluscicidal agent against the water snail Biomphalaria glabrata, which actually is a vector of the human parasitic disease schistosomiasis. Thus, treatment of diol $\mathbf{3 3 3}$ with H-G II catalyst (6) in the presence of pent-1-en-3-one gave compound 334 in 76\% yield as a 10:1 mixture of diastereomers. This pyran derivative is the result of an initial double CM reaction, followed by an oxa-Michael cyclization. In a second CM round, compound 334 was treated with the Blechert catalyst $\mathbf{7}$ in an ethylene atmosphere to yield olefin 335 in $70 \%$ yield. A few more steps from 335 completed a concise total synthesis of cyanolide A (332) (Scheme 38).

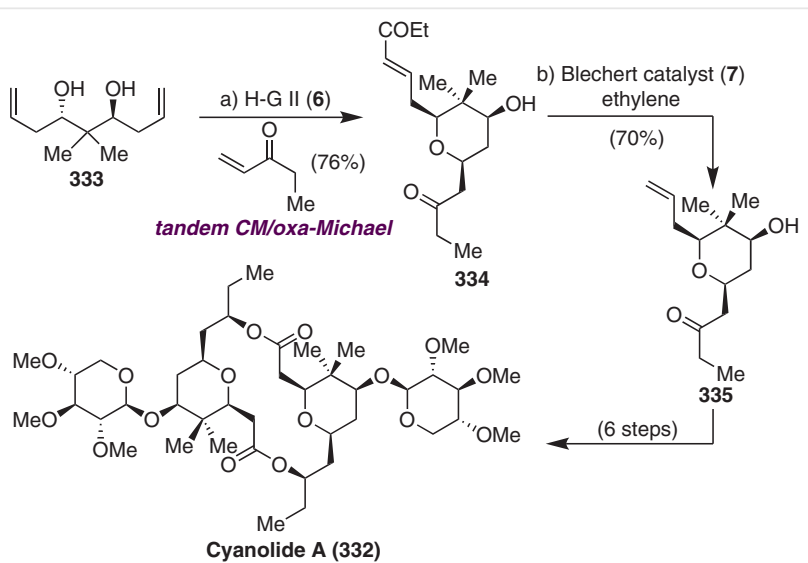

Scheme 38 Total synthesis of cyanolide A

Another such application is the synthesis of the tetrahydropyran-containing natural products decytospolide A (336) and B (337) by Kommu and co-workers (Scheme 39), ${ }^{173}$ which was rapidly achieved when the hydroxy olefin 338 was subjected to treatment by the H-G II catalyst (6) in the presence of pent-1-en-3-one to provide the pyrans 339 and $\mathbf{3 4 0}$ in 78\% combined yield and as a 9:1 mixture of stereoisomers, in favor of the desired 2,6-cis-pyran $\mathbf{3 4 0}$. Re-

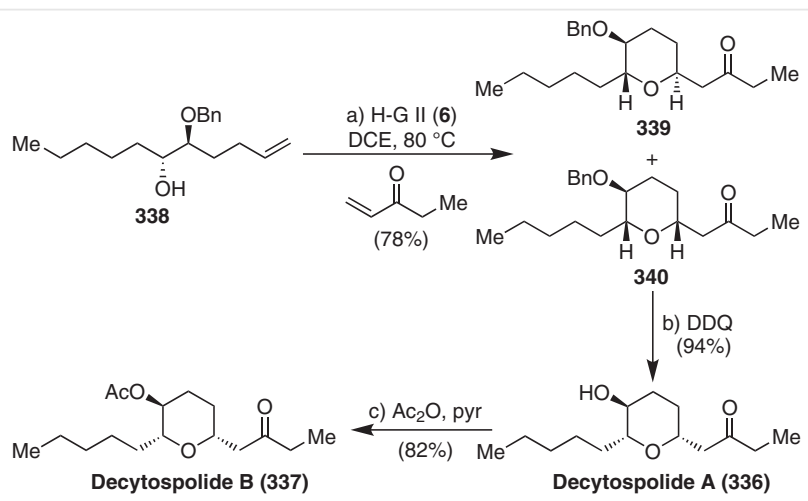

Scheme 39 Total synthesis of decytospolide A and B 
moval of the benzyl group of $\mathbf{3 4 0}$ afforded decytospolide A (336), whose acetylation provided decytospolide B (337) (Scheme 39).

An interesting approach towards the synthesis of isoquinoline-type alkaloids, such as oxychelerythrine (341a), oxysanguinarine (341b), oxynitidine (341c), and oxyvicine (341d), has been described by Sutherland and co-workers ${ }^{174}$ based on a tandem Overman rearrangement/RCM for rapid access to amino-substituted 1,4-dihydronaphthalene scaffolds, which represent key precursors for the synthesis of the benzo[c]phenanthridine system found in these natural products (Scheme 40). The one-pot Overman rearrangement/RCM was efficiently achieved after extensive optimization, finding that when $\mathbf{3 4 2}$ was converted into the corresponding trichloroacetimidate, heated to $160{ }^{\circ} \mathrm{C}$ in the presence of potassium carbonate and then submitted to the action of the Grubbs II catalyst (4) at room temperature, the corresponding 1,4-dihydronaphthalene $\mathbf{3 4 3}$ was obtained in $81 \%$ yield. From this privileged compound, they completed the syntheses of the alkaloids 341a-d, after aromatization of 343, followed by coupling with the corresponding 2bromobenzoic acid derivatives, and an intramolecular biaryl Heck coupling reaction, in a very highly efficient manner. In the final Heck coupling (step $h$ of the sequence), Sutherland and co-workers employed the more stable Hermann-Beller palladacycle catalyst, given the very high temperature $\left(160^{\circ} \mathrm{C}\right)$ required for the intramolecular coupling of their precursors 344a-d (Scheme 40). A related tandem Overman rearrangement and ring-closing enyne metathesis, followed by a Diels-Alder reaction was utilized by them in the synthesis of amino-substituted indanes and tetralins. ${ }^{175}$

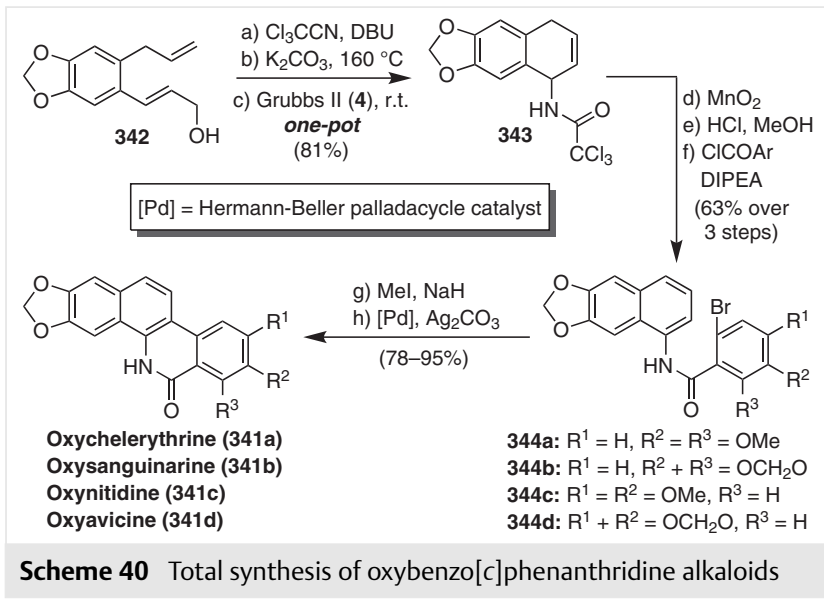

\section{Enyne Metathesis in Total Synthesis}

As in previous sections, in this section we will focus on recent contributions recorded in the last few years (2012 to early 2018), taking into account that the ring-closing enyne-metathesis (RCEYM) reaction has been similarly covered in numerous reviews. ${ }^{176}$

\subsection{Total Syntheses Based on a Ring-Closing Enyne-Metathesis Reaction}

The synthetic value of an intramolecular metathesis reaction of an enyne (RCEYM) is due to the versatility that is offered by the resulting cyclic dienes, which can be utilized in subsequent transformations, such as cycloaddition reactions. On the other hand, in contrast to other metathesis processes, the enyne metathesis can be promoted by other metal catalysts, such as $\mathrm{Pt}^{2+}, \mathrm{Pt}^{4+}$, or Ir, or even Lewis acids, by a different mechanism, but with the same result. Interestingly, in contrast to the alkene RCM, for the enyne RCM, the mode of the ring closure can be different depending on the size of the cyclic system. ${ }^{177}$ Thus, whereas in small- and medium-sized rings, the cyclization pathway goes through an exo-mode that delivers the product type $\mathbf{A}$, in a macrocyclization process, the ring closure can go through an endo-pathway, owing to the increased flexibility of the large ring system, that should afford the product type $\mathbf{B}$. A clear example of the formation of this class of type $\mathbf{B}$ compounds is the synthesis of 6-deoxyerythronolide $B(\mathbf{3 4 5})$ by Krische and co-workers (Scheme 41), ${ }^{178}$ who prepared macrocyclic $\mathbf{3 4 7}$ in $89 \%$ yield when the enyne $\mathbf{3 4 6}$ was treated with H-G II catalyst (6) in an atmosphere of ethylene at 110 ${ }^{\circ} \mathrm{C}$, with no detection of regioisomers. With the formation of the 14-membered macrocycle, the completion of the synthesis of the deoxyerythronolide B (345) was delineated through a synthetic sequence that included selective oxidation of the exocyclic double bond, reduction of the resulting enone through a Ni-catalyzed conjugate reduction, stereoselective methylation of the resulting ketone $\mathbf{3 4 8}$, and final removal of the protective groups via catalytic hydrogenation (Scheme 41). Given the usual involvement of the enyne RCM products in subsequent transformations of the resulting diene in a tandem process, the majority of cases found in the literature correspond to this category and will be discussed later in Section 3.3.

\subsection{Total Syntheses Based on an Enyne Cross-Me- tathesis Reaction}

Several problems are associated with the selectivity of an intermolecular enyne metathesis, for example alkenealkene and alkyne-alkyne metathesis processes can compete with the alkene-alkyne coupling, as well as the possible formation of geometric $E / Z$ mixtures. Indeed, these problems are the likely reasons for the limited use of this modality of metathesis versus the intramolecular variant. Due to the scarcity of examples in which an enyne crossmetathesis is employed in the realm of total synthesis, it is worth emphasizing those where the reaction has been suc- 


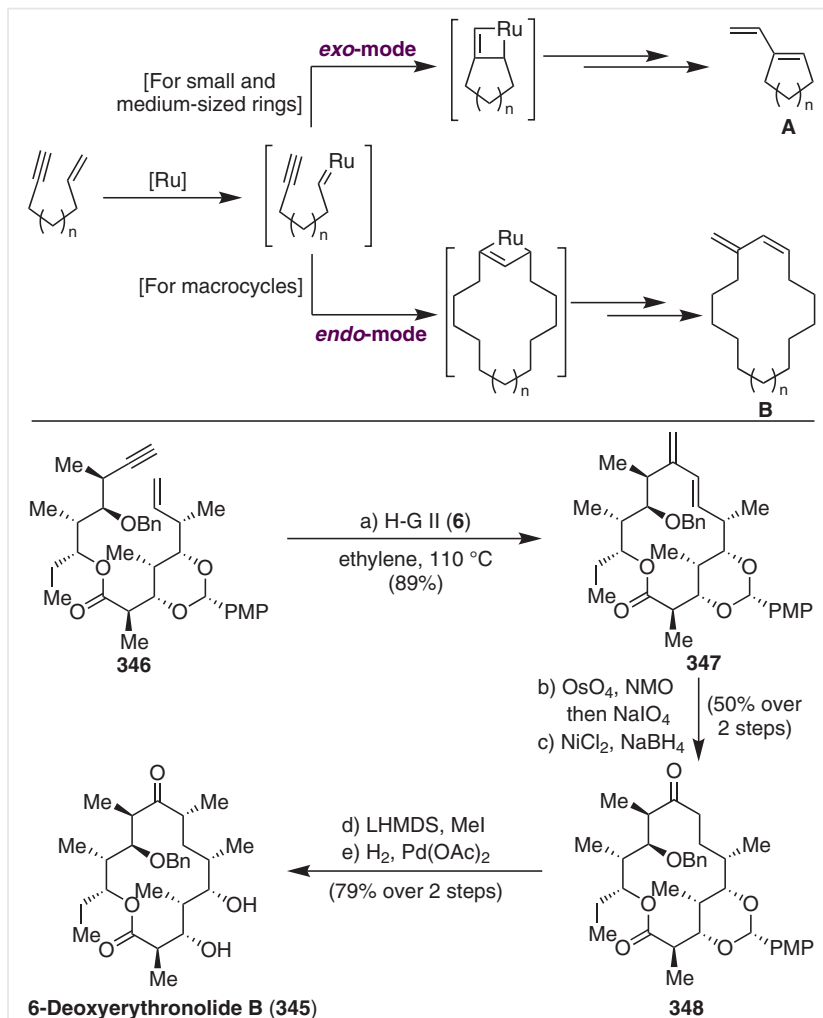

Scheme 41 Different pathways of the ring-closing enyne metathesis and total synthesis of 6-deoxyerythronolide B

cessfully applied. Such a case is the synthesis of amphidinolide P (349) by Diver and Jecs (Scheme 42), ${ }^{179}$ in which an enyne cross-metathesis allowed access to the main backbone of the natural product. In practice, alkyne $\mathbf{3 5 0}$ and alkene $\mathbf{3 5 1}$ were coupled by treatment with the H-G II catalyst (6) at low temperature $\left(-20^{\circ} \mathrm{C}\right)$ to give diene $\mathbf{3 5 2}$ in $72 \%$ yield and as a $4.5: 1 \mathrm{E} / \mathrm{Z}$ mixture of geometric isomers. The completion of the synthesis was achieved according to the Williams protocol ${ }^{180}$ to obtain pure amphidinolide $\mathrm{P}$ (349) in $38 \%$ overall yield. Surprisingly, when they attempted the synthesis of this natural product via an enyne RCM, they failed to obtain any ring-closure product, either from 353 or from the more stable TMS derivative 354. However, when 353 was subjected to the Grubbs II catalyst (4) in an ethylene atmosphere, they could obtain, in almost quantitative yield, the 1,3-diene 355, which was envisioned as a suitable precursor for a final RCM step. In this case, they observed that the RCM reaction of its corresponding silyl enol ether, compound 356, with the Grubbs II catalyst (4) proceeded in a better yield, compared with the direct RCM reaction of the diene 355, likely due to the introduction of additional rigidity in the system that would favor the connection of the involved alkenes. The RCM product, obtained as a mixture of the corresponding silyl enol ether and ketone, was transformed into amphidinolide $\mathrm{P}(\mathbf{3 4 9})$ by reaction with
HF.pyridine in $67 \%$ yield over two steps (Scheme 42 ). This contribution joins the synthesis by Lee and co-workers based on an RCM approach. ${ }^{181}$

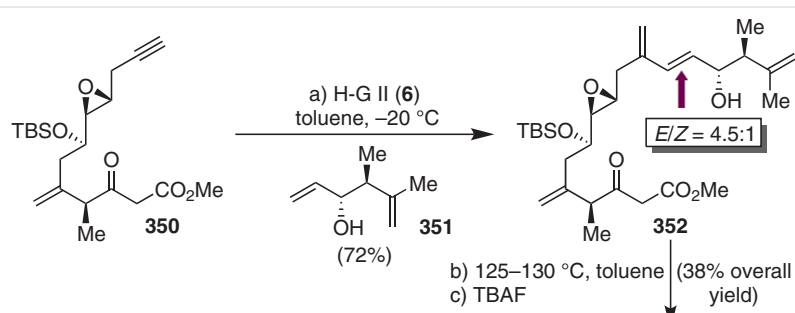

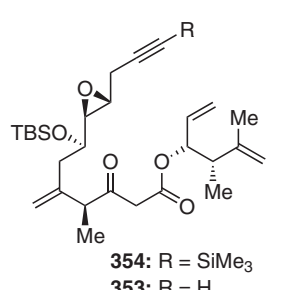

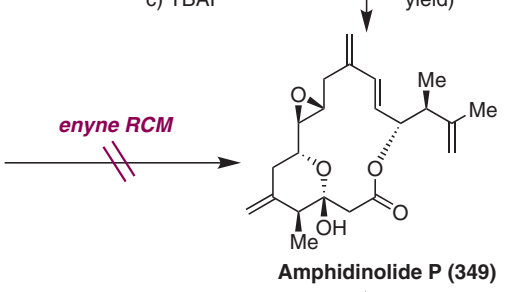
354: $\mathrm{R}=\mathrm{SiMe}$

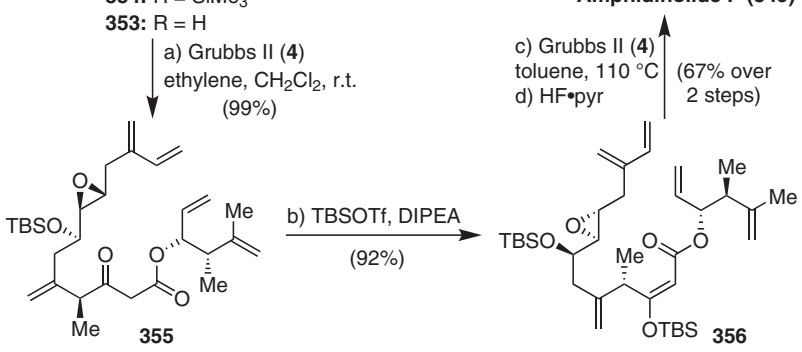

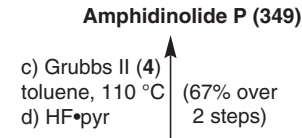

Scheme 42 Total synthesis of amphidinolide P

\subsection{Enyne Metathesis in Tandem Reactions}

Among the different variants of the metathesis reactions that employ enynes as starting precursors, those that involve the enyne metathesis as part of a cascade process have been the most exploited, due to their great potential for the generation of complex polycyclic systems in a single step. Given the synthetic consequences of such processes, enyne metathesis in cascade processes has occupied a strategic position in the synthesis of natural products containing complex polycyclic systems and has been the topic of several comprehensive reviews. ${ }^{182}$ One finds two well-differentiated types of tandem processes involving enyne metathesis: (a) Multiple intramolecular metathesis reactions in a programmed polyenyne system. In this case, the polyenyne precursor is properly designed to trigger a highly orchestrated cascade that ensures the correct regiochemical outcome, once the initial metal carbene is formed in the correct position. (b) A tandem process consisting of an initial enyne ring-closing metathesis, followed by a second reaction, usually a cycloaddition reaction, of the resulting diene. In the first case (a), we find a relevant example in the formal synthesis of englerin A (357) by Parker and Lee (Scheme 43). ${ }^{183}$ The intriguing structure of this natural product, in conjunction with its striking pharmaceutical 
properties, has prompted intense research activity directed towards its total synthesis, as well as the generation of analogues for medicinal chemistry studies.

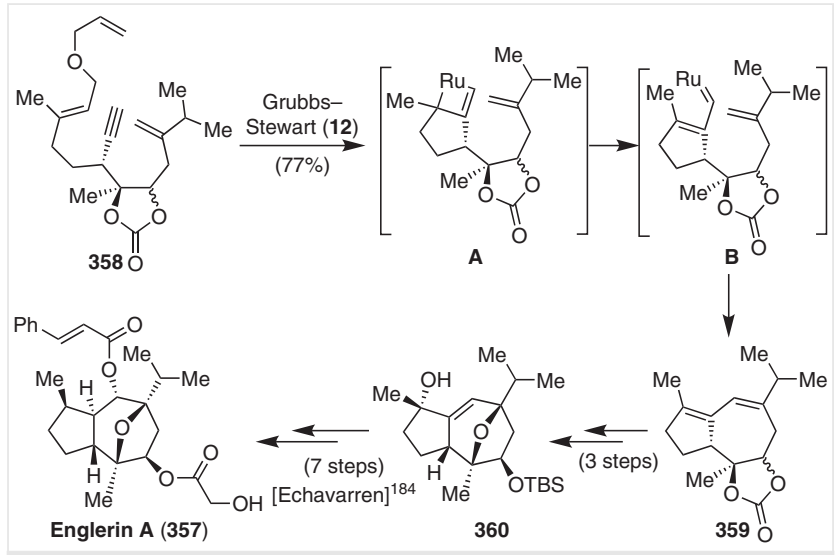

Scheme 43 Total synthesis of englerin A

Among the seminal and elegant contributions developed for the synthesis of this natural product, the one by Parker and Lee was based on a ene-yne-ene metathesis cyclization in a tandem process. In order to secure the initiation process in the correct direction, they developed a relay metathesis cascade from precursor $\mathbf{3 5 8}$, in form of a diastereomeric mixture, which was readily available from geraniol in seven steps. Thus, when compound $\mathbf{3 5 8}$ was treated with the Grubbs-Stewart catalyst (12), the expected tricyclic derivative $\mathbf{3 5 9}$ was obtained in $77 \%$ combined yield of both stereoisomers, which could be separated by chromatographic methods. The power of this tandem metathesis reaction is reflected by the fact that only the guaiadiene system was generated in a strict order of events through ruthenium carbene species $\mathbf{A}$ and $\mathbf{B}$ due to the triggering effect exerted by the terminal allyl ether. The formation of the oxygen bridge present in the natural product was then accomplished by means of an oxymercuration and subsequent demercuration process that afforded the advanced intermediate $\mathbf{3 6 0}$. The transformation of this compound into englerin A (357) has already been described by Echavarren in seven steps (Scheme 43). ${ }^{184}$

Another representative and unique example is the synthesis of the complex tetracyclic diterpenes belonging to the kempene family, such as the kempenone 361, which was isolated from the defense secretion of higher termites Nasutitermes octopolis. In contrast to the long multistep approaches reported by Paquette and Deslongchamps for the construction of the tetracyclic core of these terpenes, ${ }^{185}$ Metz and co-workers reported the preparation of this polycyclic system in one step and in excellent yield from the dienyne 362 (Scheme 44), which was prepared from the Wieland-Miescher ketone in 20 steps. ${ }^{186}$ Thus, exposure of 362 to the Grubbs II catalyst (4) afforded the tetracyclic de- rivative 363 in an astonishing 97\% yield. Whereas the reduction of the resulting tetracyclic ketone $\mathbf{3 6 3}$ with L-Selectride provided the alcohol $\mathbf{3 6 4}$ with the opposite stereochemistry to that of the natural product, reduction of the bicyclic ketone precursor $\mathbf{3 6 2}$ provided the correct diastereomer 365 under the same reduction conditions. In a similar way as for $\mathbf{3 6 2}$, dienyne $\mathbf{3 6 5}$ was subjected to treatment by the Grubbs II catalyst (4) to obtain the tetracyclic alcohol 366 in almost quantitative yield (99\%). From this compound, the synthesis of the kempenone $\mathbf{3 6 1}$ was achieved in nine additional steps (Scheme 44).
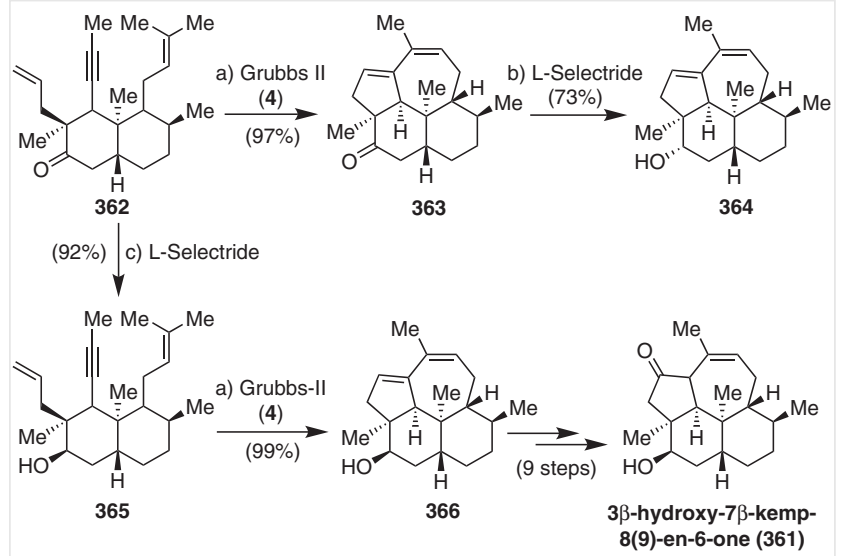

Scheme 44 Total synthesis of kempenone

Yet another instructive example for this section is the elegant synthesis of $( \pm$ )-morphine (367) by Smith and coworkers (Scheme 45), ${ }^{187}$ in which the intricate pentacyclic system contained in this fascinating natural product was generated utilizing a cascade ene-yne-ene ring-closing metathesis of the highly functionalized benzofuran 368, prepared in just six steps from commercially available starting materials. In the crucial metathesis event, the catalytic action of the H-G II catalyst (6) smoothly promoted a sequential cascade of events, initiated with an enyne-RCM reaction, that generated the ruthenium alkylidene intermediate A, and continued with a final RCM reaction to produce tetracyclic compound 369. Despite this product being isolated in an impressive $94 \%$ yield, they decided to continue with the synthetic sequence without isolation of the resulting tetracycle 369. The compound was then subjected to a 1,6addition reaction by treatment with TFA and then sodium carbonate. As a result, a 10:1 mixture of compounds corresponding to neopinone (370) and codeinone (371) was obtained. The treatment of this mixture with $\mathrm{HCl}$, followed by $\mathrm{NaOH}$ workup, allowed for the isomerization of neopinone (370) to codeinone (371). The reduction of $\mathbf{3 7 1}$ with sodium borohydride afforded codeine (372) as a single diastereomer in $65 \%$ overall yield from 368. Finally, demethylation of codeine with boron tribromide yielded racemic morphine (367) in $86 \%$ yield (Scheme 45 ). 


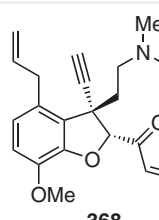

368

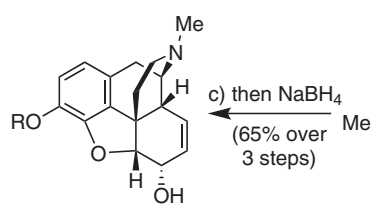

b) $\mathrm{BBr}_{3}$ - Codeine (372): $\mathrm{R}=\mathrm{Me}$

$(86 \%) \rightarrow$ Morphine (367): $\mathrm{R}=\mathrm{H}$

Scheme 45 Total synthesis of $( \pm)$-morphine

An interesting example of the synthetic application of domino metathesis in the field of the alkaloid-type natural products is the recent syntheses of virgidivarine (373) and virgiboidine (374), which are piperidine and piperidinoquinolizidine alkaloids isolated from the leaves of African leguminosae Virgilia divaricata and Virgilia oroboides and whose biological activities have not been studied. Blechert and co-workers (Scheme 46) ${ }^{188}$ planned the construction of the common dipiperidine core of these natural products via a ene-ene-yne ring-rearrangement metathesis (RRM) from the dienic system represented by compound 375, foreseeing an initial ROM process of the cyclopentene unit, followed by a double alkene RCM-enyne RCM process of the resulting ROM intermediate. Thus, when precursor $\mathbf{3 7 5}$, prepared from cis-cyclopent-2-ene-1,4-diol via enzymatic desymmetrization, was exposed to the H-G II catalyst (6) under ethylene atmosphere, compound $\mathbf{3 7 6}$ was obtained in a remarkable $83 \%$ yield, according to the expected mechanistic course delineated by them. Combined with the tandem metathesis reactions, the resulting metathesis product was transformed into the aldehyde $\mathbf{3 7 7}$ by oxidative treatment in 33\% overall yield in one pot. From this aldehyde, both alkaloids were prepared, requiring ten steps to synthesize virgidivarine (373), followed by the synthesis of virg-

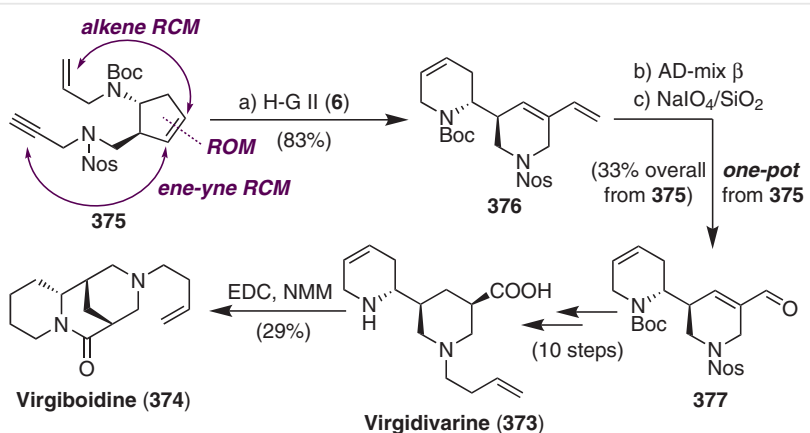

Scheme 46 Total synthesis of virgidivarine and virgiboidine iboidine (374), after a final lactamization reaction of $\mathbf{3 7 3}$ with EDC (Scheme 46).

With regards to recent examples, special attention is deserved for the synthesis of the anticancer alkaloids flueggine A (378) and virosine B (379) by Li, Yang, and co-workers (Scheme 47). ${ }^{189}$ These compounds, belonging to the securinega family, possess unique structural features and interesting biological properties that cover a wide range of activities. The synthesis of these compounds was based on an elegant RRCM of a dienyne system for the controlled construction of the core structure represented by norsecurinine (385). Thus, their syntheses were envisioned to proceed via a 1,3-dipolar cycloaddition between norsecurinine (385) and nitrone $\mathbf{3 8 6}$, which would be prepared from norsecurinine (385) by oxidative treatment with $\mathrm{mCP}-$ BA. In a similar strategy towards the related alkaloid securinine, Honda and co-workers (Scheme 47) ${ }^{190}$ attempted its synthesis through a tandem RCM of the dienyne $\mathbf{3 8 0}$. However, when this precursor was reacted with different ruthenium catalysts, such as the Grela-Grubbs-Hoveyda catalyst (10), the desired $\gamma$-lactone $\mathbf{3 8 1}$ was not detected, obtaining instead the $\delta$-lactone $\mathbf{3 8 2}$ in 69\% yield. The preference of the catalyst to react with the butenyl group rather than the acrylate moiety, through intermediate $\mathbf{A}$, could explain the outcome of this reaction. In an attempt to favor the formation of the required ruthenium complex at the less reactive alkene, Li, Yang, and co-workers ${ }^{189}$ proposed the trienyne 383 (Scheme 47) as a suitable precursor to promote the preferential formation of intermediate $\mathbf{C}$ through the initiation of the reaction at the less sterically encumbered terminal olefin. In fact, when compound $\mathbf{3 8 3}$ was subjected to the action of the Zhan-1 b catalyst (11), among others, compound $\mathbf{3 8 4}$ was obtained in a reproducible and acceptable $64 \%$ yield. The completion of the synthesis of norsecurinine was undertaken in three additional steps, allylic bromination, Boc deprotection, and a nucleophilic cyclization under basic conditions. After some additional experimentation, they found that this transformation could be achieved in only one step by exposure of the resulting bromide to the acid $\mathrm{AgSbF}_{6}$ in an improved $85 \%$ yield. Finally, the preparation of the nitrone $\mathbf{3 8 6}$ from norsecurinine (385), according to the Magnus protocol, ${ }^{191}$ was followed by a cycloaddition reaction with $\mathbf{3 8 5}$ to obtain natural product flueggine A (378) in $77 \%$ yield. In a related approach, they also prepared virosaine $B(\mathbf{3 7 9})$ by an intramolecular cycloaddition of nitrone $\mathbf{3 8 8}$, prepared from the isomer allonorsecurinine (387) in three steps (Scheme 47).

In the second group of the cascade reactions involving enyne-RCM processes, we wish to highlight those that combine the metathesis reaction with a Diels-Alder cycloaddition of the resulting diene as a way for the construction of a bicyclic system in a rapid and efficient fashion. Within this category of tandem reactions, the synthesis of the norsesquiterpene-type alkaloids, such as the anticancer alkaloid 

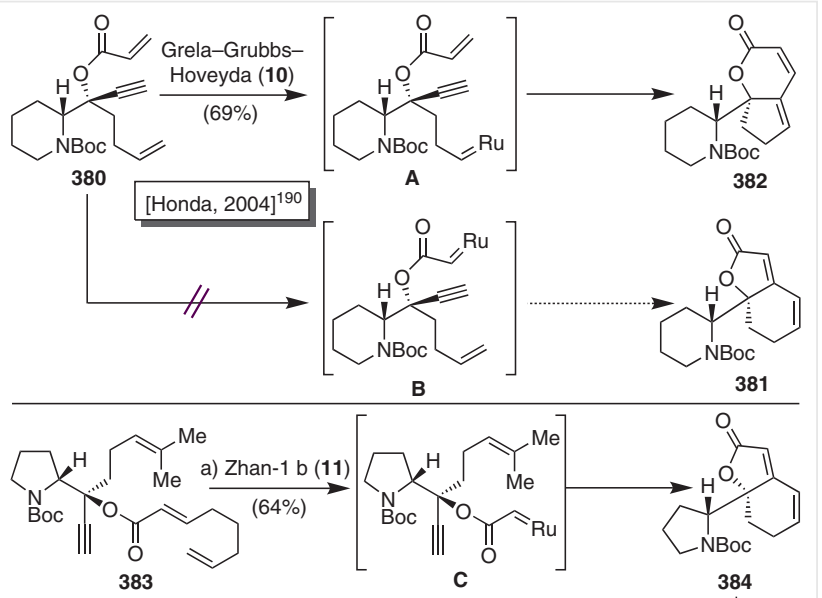

b) NBS, AIBN

c) $\mathrm{AgSbF}_{6} \quad(51 \%)$
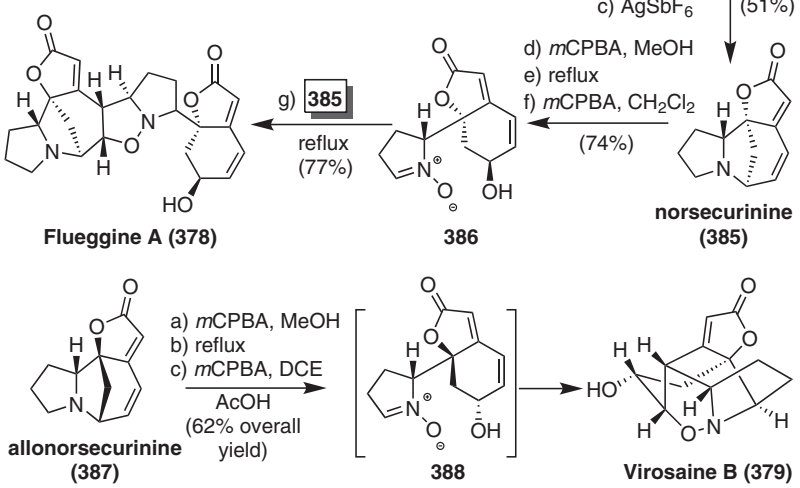

Scheme 47 Total synthesis of flueggine A and virosaine B

389, which were isolated from the culture of mushroomforming fungus Flammulina velutipes, was accomplished using a tandem enyne-RCM/Diels-Alder/aromatization sequence in one-pot by Reddy and co-workers (Scheme 48). ${ }^{192}$ Thus, the treatment of the acyclic precursor $\mathbf{3 9 0}$ with the Grubbs I catalyst (3) in toluene at $50{ }^{\circ} \mathrm{C}$ was followed by a Diels-Alder reaction with dimethyl acetylenedicarboxylate and then, treatment with DDQ of the resulting Diels-Alder adduct 391, which was not isolated, to provide the final compound $\mathbf{3 9 2}$ in a moderate $42 \%$ overall yield. The elaboration of this product towards the final alkaloid 389 was accomplished without issues in three additional steps in $49 \%$ overall yield (Scheme 48 ).

\section{Alkyne Metathesis in Total Synthesis}

\subsection{Total Syntheses Based on a Ring-Closing Alkyne-Metathesis Reaction}

The wide range of reactivities that alkynes possess, compared with alkenes, imparts alkyne metathesis as a very powerful tool with a broader field of synthetic oppor-
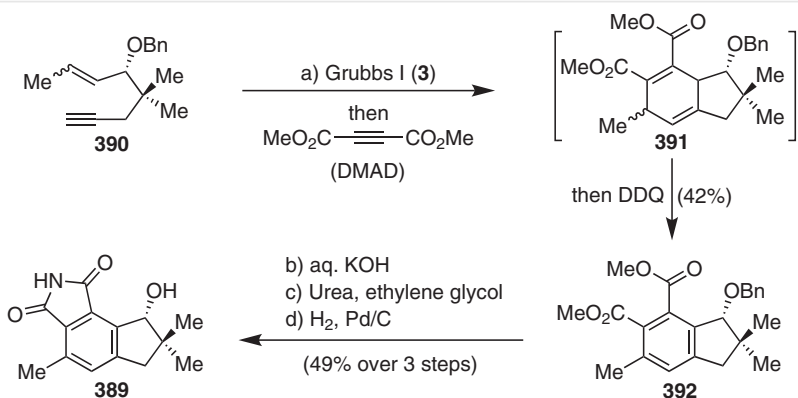

Scheme 48 Total synthesis of the norsesquiterpene alkaloid

tunities. Thus, some advantages of alkynes over alkenes include the stereocontrolled partial reduction of the triple bond, which allows stereoselective access to the E- or Zalkene, and its excellent reactivity against electrophilic metals such as $\mathrm{Ag}$, Pt, or $\mathrm{Hg}$, which allows for further functionalization. On the other hand, the catalysts required for the alkyne-metathesis reactions are completely different. From the first Mortreux system developed in 1974, ${ }^{193}$ the evolution towards more efficient, stable and functional group tolerant catalysts, developed first in 1982 by Schrock (393) $)^{194}$ and later in 1999 by Fürstner (394) ${ }^{195}$ (Figure 7), has propelled the alkyne-metathesis reaction to become an excellent synthetic tool for the generation of macrocyclic structures as applied to the synthesis of natural products and bioactive compounds. Since the first example of an alkyne ring-closing metathesis in 1999 by Fürstner, ${ }^{196}$ we can find in the literature many applications of this type of reaction in the preparation of complex macrocyclic natural products, some of the which have been linked to the development of even more efficient and stable catalysts (395399) since 2011. ${ }^{197}$ As for the catalysts used in alkene metathesis, the catalysts for alkyne metathesis are precata-
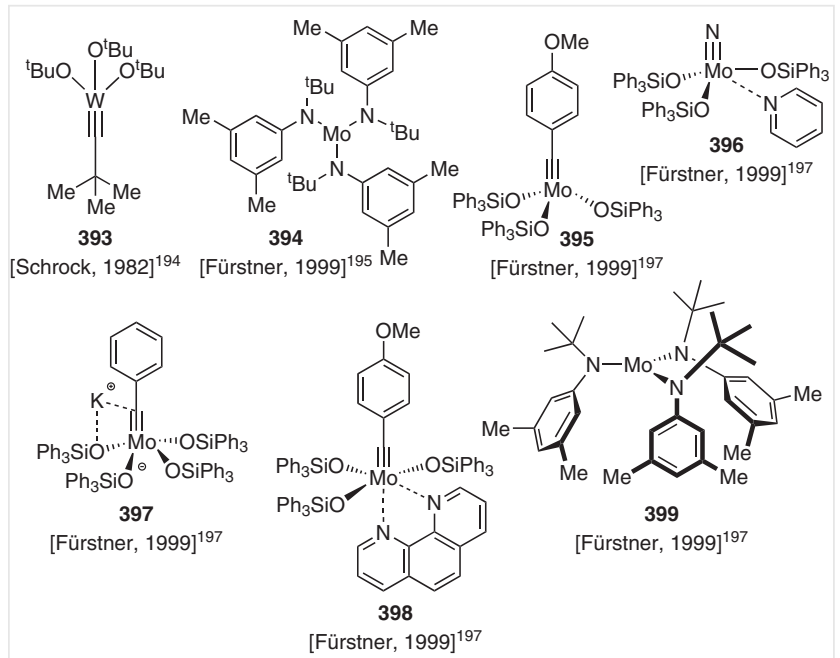

Figure 7 Common catalysts used for alkyne-metathesis reactions 
lysts, which are activated to form the active species responsible for catalytic action. In fact, precatalysts 394 or 399 are activated by reaction with $\mathrm{CH}_{2} \mathrm{Cl}_{2}$ to form in situ the corresponding monochloro derivatives, which are the catalytically active species. ${ }^{198}$ One of the main architects of the responsible for the spectacular irruption of this reaction in modern organic synthesis has been Fürstner, who by both his seminal contributions in total synthesis and his work on the development of new catalysts has reached spectacular progress and promoted the field. During his prolific and impressive research career, many reviews have been reported about this reaction covering the main contributions of the Fürstner group as well as of other groups. ${ }^{199}$ The contributions reported in the period 2015-2017, however, have not been covered and thus will be reviewed in this section.

Thus, selected examples are illustrated in Scheme 49, in which the natural products lactimidomycin (400), ${ }^{200}$ mandelalide A (401), ${ }^{201}$ amphidinolide $\mathrm{F}$ (402), ${ }^{202}$ brefeldin A (403), ${ }^{203}$ leidodermatolide (404), ${ }^{204}$ tulearin A (405), ${ }^{205}$ or brominated 4-pyrone-type natural products ${ }^{206}$ (e.g., 406) were efficiently synthesized from their corresponding acyclic dialkynes which gave the corresponding alkyne macrocycles 407-412 in good to excellent yields. In the depicted representative cases, the alkynes were reduced to the corresponding $E$-alkenes (cases of natural products 400, 403, and 405), Z-alkenes (cases of 401 and 404), or even, not transformed, such as the cases of the 4-pyrone 406. For the particular case of amphidinolide $F$ (402), the alkyne was subjected to a hydration reaction to obtain a ketone under platinum catalysis. Similarly relevant are the syntheses of WF-1360F (413), ${ }^{207}$ cruentaren A (31), ${ }^{208}$ and haliclonin A (414), ${ }^{209}$ reported by the Altmann, Barrett, and Huang groups, respectively, in which after the alkyne macrocycle formation via a RCAM reaction, the resulting macrocyclic alkynes 415-417 were reduced to the E-olefin in the case of $\mathbf{4 1 5}$ or to the Z-olefins by means of a Lindlar catalyst mediated hydrogenation for $\mathbf{4 1 6}$ and $\mathbf{4 1 7}$ (Scheme 50).

More intriguing and challenging are the cases in which the introduction of a methyl group into the alkyne is required to be transformed into a methyl-branched alkene in a regio- and stereocontrolled manner. Such cases can be found in the synthesis of the natural products 5,6-dihydrocineromycin B (418), disciformycin B (419), and nannocystin $A x(\mathbf{4 2 0})$ by the Fürstner group. To this aim, the recent methodology developed by this group, based on the ruthe-

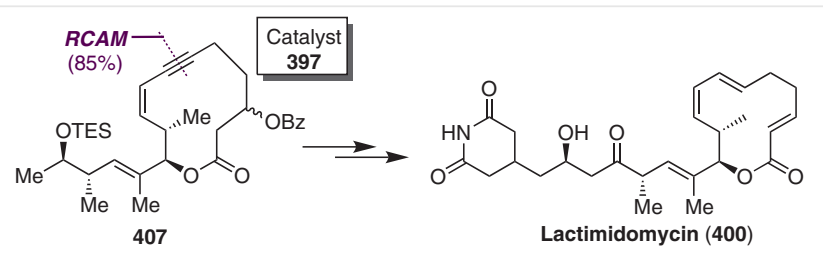

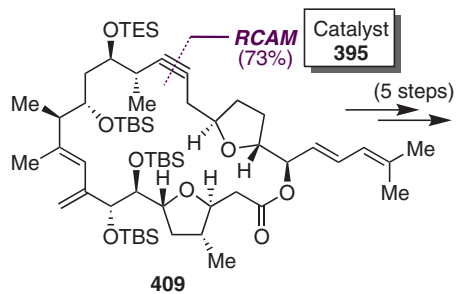

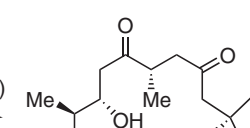

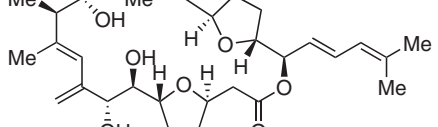

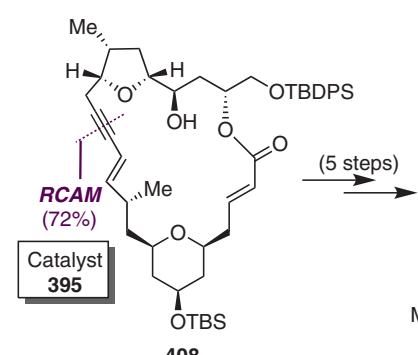
408

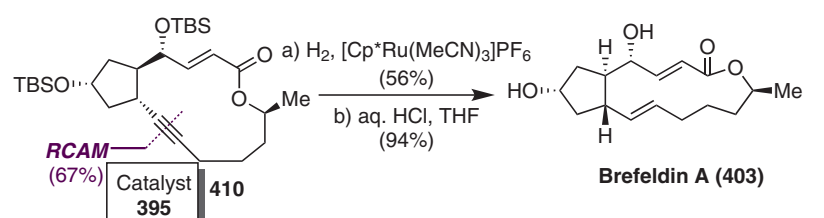

TBSO

\begin{tabular}{lll} 
RCAM $(72 \%)$ & $\begin{array}{c}\text { Catalyst } \\
399\end{array}$ \\
\hline
\end{tabular}

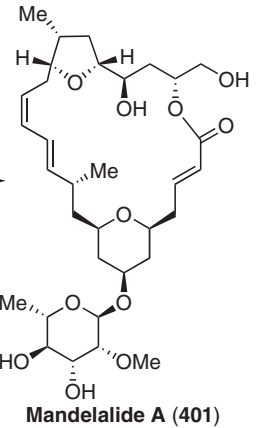

Me

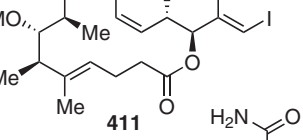<smiles>[13CH3][13CH3]</smiles>
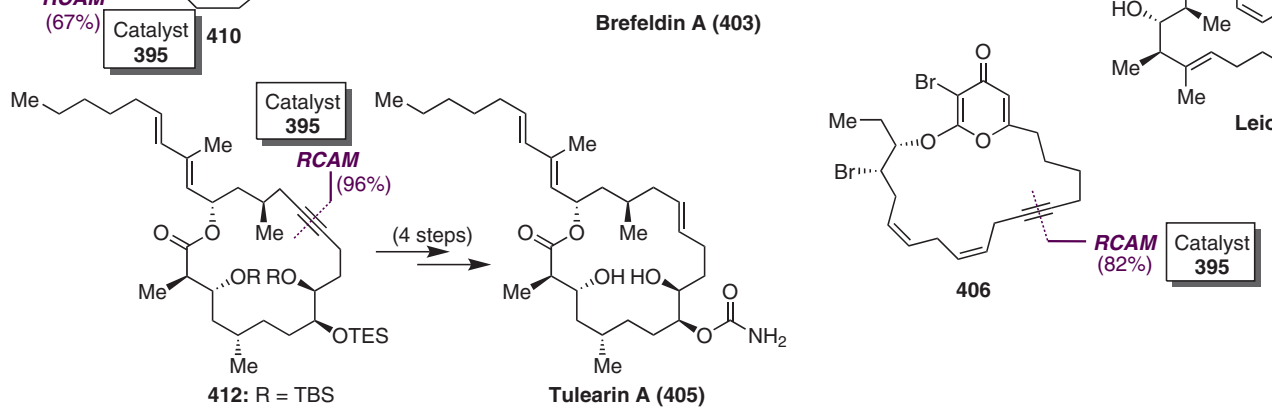

Scheme 49 Selected natural products synthesized via a RCAM reaction by the Fürstner Group (2013-early 2018) 
<smiles>CC(C)[C@H]1C[C@H]2C[C@@H]1C2</smiles>

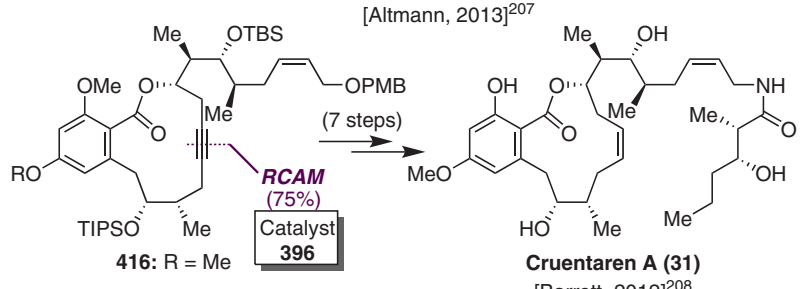

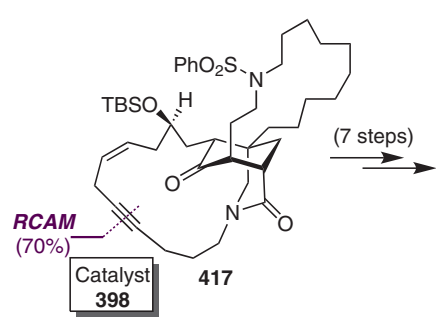

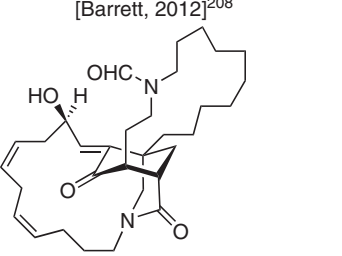

$(-)$-Haliclonin A (414) [Huang, 2016] $]^{209}$

Scheme 50 Selected natural products synthesized via a RCAM reaction by other research groups (2013-early 2018)

nium-catalyzed trans-hydrostannation of alkynes, was envisioned as a solution to this synthetic problem given the excellent levels of regioselectivity exhibited by this reaction when applied to unprotected propargyl alcohol derivatives. Thus, in the case of 5,6-dihydrocineromycin B (418) (Scheme 51), ${ }^{210}$ when alkyne 421, smoothly obtained from the corresponding acyclic dialkyne by reaction with the molybdenum alkylidyne complex $\mathbf{3 9 7}$, was desilylated by reaction with HF, the resulting propargyl alcohol was treated with $\mathrm{Bu}_{3} \mathrm{SnH}$ in the presence of the ruthenium catalyst $\left[\mathrm{Cp}^{*} \mathrm{RuCl}_{2}\right]_{\mathrm{n}}$. As a result, the corresponding $\alpha$-alkenylstannane was obtained as a single isomer. Having introduced the stannyl group, a Stille reaction was carried out by exposure to copper thiophene-2-carboxylate (CuTC), $\left[\mathrm{Ph}_{2}-\right.$ $\left.\mathrm{PO}_{2}\right]\left[\mathrm{NBu}_{4}\right]$, and $\mathrm{Pd}\left(\mathrm{PPh}_{3}\right)_{4}$ in the presence of methyl iodide to afford the final natural product $\mathbf{4 1 8}$ in excellent yield. It is important to highlight the importance of the order of addition and stoichiometry of the reactants in this reaction to avoid undesired protodestannation processes. In a similar situation, the macrocyclic alkyne $\mathbf{4 2 2}$ (Scheme 51), ${ }^{211}$ obtained in excellent yield from its corresponding dialkyne precursor by reaction with precatalyst $\mathbf{3 9 9}$, required the installation of the methyl group for the synthesis of disciformycin $A$ and $B$, interesting macrolides-type antibiotics with considerable activity against resistant Gram-positive bacteria. As the previous case, the transformation of compound 422 into its hydroxy derivative was followed by a rapid trans-hydrostannation reaction. In contrast to the previous case, as to other numerous examples carried out by the Fürstner group, on this occasion a 3:1 mixture of stannyl regioisomers, in favor of $\mathbf{4 2 3}$, was obtained, likely due to the competing interactions of the hydroxy group, via hydrogen bonding, with the ruthenium catalyst and with the neighboring ester carbonyl group. In addition to this lack of regioselectivity, the observation that the stannyl derivative was quite sensitive forced them to continue with the crude product mixture to the following step, which consisted of a

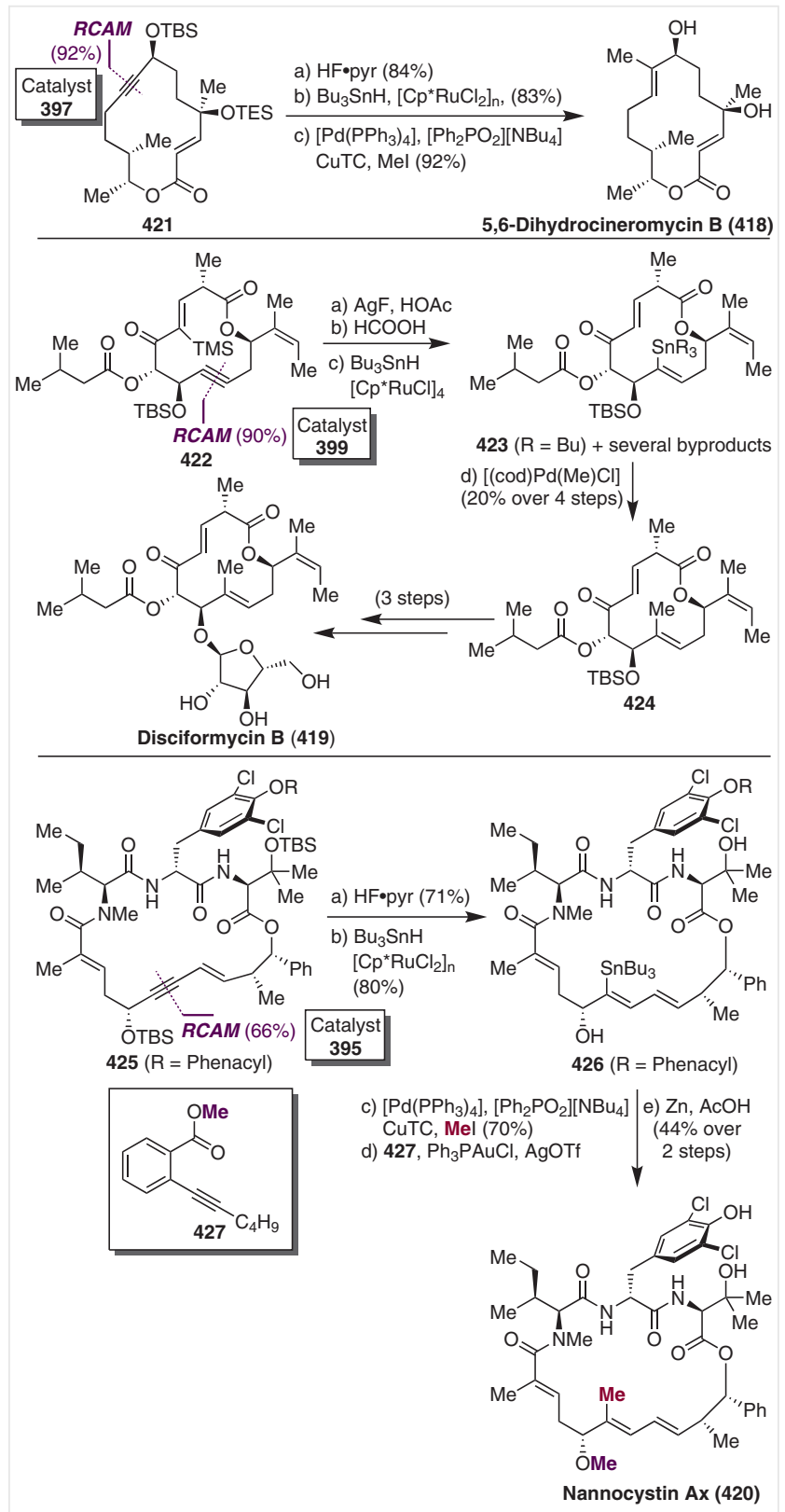

Scheme 51 Selected natural products synthesized via RCAM/hydrostannation reactions by the Fürstner group 
methylation reaction. Once again, this reaction proved to be sluggish, as a mixture of products was obtained under conventional conditions.

In light of these unsatisfactory results, they decided to use stoichiometric amounts of the methyl donor $[(\operatorname{cod}) \mathrm{Pd}(\mathrm{Me}) \mathrm{Cl}]$ to obtain the desired product 424 in $20 \%$ overall yield after four steps from $\mathbf{4 2 2}$. Final glycosidation and global deprotection provided the elusive disciformycin $B(420)$ in the first instance, and then disciformycin A after an isomerization reaction. Similarly challenging proved to be the synthesis of nannocystin Ax (420) (Scheme 51), ${ }^{212} \mathrm{a}$ cytotoxic cyclodepsipeptide isolated from myxobacteria. After a successful alkyne RCM reaction that provided macrocyclic alkyne $\mathbf{4 2 5}$ in $66 \%$ yield by the action of catalyst 395, the hydroxy-directed hydrostannation was achieved by sequential desilylation and treatment with $\mathrm{Bu}_{3} \mathrm{SnH}$, in the presence of catalytic amounts of $\left[\mathrm{Cp}^{*} \mathrm{RuCl}_{2}\right]_{\mathrm{n}}$, to obtain the corresponding stannane $\mathbf{4 2 6}$ as a single regio- and stereoisomer. The methylation was then achieved according to previous conditions to provide the desired methyl derivative in a reasonably good yield (70\%). The methylation of the hydroxy group proved to be similarly challenging, finding, after extensive experimentation, that the methyl ester 427 provided a proper source of electrophilic methyl by its in situ generation in a gold-catalyzed cyclization. Final reductive cleavage of the phenacyl group furnished the targeted natural product $\mathbf{4 2 0}$ (Scheme 51).

Beyond the transformation of the alkyne into an alkene or even a methyl-substituted alkene, as discussed vide supra, the reactivity of the alkyne functional group allows the construction of a heterocyclic ring, providing further extraordinary opportunities to access more complex structural systems compared to the alkene chemistry.

These post-metathetic transformations have been similarly explored by the Fürstner group in the synthesis of a plethora of natural products. In this set of new synthetic opportunities, the syntheses of enigmazole A (428) (Scheme 52), ${ }^{213}$ polycavernoside A (429) (Scheme 52), ${ }^{214}$ kendomycin (430) (Scheme 53), ${ }^{215}$ and lytharanidine (431) (Scheme 53) ${ }^{216}$ represent excellent examples of this synthetic potential. In all these cases, the macrocyclic alkynes 432-435 were efficiently synthesized from their corresponding acyclic dialkynes. From these alkynes, in the cases of enigmazole A, polycavernoside A, and kendomycin, a transannular pyran (for enigmazole $A$ ) and a furan ring (for polycavernoside $A$ and kendomycin) were efficiently constructed by means of activation of the alkyne with goldbased catalysts $\mathbf{4 3 6}-\mathbf{4 3 8}^{217}$ to provide compounds $\mathbf{4 3 9}$ 441. In the cases of polycavernoside $A$ and kendomycin, the syntheses were formal, having been described their total synthesis by Lee and Woo $^{218}$ and Mulzer and co-workers ${ }^{219}$ from advanced precursors 440 and 442, respectively. On the other hand, for the synthesis of lytharanidine (431), formation of a piperidine ring was required, which was achieved by a sequence of redox isomerization, followed by transannular aza-Michael addition from macrocyclic alkyne $\mathbf{4 3 5}$ (Schemes 52 and 53).

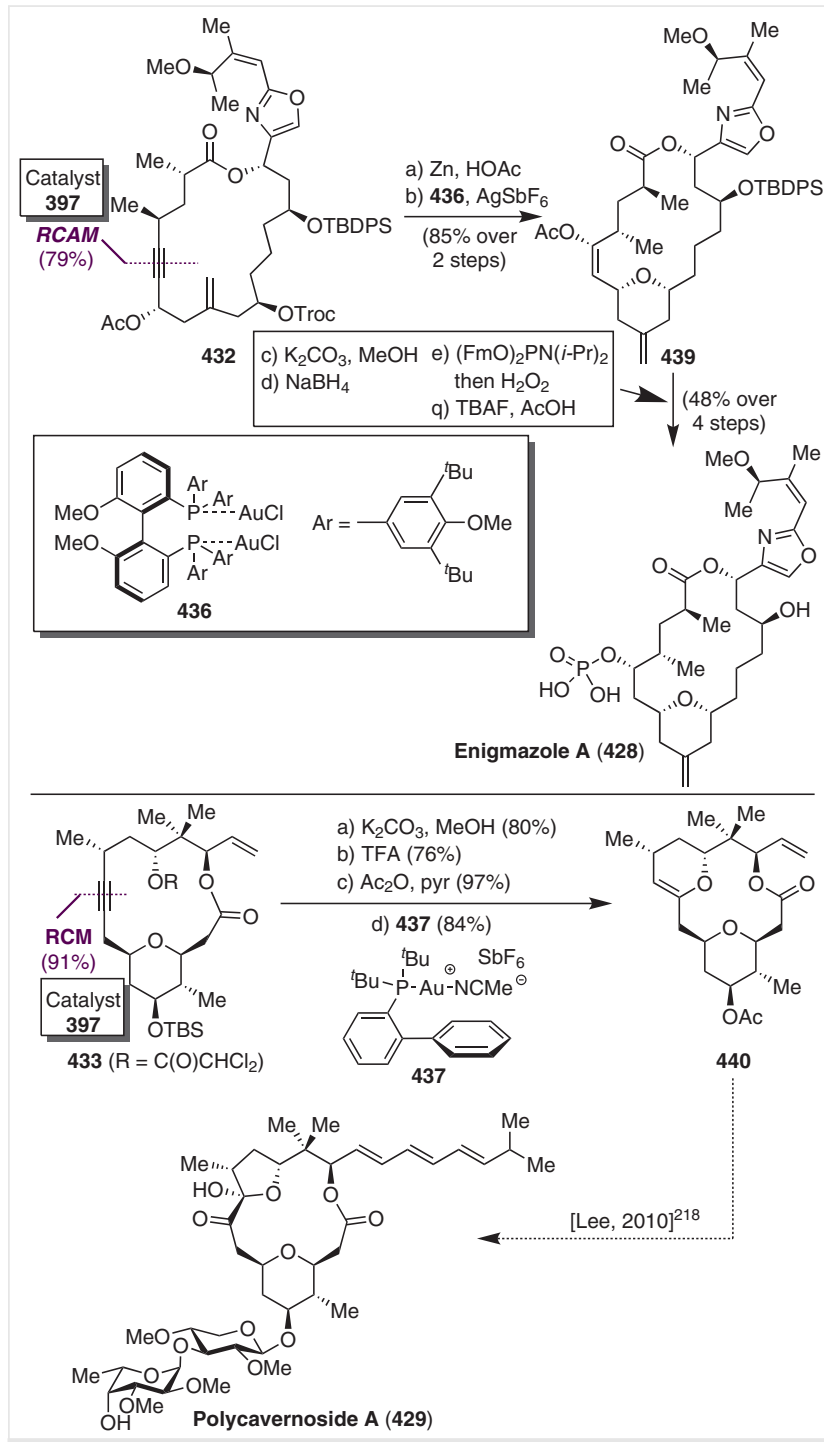

Scheme 52 Selected natural products synthesized via a RCAM/gold catalysis by the Fürstner group

An intriguing last case is the synthesis of ivorenolide $B$ (443) by the Fürstner group based upon a macrocyclization of a diterminal diyne to prepare the 1,3-diyne system found in this unprecedented natural product (Scheme 54) ${ }^{220}$ Ivorenolide $\mathrm{B}$ belongs to a family of macrolides isolated from the stem bark of Khaya ivorensis, which has been reported to inhibit concanavalin A induced T-cell and lipopolysaccharide-induced B cell proliferations. This noteworthy biological activity confers it a clinical application as an immunosuppressive agent comparable to cyclosporine A. The synthesis by the Fürstner group was delineated according 

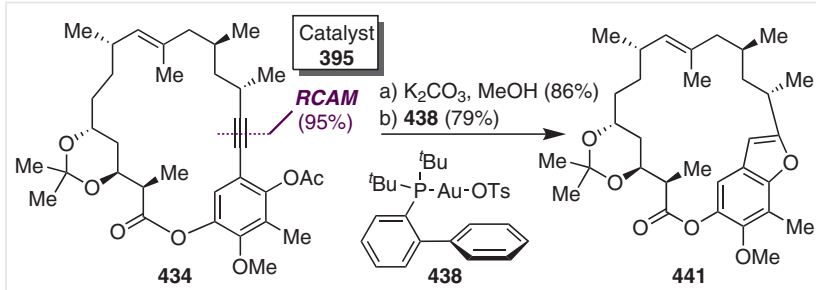

c) $h v(85 \%) \mid$ e) $\mathrm{HCl}$ d) $\mathrm{NaBH}_{4} \quad(89 \%$ over

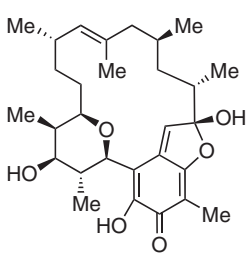
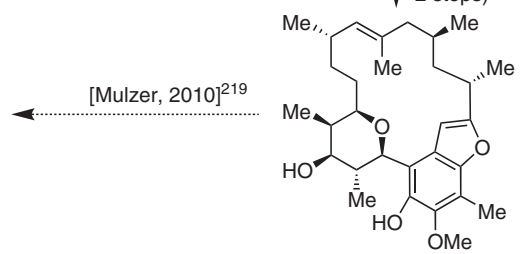

Kendomycin (430)

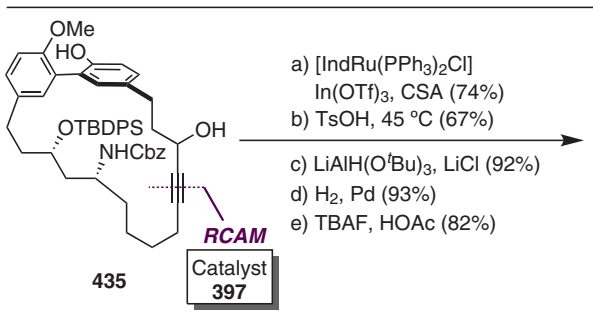

442

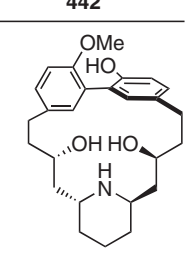

Lythranidine (431)
Scheme 53 Selected natural products synthesized via a RCAM/gold catalysis by the Fürstner group

to a RCAM reaction of the diterminal acyclic diyne $\mathbf{4 4 4}$, which by treatment with catalyst $\mathbf{3 9 5}$ furnished in a remarkable $82 \%$ yield the desired [17]-membered ring $\mathbf{4 4 5}$ with the embedded 1,3-diyne unit and no detection of side products derived from ring contraction or oligomerization processes. The subsequent epoxidation, performed in a regio- and stereoselective manner with $m \mathrm{CPBA}$, followed by silyl ether deprotection provided the targeted ivorenolide B (443) (Scheme 54). This synthesis improved notably by Yue and co-workers, ${ }^{221}$ who, based on a RCM reaction, provided the macrocyclic lactone $\mathbf{4 4 6}$ as a 1.5:1 mixture with the $E$ -
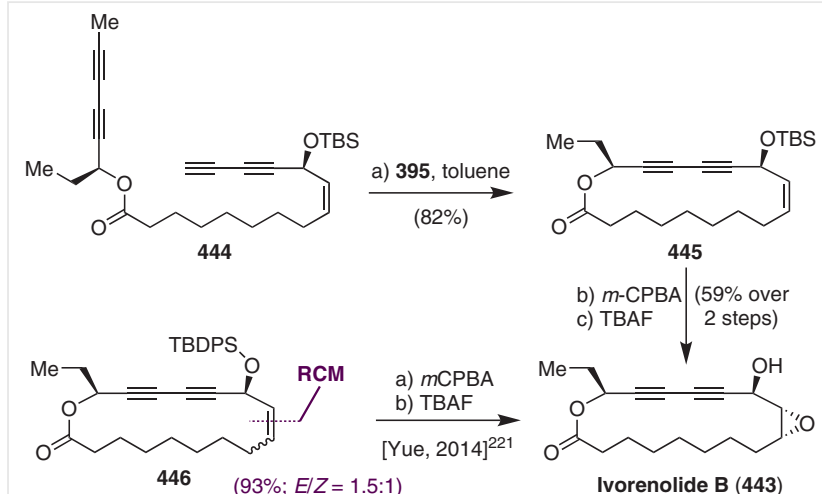

Ivorenolide B (443)

Scheme 54 Total synthesis of ivorenolide B olefin as the major isomer. Despite this stereochemical problem, this synthesis allowed the absolute configuration of the natural product to be confirmed (Scheme 54).

\subsection{Other Types of Alkyne-Metathesis Reactions}

To conclude this review, it is necessary to mention that, as in alkene metathesis reactions, we can find also examples of the use of the alkyne cross-metathesis 222 or tethered RCAM reactions. ${ }^{223}$ Despite the power and scope that the alkyne metathesis demonstrates, utilization of these alkyne metathesis variants in the context of total synthesis is not well represented, with most examples being found mainly in polymerization reactions. ${ }^{224}$ Nevertheless, given the potential and efficiency of the methodology, there is no doubt that the trend will be an increase in the use of this chemistry in the construction of natural products.

\section{Conclusions}

As amply demonstrated in the literature, metathesis reactions are recognized as one of the most important and powerful reactions in the last decades rendering their main inventors the Nobel Prize in 2005. The synthetic value and great potential of these reactions have been driven by the tremendous progress witnessed in recent years regarding the design and development of efficient and stable catalysts based on metallocarbenes. As a consequence, these reactions enjoy broad scope and generality and a great deal of flexibility for structural diversity. Furthermore, as proof of these features is their extensive utilization in the field of organic synthesis, with particular impact in the total synthesis of natural products. These reactions in their different modalities (alkene-, enyne-, and alkyne-metathesis reactions), versions (intra- and intermolecular reactions), and strategies (tethered, relay, stereoselective metathesis, among others) have become a standard tool in the modern organic synthesis laboratory, being determinant in the completion of a wide array of natural products. In the present review we have covered the most relevant contributions on this field in the last five years, demonstrating the increasing value and flurry of synthetic opportunities that these reactions provide.

\section{Funding Information}

This work was supported financially by the Ministerio de Economía y Competitividad (MINECO) (Reference CTQ2014-60223-R)

\section{Acknowledgment}

I. C.-S. thanks the Ministerio de Educación, Cultura y Deporte (FPU Programme) for a predoctoral fellowship. The authors thank Dr. J. I. 
Trujillo (Pfizer, Groton, CT) for assistance in the preparation of this manuscript.

\section{References}

(1) Metathesis reactions include not only alkene, enyne, and alkyne metatheses, but also carbonyl-olefin metathesis, which are not included in this review. For representative reviews about these reactions see: (a) Ravindar, L.; Lekkala, R.; Rakesh, K. P.; Asiri, A. A.; Marwani, H. M.; Quin, H.-L. Org. Chem. Front. 2018, 5, 1381. (b) Ludwig, J. R.; Schindler, C. S. Synlett 2017, 28, 1501.

(2) Handbook of Metathesis; Grubbs, R. H., Ed.; Wiley-VCH: Weinheim, 2015, 2nd ed., Vols. 1-3.

(3) McGinnis, J.; Katz, T. J.; Hurwitz, S. J. Am. Chem. Soc. 1976, 98, 605.

(4) Hérisson, J.-L.; Chauvin, Y. Makromol. Chem. 1971, 141, 161.

(5) Schrock, R. R.; Murdzek, J. S.; Bazan, G. C.; Robbins, J.; DiMare, M.; O’Regan, M. J. Am. Chem. Soc. 1990, 112, 3875.

(6) Fu, G. C.; Nguyen, S. T.; Grubbs, R. H. J. Am. Chem. Soc. 1993, 115, 9856.

(7) Schwab, P.; France, M. B.; Ziller, J. W.; Grubbs, R. H. Angew. Chem., Int. Ed. Engl. 1995, 34, 2039.

(8) Scholl, M.; Ding, S.; Lee, C. W.; Grubbs, R. H. Org. Lett. 1999, 1, 953.

(9) Harrity, J. P. A.; La, D. S.; Cefalo, D. R.; Visser, M. S.; Hoveyda, A. H. J. Am. Chem. Soc. 1998, 120, 2343.

(10) Garber, S. B.; Kingsbury, J. S.; Gray, B. L.; Hoveyda, A. H. J. Am. Chem. Soc. 2000, 122, 8168.

(11) Wakamatsu, H.; Blechert, S. Angew. Chem. Int. Ed. 2002, 41, 2403.

(12) Fürstner, A.; Grabowski, J.; Lehmann, C. W. J. Org. Chem. 1999, $64,8275$.

(13) Jafarpour, L.; Schanz, H.-J.; Stevens, E. D.; Nolan, S. P. Organometallics 1999, 18, 5416

(14) Grela, K.; Harutyunyan, S.; Michrowska, A. Angew. Chem. Int. Ed. 2002, 41, 4038.

(15) Zhan, Z. J. US 20070043180, 2007; Chem. Abstr. 2007, 146, 142834

(16) Stewart, I. C.; Ung, T.; Pletnev, A. A.; Berlin, J. M.; Grubbs, R. H.; Schrodi, Y. Org. Lett. 2007, 9, 1589.

(17) Love, J. A.; Morgan, J. P.; Trnka, T. M.; Grubbs, R. H. Angew. Chem. Int. Ed. 2002, 41, 4035.

(18) Williams, M. J.; Kong, J.; Chung, C. K.; Brunskill, A.; Campeau, L.C.; McLaughlin, M. Org. Lett. 2016, 18, 1952.

(19) (a) Malcolmson, S. J.; Meek, S. J.; Sattely, E. S.; Schrock, R. R.; Hoveyda, A. H. Nature (London) 2008, 456, 933. (b) Lee, Y.-L.; Schrock, R. R.; Hoveyda, A. H.J. Am. Chem. Soc. 2009, 131, 10652. (c) Sattely, E. S.; Meek, S. J.; Malcolmson, S. J.; Schrock, R. R.; Hoveyda, A. H. J. Am. Chem. Soc. 2009, 131, 943. (d) Yu, M.; Wang, C.; Kyle, A. F.; Jakubec, P.; Dixon, D. J.; Schrock, R. R.; Hoveyda, A. H. Nature (London) 2011, 479, 88. (e) Wang, C.; Haeffner, F.; Schrock, R. R.; Hoveyda, A. H. Angew. Chem. Int. Ed. 2013, 52, 1939.

(20) Jiang, A. J.; Simpson, J. H.; Müller, P.; Schrock, R. R. J. Am. Chem. Soc. 2009, 131, 7770.

(21) (a) Rosebrugh, L. E.; Herbert, M. B.; Marx, V. M.; Keitz, B. K.; Grubbs, R. H. J. Am. Chem. Soc. 2013, 135, 1276. (b) Cannon, J. S.; Grubbs, R. H. Angew. Chem. Int. Ed. 2013, 52, 9001.

(22) (a) Khan, R. K. M.; Torker, S.; Hoveyda, A. H. J. Am. Chem. Soc. 2013, 135, 10258. (b) Koh, M. J.; Khan, R. K. M.; Torker, S.; Yu, M.; Mikus, M. S.; Hoveyda, A. H. Nature (London) 2015, 517, 181.

(23) Hong, S. H.; Grubbs, R. H. J. Am. Chem. Soc. 2006, 128, 3508.
(24) Kingsbury, J. S.; Garber, S. B.; Giftos, J. M.; Gray, B. L.; Okamoto, M. M.; Farrer, R. A.; Fourkas, J. T.; Hoveyda, A. H. Angew. Chem. Int. Ed. 2001, 40, 4251.

(25) (a) Lin, Y. A.; Chalker, J. M.; Davis, B. G. ChemBioChem 2009, 10, 959. (b) Burtscher, D.; Grela, K. Angew. Chem. Int. Ed. 2009, 48, 442.

(26) All these metal-carbene complexes are indeed precatalysts or initiators rather than catalysts because they are not recovered unchanged at the end of the process. As the term 'catalyst' is generally accepted in the literature, we have opted to use this term in this review.

(27) For an excellent review about the evolution of catalyst design, see: Hoveyda, A. H. J. Org. Chem. 2014, 79, 4763.

(28) Selected reviews on applications of the metathesis reactions in total synthesis: (a) Ivin, K. J. J. Mol. Catal. A: Chem. 1998, 133, 1. (b) Prunet, J. Angew. Chem. Int. Ed. 2003, 42, 2826. (c) Schrock, R. R.; Hoveyda, A. H. Angew. Chem. Int. Ed. 2003, 42, 4592. (d) Mulzer, J.; Öhler, E. Top. Organomet. Chem. 2004, 13, 269. (e) Rouge dos Santos, A.; Kaiser, C. R. Quim. Nova 2008, 31, 655. (f) Hoveyda, A. H.; Malcolmson, S. J.; Meek, S. J.; Zhugralin, A. R. Angew. Chem. Int. Ed. 2010, 49, 34. (g) Fürstner, A. Chem. Commun. 2011, 47, 6505. (h) Lei, X.; Li, H. Top. Curr. Chem. 2012, 327, 163. (i) Bose, S.; Ghosh, S. Proc. Indian Natl. Sci. Acad. 2014, $80,37$.

(29) Nicolaou, K. C.; Bulger, P. G.; Sarlah, D. Angew. Chem. Int. Ed. 2005, 44, 4490.

(30) Gradillas, A.; Pérez-Castells, J. Angew. Chem. Int. Ed. 2006, 45, 6086.

(31) Prunet, J. Eur. J. Org. Chem. 2011, 3634.

(32) Vanderwal, C. D.; Atwood, B. R. Aldrichimica Acta 2017, 50, 17.

(33) Metathesis in Natural Product Synthesis; Cossy, J.; Arseniyadis, S.; Meyer, C., Eds.; Wiley-VCH: Weinheim, 2010.

(34) Selected reviews on metathesis reactions in synthesis of specific types of natural products: (a) Mulzer, J.; Öhler, E.; Enev, V. S.; Hanbauer, M. Adv. Synth. Catal. 2002, 344, 573. (b) Felpin, F.X.; Lebreton, J. Eur. J. Org. Chem. 2003, 3693. (c) Mutlak, H.; Hassan, A. Chem. Commun. 2010, 46, 9100. (d) Morzycki, J. W. Steroids 2011, 76, 949. (e) Demonceau, A.; Dragutan, I.; Dragutan, V.; Le Gendre, P. Curr. Org. Synth. 2012, 9, 779. (f) Bajwa, N.; Jennings, M. P. Strategies Tactics Org. Synth. 2012, 8, 153. (g) Yu, X.; Sun, D. Molecules 2013, 18, 6230. (h) Nguyen, T. V.; Hartmann, J. M.; Enders, D. Synthesis 2013, 45, 845. (i) Lazarski, K. E.; Moritz, B. J.; Thomson, R. J. Angew. Chem. Int. Ed. 2014, 53, 10588. (j) Wojtkielewicz, A. Curr. Org. Synth. 2013 , 10, 43. (k) Fuwa, H.; Sasaki, M. Bull. Chem. Soc. Jpn. 2016, 89, 1403. (l) Jacques, R.; Pal, R.; Parker, N. A.; Sear, C. E.; Smith, P. W.; Ribaucourt, A.; Hodgson, D. M. Org. Biomol. Chem. 2016, 14, 5875.

(35) (a) Glaus, F.; Altmann, K.-H. Angew. Chem. Int. Ed. 2012, 51, 3405. (b) Winter, P.; Hiller, W.; Christmann, M. Angew. Chem. Int. Ed. 2012, 51, 3396. (c) Tang, W.; Prusov, E. V. Angew. Chem. Int. Ed. 2012, 51, 3401.

(36) Tang, W.; Prusov, E. V. Org. Lett. 2012, 14, 4690.

(37) Villa, R.; Mandel, A. L.; Jones, B. D.; La Clair, J. J.; Burkart, M. D. Org. Lett. 2012, 14, 5396.

(38) Kusuma, B. R.; Brandt, G. E. L.; Blagg, B. S. J. Org. Lett. 2012, 14, 6242.

(39) Oh, H.-S.; Kang, H.-Y.J. Org. Chem. 2012, 77, 1125.

(40) Ghosh, A. K.; Cheng, X.; Bai, R.; Hamel, E. Eur.J. Org. Chem. 2012, 4130.

(41) Hara, A.; Morimoto, R.; Iwasaki, Y.; Saitoh, T.; Ishikawa, Y.; Nishiyama, S. Angew. Chem. Int. Ed. 2012, 51, 9877.

(42) Pawar, A. B.; Prasad, K. R. Chem. Eur. J. 2012, 18, 15202. 
(43) Becker, J.; Butt, L.; von Kiedrowski, V.; Mischler, E.; Quentin, F.; Hiersemann, M. Org. Lett. 2013, 15, 5982.

(44) Fuwa, H.; Ishigai, K.; Hashizume, K.; Sasaki, M. J. Am. Chem. Soc. 2012, 134, 11984.

(45) Kondoh, A.; Arlt, A.; Gabor, B.; Fürstner, A. Chem. Eur. J. 2013, 19, 7731.

(46) Del Valle, D. J.; Krische, M. J. J. Am. Chem. Soc. 2013, 135, 10986.

(47) Fuwa, H.; Yamagata, N.; Saito, A.; Sasaki, M. Org. Lett. 2013, 15, 1630.

(48) Takada, A.; Uda, K.; Ohtani, T.; Tsukamoto, S.; Takahashi, D.; Toshima, K. J. Antibiot. 2013, 66, 155.

(49) Terayama, N.; Yasui, E.; Mizukami, M.; Miyashita, M.; Nagumo, S. Org. Lett. 2014, 16, 2794.

(50) Saidhareddy, P.; Ajay, S.; Shaw, A. K. RSC Adv. 2014, 4, 4253.

(51) Kanoh, N.; Kawamata, A.; Itagaki, T.; Miyazaki, Y.; Yahata, K.; Kwon, E.; Iwabuchi, Y. Org. Lett. 2014, 16, 5216.

(52) (a) Hallside, M. S.; Brzozowski, R. S.; Wuest, W. M.; Phillips, A. J. Org. Lett. 2014, 16, 1148. (b) Kuilya, T. K.; Goswami, R. K. Org. Lett. 2017, 19, 2366.

(53) Chatterjee, S.; Guchhait, S.; Goswami, R. K. J. Org. Chem. 2014, $79,7689$.

(54) Fujiwara, K.; Suzuki, Y.; Koseki, N.; Aki, Y.-i.; Kikuchi, Y.; Murata, S.-i.; Yamamoto, F.; Kawamura, M.; Norikura, T.; Matsue, H.; Murai, A.; Katoono, R.; Kawai, H.; Suzuki, T. Angew. Chem. Int. Ed. 2014, 53, 780.

(55) (a) Bali, A. K.; Sunnam, S. K.; Prasad, K. R. Org. Lett. 2014, 16, 4001. (b) Sharma, B. M.; Gontala, A.; Kumar, P. Eur. J. Org. Chem. 2016, 1215.

(56) Pradhan, T. R.; Das, P. P.; Mohapatra, D. K. Synthesis 2014, 46, 1177.

(57) Kumar, S. M.; Prasad, K. R. Chem. Asian J. 2014, 9, 3431.

(58) Ohba, K.; Nakata, M. Org. Lett. 2015, 17, 2890.

(59) (a) Kaufmann, E.; Hattori, H.; Miyatake-Ondozabal, H.; Gademann, K. Org. Lett. 2015, 17, 3514. (b) Miyatake-Ondozabal, H.; Kaufmann, E.; Gademann, K. Angew. Chem. Int. Ed. 2015, 54, 1933.

(60) (a) Li, H.; Xie, H.; Zhang, Z.; Xu, Y.; Lu, J.; Gao, L.; Song, Z. Chem. Commun. 2015, 51, 8484. (b) Zhang, Z.; Xie, H.; Li, H.; Gao, L.; Song, Z. Org. Lett. 2015, 17, 4706.

(61) Yu, M.; Schrock, R. R.; Hoveyda, A. H. Angew. Chem. Int. Ed. 2015, $54,215$.

(62) Suzuki, T.; Fujimura, M.; Fujita, K.; Kobayashi, S. Tetrahedron 2017, 73, 3652.

(63) Sakamoto, K.; Hakamata, A.; Tsuda, M.; Fuwa, H. Angew. Chem. Int. Ed. 2018, 57, 3801.

(64) Jakubec, P.; Hawkins, A.; Felzmann, W.; Dixon, D. J. J. Am. Chem. Soc. 2012, 134, 17482.

(65) Miura, Y.; Hayashi, N.; Yokoshima, S.; Fukuyama, T. J. Am. Chem. Soc. 2012, 134, 11995.

(66) Chausset-Boissaire, L.; Árvai, R.; Cumming, G. R.; Guénée, L.; Kündig, E. P. Org. Biomol. Chem. 2012, 10, 6473.

(67) Pfeiffer, B.; Speck-Gisler, S.; Barandun, L.; Senft, U.; de Groot, C.; Lehmann, I.; Ganci, W.; Gertsch, J.; Altmann, K.-H. J. Org. Chem. 2013, 78, 2553.

(68) Mahipal, B.; Singh, A.; Ummanni, R.; Chandrasekhar, S. RSC Adv. 2013, 3, 15917.

(69) Toya, H.; Satoh, T.; Okano, K.; Takasu, K.; Ihara, M.; Takahashi, A.; Tanaka, H.; Tokuyama, H. Tetrahedron 2014, 70, 8129.

(70) Rensing, D. T.; Uppal, S.; Blumer, K. J.; Moeller, K. D. Org. Lett. 2015, 17, 2270.

(71) Huang, J.; Wang, Z. Org. Lett. 2016, 18, 4702.

(72) Clark, J. S.; Xu, C. Angew. Chem. Int. Ed. 2016, 55, 4332.

(73) Xu, B.; Li, G.; Li, J.; Shi, Y. Org. Lett. 2016, 18, 2028.
(74) Reddy, D. P.; Zhang, N.; Yu, Z.; Wang, Z.; He, Y. J. Org. Chem. 2017, 82, 11262.

(75) Revu, O.; Prasad, K. R. J. Org. Chem. 2017, 82, 438.

(76) Toelle, N.; Weinstabl, H.; Gaich, T.; Mulzer, J. Angew. Chem. Int. Ed. 2014, 53, 3859.

(77) Zhu, L.; Liu, Y.; Ma, R.; Tong, R. Angew. Chem. Int. Ed. 2015, 54, 627.

(78) Frichert, A.; Jones, P. G.; Lindel, T. Angew. Chem. Int. Ed. 2016, 55, 2916.

(79) Zhang, P.-P.; Yan, Z.-M.; Li, Y.-H.; Gong, J.-X.; Yang, Z. J. Am. Chem. Soc. 2017, 139, 13989.

(80) Matsuzawa, A.; Shiraiwa, J.; Kasamatsu, A.; Sugita, K. Org. Lett. 2018, 20, 1031.

(81) (a) Wadsworth, A. D.; Furkert, D. P.; Sperry, J.; Brimble, M. A. Org. Lett. 2012, 14, 5374. (b) Wadsworth, A. D.; Furkert, D. P.; Brimble, M. A. J. Org. Chem. 2014, 79, 11179.

(82) Schafroth, M. A.; Zuccarello, G.; Krautwald, S.; Sarlah, D.; Carreira, E. M. Angew. Chem. Int. Ed. 2014, 53, 13898.

(83) (a) Trost, B. M.; Dogra, K. Org. Lett. 2007, 9, 861. (b) Song, Y.; Hwang, S.; Gong, P.; Kim, D.; Kim, S. Org. Lett. 2008, 10, 269.

(84) Yang, J.; Knueppel, D.; Cheng, B.; Mans, D.; Martin, S. F. Org. Lett. 2015, 17, 114.

(85) Chapman, L. M.; Beck, J. C.; Wu, L.; Reisman, S. E. J. Am. Chem. Soc. 2016, 138, 9803.

(86) Takamura, H.; Kikuchi, T.; Endo, N.; Fukuda, Y.; Kadota, I. Org. Lett. 2016, 18, 2110.

(87) Chuang, K. V.; Xu, C.; Reisman, S. E. Science (Washington, D. C.) 2016, 353, 912.

(88) (a) Nagatomo, M.; Koshimizu, M.; Masuda, K.; Tabuchi, T.; Urabe, D.; Inoue, M. J. Am. Chem. Soc. 2014, 136, 5916. (b) Koshimizu, M.; Nagatomo, M.; Inoue, M. Angew. Chem. Int. Ed. 2016, 55, 2493. (c) Masuda, K.; Koshimizu, M.; Nagatomo, M.; Inoue, M. Chem. Eur. J. 2016, 22, 230.

(89) For reviews on catalytic enantioselective olefin metathesis, see: (a) ref. 27. (b) Montgomery, T. P.; Johns, A. M.; Grubbs, R. H. Catalysts 2017, 7, 87

(90) Kang, T.; White, K. L.; Mann, T. J.; Hoveyda, A. H.; Movassaghi, M. Angew. Chem. Int. Ed. 2017, 56, 13857.

(91) Cheng, B.; Sunderhaus, J. D.; Martin, S. F. Tetrahedron 2015, 71, 7323.

(92) Vincent, G.; Mansfield, D. J.; Vors, J.-P.; Ciufolini, M. A. Org. Lett. 2006, 8, 2791.

(93) Lu, H.-H.; Hinkelmann, B.; Tautz, T.; Li, J.; Sasse, F.; Franke, R.; Kalesse, M. Org. Biomol. Chem. 2015, 13, 8029.

(94) Canterbury, D. P.; Scott, K. E. N.; Kubo, O.; Jansen, R.; Cleveland, J. L.; Micalizio, G. C. ACS Med. Chem. Lett. 2013, 4, 1244.

(95) Trost, B. M.; Yang, H.; Dong, G. Chem. Eur. J. 2011, 17, 9789.

(96) Dumeunier, R.; Gregson, T.; MacCormick, S.; Omori, H.; Thomas, E. J. Org. Biomol. Chem. 2017, 15, 2768.

(97) Kim, B.; Sohn, T.-i.; Kim, D.; Paton, R. S. Chem. Eur. J. 2018, 24, 2634.

(98) Fujiwara, K. Top. Heterocycl. Chem. 2006, 5, 97.

(99) Hansen, E. C.; Lee, D. Org. Lett. 2004, 6, 2035.

(100) Monfette, S.; Eyholzer, M.; Roberge, D. M.; Fogg, D. E. Chem. Eur. J. 2010, 16, 11720.

(101) Skowerski, K.; Czarnocki, S. J.; Knapkiewicz, P. ChemSusChem 2014, 7, 536.

(102) Morin, E.; Raymond, M.; Dubart, A.; Collins, S. K. Org. Lett. 2017, 19, 2889.

(103) Chen, R.; Li, L.; Lin, N.; Zhou, R.; Hua, Y.; Deng, H.; Zhang, Y. Org. Lett. 2018, 20, 1477.

(104)Weiß, C.; Bogner, T.; Sammet, B.; Sewald, N. Beilstein J. Org. Chem. 2012, 8, 2060. 
(105) Yadav, J. S.; Das, S. K.; Sabitha, G. J. Org. Chem. 2012, 77, 11109.

(106) Persich, P.; Kerschbaumer, J.; Helling, S.; Hildmann, B.; Wibbeling, B.; Haufe, G. Org. Lett. 2012, 14, 5628.

(107) Reddy, C. R.; Jithender, E.; Prasad, K. R. J. Org. Chem. 2013, 78, 4251.

(108) Yajima, A.; Kawajiri, A.; Mori, A.; Katsuta, R.; Nukada, T. Tetrahedron Lett. 2014, 55, 4350.

(109) Konda, S.; Bhaskar, K.; Nagarapu, L.; Akkewar, D. M. Tetrahedron Lett. 2014, 55, 3087.

(110) Davies, S. G.; Lee, J. A.; Roberts, P. M.; Stonehouse, J. P.; Thomson, J. E. J. Org. Chem. 2012, 77, 7028.

(111) Dayaker, G.; Krishna, P. R. Helv. Chim. Acta 2014, 97, 868.

(112) Gao, Y.; Shan, Q.; Liu, J.; Wang, L.; Du, Y. Org. Biomol. Chem. 2014, 12, 2071.

(113) Kamal, A.; Balakrishna, M.; Reddy, P. V.; Rahim, A. Tetrahedron: Asymmetry 2014, 25, 148.

(114) Suzuki, A.; Sasaki, M.; Nakagishi, T.; Ueda, T.; Hoshiya, N.; Uenishi, J. Org. Lett. 2016, 18, 2248.

(115) Srinivas, E.; Dutta, P.; Ganganna, B.; Alghamdi, A. A.; Yadav, J. S. Synthesis 2016, 48, 1561.

(116) von Kiedrowski, V.; Quentin, F.; Hiersemann, M. Org. Lett. 2017, 19, 4391.

(117) Reddy, G. S.; Padhi, B.; Bharath, Y.; Mohapatra, D. K. Org. Lett. 2017, 19, 6506.

(118) Cheng, H.; Zhang, Z.; Yao, H.; Zhang, W.; Yu, J.; Tong, R. Angew. Chem. Int. Ed. 2017, 56, 9096.

(119) Gregg, C.; Gunawan, C.; Ng, A. W. Y.; Wimala, S.; Wickremasinghe, S.; Rizzacasa, M. A. Org. Lett. 2013, 15, 516.

(120) Paterson, I.; Findlay, A. D.; Noti, C. Chem. Asian J. 2009, 4, 594.

(121) Kumar, D. A.; Meshram, H. M. Synth. Commun. 2013, 43, 1145.

(122) Ghosh, A. K.; Veitschegger, A. M.; Sheri, V. R.; Effenberger, K. A.; Prichard, B. E.; Jurica, M. S. Org. Lett. 2014, 16, 6200.

(123) (a) Ghosh, A. K.; Chen, Z.-H. Org. Lett. 2013, 15, 5088. (b) Ghosh, A. K.; Chen, Z.-H.; Effenberger, K. A.; Jurica, M. S. J. Org. Chem. 2014, 79, 5697.

(124) Kita, M.; Oka, H.; Usui, A.; Ishitsuka, T.; Mogi, Y.; Watanabe, H.; Tsunoda, M.; Kigoshi, H. Angew. Chem. Int. Ed. 2015, 54, 14174.

(125) Glaus, F.; Altmann, K.-H. Angew. Chem. Int. Ed. 2015, 54, 1937.

(126) Erb, W.; Grassot, J.-M.; Linder, D.; Neuville, L.; Zhu, J. Angew. Chem. Int. Ed. 2015, 54, 1929.

(127)Jeanne-Julien, L.; Masson, G.; Astier, E.; Genta-Jouve, G.; Servajean, V.; Beau, J.-M.; Norsikian, S.; Roulland, E. Org. Lett. 2017, 19, 4006

(128)(a) Takahashi, S.; Satoh, D.; Hayashi, M.; Takahashi, K.; Yamaguchi, K.; Nakamura, T.; Koshino, H. J. Org. Chem. 2016, 81, 11222. (b) Takahashi, S.; Hongo, Y.; Tsukagoshi, Y.; Koshino, H. Org. Lett. 2008, 10, 4223.

(129) Alfonso, D.; Colman-Saizarbitoria, T.; Zhao, G.-X.; Shi, G.; Ye, Q.; Schwedler, J. T.; McLaughlin, J. L. Tetrahedron 1996, 52, 4215.

(130) Cheng-Sánchez, I.; García-Ruiz, C.; Guerrero-Vásquez, G. A.; Sarabia, F. J. Org. Chem. 2017, 82, 4744.

(131) Shimada, J.; Kwon, H. J.; Sawamura, M.; Schreiber, S. L. Chem. Biol. 1995, 2, 517.

(132) García-Ruiz, C.; Cheng-Sánchez, I.; Sarabia, F. Org. Lett. 2015, 17, 5558.

(133) Bisterfeld, C.; Holec, C.; Böse, D.; Marx, P.; Pietruszka, J. J. Nat. Prod. 2017, 80, 1563.

(134) Fu, G. C.; Grubbs, R. H. J. Am. Chem. Soc. 1992, 114, 5426.

(135)Cusak, A. Chem. Eur. J. 2012, 18, 5800.

(136) Matsui, R.; Seto, K.; Fujita, K.; Suzuki, T.; Nakazaki, A.; Kobayashi, S. Angew. Chem. Int. Ed. 2010, 49, 10068.

(137) Hoye, T. R.; Jeon, J.; Kopel, L. C.; Ryba, T. D.; Tennakoon, M. A.; Wang, Y. Angew. Chem. Int. Ed. 2010, 49, 6151.
(138) Evans, P. A.; Cui, J.; Gharpure, S. J.; Polosukhin, A.; Zhang, H. R. J. Am. Chem. Soc. 2003, 125, 14702.

(139) Chowdhury, P. S.; Kumar, P. Eur. J. Org. Chem. 2013, 4586.

(140) Kumar, T. V.; Shankaraiah, G.; Babu, K. S.; Rao, J. M. Tetrahedron Lett. 2013, 54, 1397.

(141) Kumar, T. V.; Reddy, G. V.; Babu, K. S.; Rao, J. M. Tetrahedron: Asymmetry 2013, 24, 594.

(142) Volchkov, I.; Lee, D. J. Am. Chem. Soc. 2013, 135, 5324.

(143) (a) Jung, J.-C.; Kache, R.; Vines, K. K.; Zheng, Y.-S.; Bijoy, P.; Valluri, M.; Avery, M. A. J. Org. Chem. 2004, 69, 9269. (b) Prantz, K.; Mulzer, J. Angew. Chem. Int. Ed. 2009, 48, 5030.

(144) Gaich, T.; Mulzer, J. Org. Lett. 2005, 7, 1311.

(145)Wang, J.; Sun, B.-F.; Cui, K.; Lin, G.-Q. Org. Lett. 2012, 14, 6354.

(146)Clark, J. S.; Romiti, F. Angew. Chem. Int. Ed. 2013, 52, 10072.

(147) Schmidt, B.; Audörsch, S. J. Org. Chem. 2017, 82, 1743.

(148) Liu, C.-W.; Yeh, T.-C.; Chen, C.-H.; Yu, C.-C.; Chen, C.-S.; Hou, D.R.; Guh, J.-H. Tetrahedron 2013, 69, 2971.

(149)Jayasinghe, S.; Venukadasula, P. K. M.; Hanson, P. R. Org. Lett. 2014, 16, 122.

(150) Bodugam, M.; Javed, S.; Ganguly, A.; Torres, J.; Hanson, P. R. Org. Lett. 2016, 18, 516.

(151) Hoye, T. R.; Jeffrey, C. S.; Tennakoon, M. A.; Wang, J.; Zhao, H. J. Am. Chem. Soc. 2004, 126, 10210.

(152)Wang, X.; Bowman, E. J.; Bowman, B. J.; Porco, J. A. Jr. Angew. Chem. Int. Ed. 2004, 43, 3601.

(153) For a review on RRCM, see: Wallace, D. J. Angew. Chem. Int. Ed. 2005, 44, 1912.

(154) Fujioka, K.; Yokoe, H.; Yoshida, M.; Shishido, K. Org. Lett. 2012, 14, 244.

(155) Arndt, H.-D.; Rizzo, S.; Nöcker, C.; Wakchaure, V. N.; Milroy, L.G.; Bieker, V.; Calderon, A.; Tran, T. T. N.; Brand, S.; Dehmelt, L.; Waldmann, H. Chem. Eur. J. 2015, 21, 5311.

(156) Wang, C.; Yu, M.; Kyle, A. F.; Jakubec, P.; Dixon, D. J.; Schrock, R. R.; Hoveyda, A. H. Chem.-Eur. J. 2013, 19, 2726.

(157) Herbert, M. B.; Suslick, B. A.; Liu, P.; Zou, L.; Dornan, P. K.; Houk, K. N.; Grubbs, R. H. Organometallics 2015, 34, 2858.

(158)(a) Johns, A. M.; Ahmed, T. S.; Jackson, B. W.; Grubbs, R. H.; Pederson, R. L. Org. Lett. 2016, 18, 772. (b) Ahmed, T. S.; Grubbs, R. H.J. Am. Chem. Soc. 2017, 139, 1532.

(159) (a) Montgomery, T. P.; Ahmed, T. S.; Grubbs, R. H. Angew. Chem. Int. Ed. 2017, 56, 11024. (b) Montgomery, T. P.; Grandner, J. M.; Houk, K. N.; Grubbs, R. H. Organometallics 2015, 36, 3940.

(160) Hartung, J.; Dornan, P. K.; Grubbs, R. H. J. Am. Chem. Soc. 2014, $136,13029$.

(161) (a) Herbert, M. B.; Grubbs, R. H. Angew. Chem. Int. Ed. 2015, 54, 5018. (b) Werrel, S.; Walker, J. C. L.; Donohoe, T. J. Tetrahedron Lett. 2015, 56, 5261.

(162) Mangold, S. L.; Grubbs, R. H. Chem. Sci. 2015, 6, 4561.

(163) (a) Mangold, S. L.; O'Leary, D. J.; Grubbs, R. H. J. Am. Chem. Soc. 2014, 136, 12469. (b) Dornan, P. K.; Wickens, Z. K.; Grubbs, R. H. Angew. Chem. Int. Ed. 2015, 54, 7134. (c) Luo, S.-X.; Cannon, J. S.; Taylor, B. L. H.; Engle, K. M.; Houk, K. N.; Grubbs, R. H. J. Am. Chem. Soc. 2016, 138, 14039. (d) Dornan, P. K.; Lee, D.; Grubbs, R. H. J. Am. Chem. Soc. 2016, 138, 6372. (e) de Léséleuc, M.; Godin, E.; Parisien-Collette, S.; Lévesque, A.; Collins, S. K. J. Org. Chem. 2016, 81, 6750. (f) Xu, C.; Shen, X.; Hoveyda, A. H. J. Am. Chem. Soc. 2017, 139, 10919.

(164) Speed, A. W. H.; Mann, T. J.; O’Brien, R. V.; Schrock, R. R.; Hoveyda, A. H. J. Am. Chem. Soc. 2014, 136, 16136.

(165) For a recent review about the use of metathesis cascade reactions in synthesis of natural products, see: Han, J.-C.; Li, C.-C. Synlett 2015, 26, 1289. 
(166) Lee, H.-Y.; Lee, S.-S.; Kim, H. S.; Lee, K. M. Eur.J. Org. Chem. 2012, 4192.

(167) Shoji, M.; Akiyama, N.; Tsubone, K.; Lash, L. L.; Sanders, J. M.; Swanson, G. T.; Sakai, R.; Shimamoto, K.; Oikawa, M.; Sasaki, M. J. Org. Chem. 2006, 71, 4227.

(168) Horeischi, F.; Guttroff, C.; Plietker, B. Chem. Commun. 2015, 51, 2259.

(169) Horeischi, F.; Biber, N.; Plietker, B. J. Am. Chem. Soc. 2014, 136, 4026.

(170) Takao, K.-i.; Nanamiya, R.; Fukushima, Y.; Namba, A.; Yoshida, K.; Tadano, K.-i. Org. Lett. 2013, 15, 5582.

(171)(a) Takao, K.-i.; Nemoto, R.; Mori, K.; Namba, A.; Yoshida, K.; Ogura, A. Chem. Eur. J. 2017, 23, 3828. (b) Takao, K.-i.; Mori, K.; Kasuga, K.; Nanamiya, R.; Namba, A.; Fukushima, Y.; Nemoto, R.; Mogi, T.; Yasui, H.; Ogura, A.; Yoshida, K.; Tadano, K.-i. J. Org. Chem. 2018, 83, 7060.

(172)Waldeck, A. R.; Krische, M. J. Angew. Chem. Int. Ed. 2013, 52, 4470.

(173) Kammari, B. R.; Bejjanki, N. K.; Kommu, N. Tetrahedron: Asymmetry 2015, 26, 296.

(174) Calder, E. D. D.; McGonagle, F. I.; Harkiss, A. H.; McGonagle, G. A.; Sutherland, A. J. Org. Chem. 2014, 79, 7633.

(175) Grafton, M. W.; Farrugia, L. J.; Sutherland, A. J. Org. Chem. 2013, $78,7199$.

(176) Selected reviews of enyne metathesis in synthesis of natural products: (a) Mori, M. Materials 2010, 3, 2087. (b) Mori, M. Adv. Synth. Catal. 2007, 349, 121. (c) Dragutan, I.; Dragutan, V.; Demonceau, A.; Delaude, L. Curr. Org. Chem. 2013, 17, 2678.

(177) A general review about enyne metathesis: Diver, S. T.; Giessert, A. J. Chem. Rev. 2004, 104, 1317.

(178) Gao, X.; Woo, S. W.; Krische, M. J. J. Am. Chem. Soc. 2013, 135 , 4223.

(179) Jecs, E.; Diver, S. T. Org. Lett. 2015, 17, 3510.

(180)Williams, D. R.; Myers, B. J.; Mi, L. Org. Lett. 2000, 2, 945.

(181) Hwang, M.-h.; Han, S.-J.; Lee, D.-H. Org. Lett. 2013, 15, 3318.

(182)(a) Li, J.; Lee, D. Eur. J. Org. Chem. 2011, 4269. (b) Kotha, S.; Meshram, M.; Tiwari, A. Chem. Soc. Rev. 2009, 38, 2065. (c) Kaliappan, K. P. Lett. Org. Chem. 2005, 2, 678.

(183) Lee, J.; Parker, K. A. Org. Lett. 2012, 14, 2682.

(184) Molawi, K.; Delpont, N.; Echavarren, A. M. Angew. Chem. Int. Ed. 2010, 49, 3517.

(185) (a) Paquette, L. A.; Sauer, D. R.; Cleary, D. G.; Kinsella, M. A.; Blackwell, C. M.; Anderson, L. G. J. Am. Chem. Soc. 1992, 114, 7375. (b) Caussanel, F.; Wang, K.; Ramachandran, S. A.; Deslongchamps, P. J. Org. Chem. 2006, 71, 7370.

(186)Wang, Y.; Jäger, A.; Gruner, M.; Lübken, T.; Metz, P. Angew. Chem. Int. Ed. 2017, 56, 15861.

(187) Chu, S.; Münster, N.; Balan, T.; Smith, M. D. Angew. Chem. Int. Ed. 2016, 55, 14306.

(188) Kress, S.; Weckesser, J.; Schulz, S. R.; Blechert, S. Eur. J. Org. Chem. 2013, 1346.

(189)Wei, H.; Qiao, C.; Liu, G.; Yang, Z.; Li, C.-c. Angew. Chem. Int. Ed. 2013, 52, 620.

(190) Honda, T.; Namiki, H.; Kaneda, K.; Mizutani, H. Org. Lett. 2004, 6, 87.

(191) Magnus, P.; Rodríguez-López, J.; Mulholland, K.; Matthews, I. Tetrahedron 1993, 49, 8059.

(192) Kashinath, K.; Jadhav, P. D.; Reddy, D. S. Org. Biomol. Chem. 2014, 12, 4098.

(193) Mortreux, A.; Blanchard, M. J. Chem. Soc., Chem. Commun. 1974, 786.
(194)Schrock, R. R.; Clark, D. N.; Sancho, J.; Wengrovius, J. H.; Rocklage, S. M.; Pedersen, S. F. Organometallics 1982, 1, 1645.

(195) Fürstner, A.; Mathes, C.; Lehmann, C. W. J. Am. Chem. Soc. 1999, $121,9453$.

(196) Fürstner, A.; Guth, O.; Rumbo, A.; Seidel, G. J. Am. Chem. Soc. 1999, 121, 11108.

(197) (a) Schaubach, S.; Gebauer, K.; Ungeheuer, F.; Hoffmeister, L.; Ilg, M. K.; Wirtz, C.; Fürstner, A. Chem. Eur.J. 2016, 22, 8494; and references therein. (b) Wu, X.; Tamm, M. Beilstein J. Org. Chem. 2011, 7, 82 .

(198) Fürstner, A.; Mathes, C.; Lehmann, C. W. Chem. Eur. J. 2001, 7, 5299.

(199) Selected reviews on alkyne metathesis: (a) Fürstner, A. Angew. Chem. Int. Ed. 2014, 53, 8587. (b) Fürstner, A. Angew. Chem. Int. Ed. 2013, 52, 2794. (c) Zhang, W.; Moore, J. S. Adv. Synth. Catal. 2007, 349, 93. (d) Fürstner, A.; Davies, P. W. Chem. Commun. 2005, 2307.

(200) Micoine, K.; Persich, P.; Llaveria, J.; Lam, M.-H.; Maderna, A.; Loganzo, F.; Fürstner, A. Chem. Eur. J. 2013, 19, 7370.

(201) (a) Willwacher, J.; Fürstner, A. Angew. Chem. Int. Ed. 2014, 53, 4217. (b) Willwacher, J.; Heggen, B.; Wirtz, C.; Thiel, W.; Fürstner, A. Chem. Eur. J. 2015, 21, 10416.

(202) (a) Valot, G.; Regens, C. S.; O'Malley, D. P.; Godineau, E.; Takikawa, H.; Fürstner, A. Angew. Chem. Int. Ed. 2013, 52, 9534. (b) Valot, G.; Mailhol, D.; Regens, C. S.; O'Malley, D. P.; Godineau, E.; Takikawa, H.; Phillipps, P.; Fürstner, A. Chem. Eur. J. 2015, 21, 2398.

(203) Fuchs, M.; Fürstner, A. Angew. Chem. Int. Ed. 2015, 54, 3978.

(204) Mailhol, D.; Willwacher, J.; Kausch-Busies, N.; Rubitski, E. E.; Sobol, Z.; Schuler, M.; Lam, M.-H.; Musto, S.; Loganzo, F.; Maderna, A.; Fürstner, A. J. Am. Chem. Soc. 2014, 136, 15719.

(205) Lehr, K.; Schulthoff, S.; Ueda, Y.; Mariz, R.; Leseurre, L.; Gabor, B.; Fürstner, A. Chem. Eur. J. 2015, 21, 219.

(206) Hoffmeister, L.; Fukuda, T.; Pototschnig, G.; Fürstner, A. Chem. Eur. J. 2015, 21, 4529.

(207) Neuhaus, C. M.; Liniger, M.; Stieger, M.; Altmann, K.-H. Angew. Chem. Int. Ed. 2013, 52, 5866.

(208) Fouché, M.; Rooney, L.; Barrett, A. G. M. J. Org. Chem. 2012, 77, 3060.

(209) Guo, L.-D.; Huang, X.-Z.; Luo, S.-P.; Cao, W.-S.; Ruan, Y.-P.; Ye, J.L.; Huang, P.-Q. Angew. Chem. Int. Ed. 2016, 55, 4064.

(210) Rummelt, S. M.; Preindl, J.; Sommer, H.; Fürstner, A. Angew. Chem. Int. Ed. 2015, 54, 6241.

(211) Kwon, Y.; Schulthoff, S.; Dao, Q. M.; Wirtz, C.; Fürstner, A. Chem. Eur. J. 2018, 24, 109.

(212) Meng, Z.; Souillart, L.; Monks, B.; Huwyler, N.; Herrmann, J.; Müller, R.; Fürstner, A. J. Org. Chem. 2018, 83, in press; DOI: 10.1021/acs.joc.7b02871.

(213) Ahlers, A.; de Haro, T.; Gabor, B.; Fürstner, A. Angew. Chem. Int. Ed. 2016, 55, 1406.

(214) Brewitz, L.; Llaveria, J.; Yada, A.; Fürstner, A. Chem. Eur. J. 2013, $19,4532$.

(215) Hoffmeister, L.; Persich, P.; Fürstner, A. Chem. Eur. J. 2014, 20 , 4396.

(216) Gebauer, K.; Fürstner, A. Angew. Chem. Int. Ed. 2014, 53, 6393.

(217) Fürstner, A. Acc. Chem. Res. 2014, 47, 925.

(218)Woo, S. K.; Lee, A. J. Am. Chem. Soc. 2010, 132, 4564.

(219) Magauer, T.; Martin, H. J.; Mulzer, J. Chem. Eur. J. 2010, 16, 507.

(220)Ungeheuer, F.; Fürstner, A. Chem. Eur. J. 2015, 21, 11387.

(221)Wang, Y.; Liu, Q.-F.; Xue, J.-J.; Zhou, Y.; Yu, H.-C.; Yang, S.-P.; Zhang, B.; Zuo, J.-P.; Li, Y.; Yue, J.-M. Org. Lett. 2014, 16, 2062. 
Synthesis

(222)For a recent representative example see: Ralston, K. J.; Ramstadius, H. C.; Brewster, R. C.; Niblock, H. S.; Hulme, A. S. Angew. Chem. Int. Ed. 2015, 54, 7086.
(223) For a recent representative example see: Guy, A.; Oger, C.; Heppekausen, J.; Signorini, C.; De Felice, C.; Fürstner, A.; Durand, T.; Galano, J.-M. Chem. Eur. J. 2014, 20, 6374.

(224)Zhang, W.; Moore, J. S. Macromolecules 2004, 37, 3973; and references therein. 